\title{
SHORELINE CHANGES AT THE REGIONAL SCALE IN TUKTOYAKTUK AND THE MACKENZIE DELTA, CALCULATED USING LANDSAT SATELLITE IMAGERY FROM 1985 TO 2013
}

\section{By}

Rachid Ramoul, BA, Ryerson University, 2011

\author{
A thesis \\ Presented to Ryerson University \\ in partial fulfillment of the \\ requirements for the degree of \\ Master of Applied Science \\ in the Program of \\ Environment Applied Science and Management
}

Toronto, Ontario, Canada, 2014

(C)Rachid Ramoul, 2014 
I hereby declare that I am the sole author of this thesis. This is a true copy of the thesis, including any required final revisions, as accepted by my examiners.

I authorize Ryerson University to lend this thesis to other institutions or individuals for the purpose of scholarly research.

I further authorize Ryerson University to reproduce this thesis by photocopying or by other means, in total or in part, at the request of other institutions or individuals for the purpose of scholarly research.

I understand that my thesis may be made electronically available to the public. 


\title{
SHORELINE CHANGES AT THE REGIONAL SCALE IN TUKTOYAKTUK AND THE MACKENZIE DELTA, CALCULATED USING LANDSAT SATELLITE IMAGERY FROM 1985 TO 2013
}

\author{
C Rachid Ramoul, 2014 \\ Master of Applied Science \\ Environmental Applied Science and Management \\ Ryerson University
}

\begin{abstract}
The Canadian Arctic has long been perceived by many as a vast area of barren and frozen land, sparsely populated, and of little importance to the country's economic growth. However, today this is no longer the case. The changing environment and increased development in this region have led to numerous environmental ramifications, one of the most prominent being shoreline changes.
\end{abstract}

The purpose of this study is to investigate the impacts climate change, natural mechanisms, and increased anthropogenic activity have had on the shoreline in the hamlet of Tuktoyaktuk in the Northwest Territories, and the surrounding Mackenzie Delta from 1985 to 2013 using Landsat satellite imagery. Shoreline changes are quantified and given a rate and directional vector over time in order to determine the predominant trends of erosion or deposition. The results of this investigation indicate that shoreline erosion is one of the leading mechanisms of shoreline change in this region. 


\section{Acknowledgments}

I would like to begin by expressing my most sincere gratitude to my supervisor, Dr. David Atkinson, whose guidance and support helped fuel my passion and kept me motivated in times of adversity. Your unfaltering supervision throughout my research was paramount in this challenging yet stimulating journey.

I would also like to thank my examining committee: Dr. Richard Meldrum (Chair), Dr. Andrew Millward, and Dr. Doug Banting. Thank you for taking the time to constructively shape my final product. Your insights are instrumental and greatly appreciated.

I am very thankful to Ryerson University for the many resources that were made available to me which allowed me to conduct my research in a peaceful and thought-provoking environment. I am also very grateful for the funding that was accorded to me and without which my work would not have been possible.

A very special thanks to my closest friend Zachary Benseddik who was present throughout every step of my master's journey and whose support and words of encouragement during the highs and lows truly helped foster a positive environment for me to succeed.

Lastly but certainly not least, I would like to take a moment to thank my amazing family. My mom Zohra, my dad Saadi, and my two sisters Rima and Yasmine who all played an invaluable part in my achievements by giving me unconditional support and love and for continuously having confidence in me. 


\section{Table of Contents}

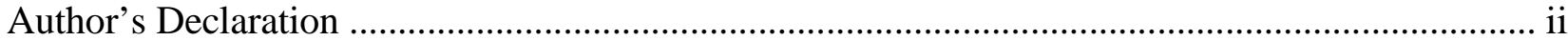

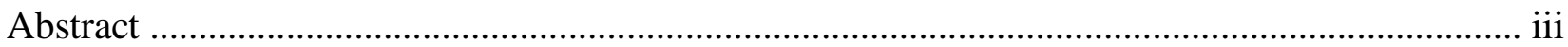

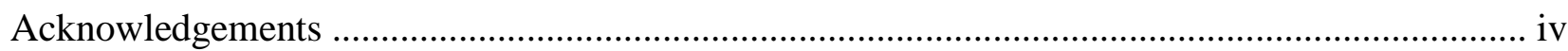

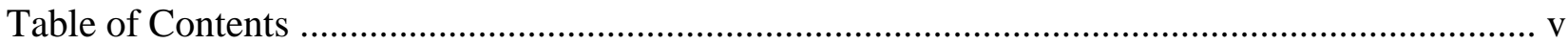

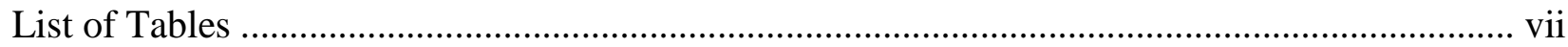

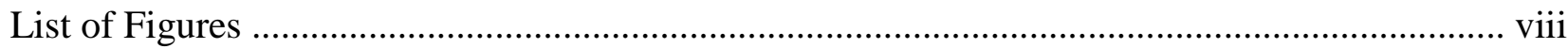

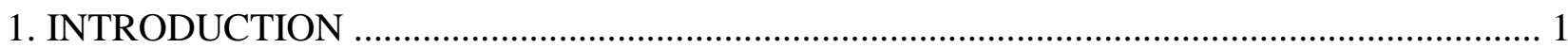

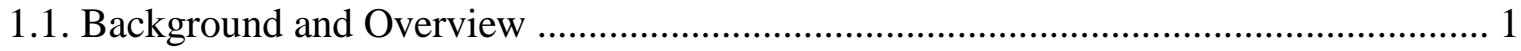

1.2. The Study Area: Tuktoyaktuk and the Mackenzie Delta .......................................... 1

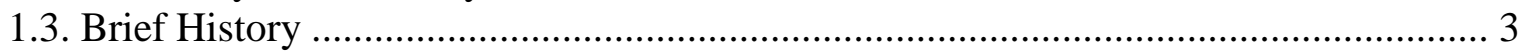

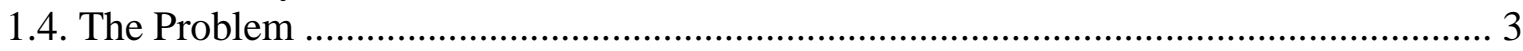

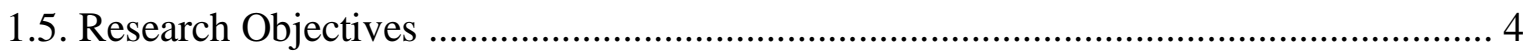

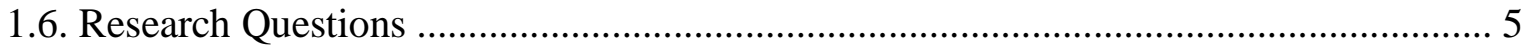

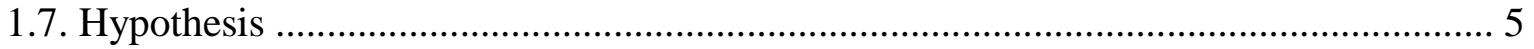

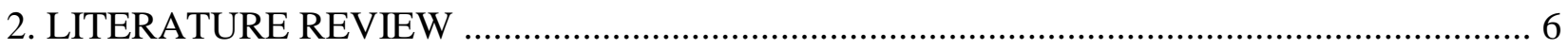

2.1. Mechanisms of Shoreline Changes .................................................................. 6

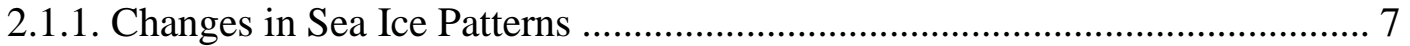

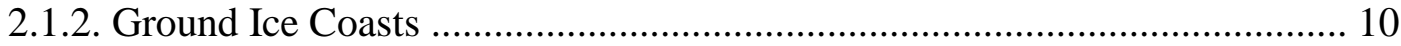

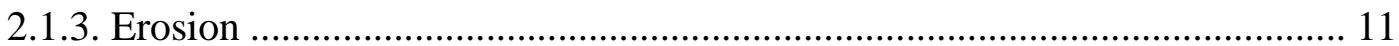

2.1.3.1. Abrasion ....................................................................................... 12

2.1.3.2. Hydraulic Action .................................................................. 12

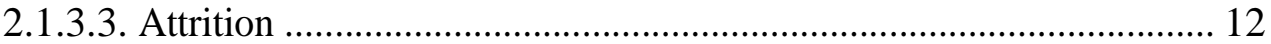

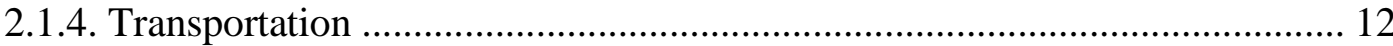

2.1.4.1. Suspension ................................................................................ 13

2.1.4.2. Saltation ................................................................................... 13

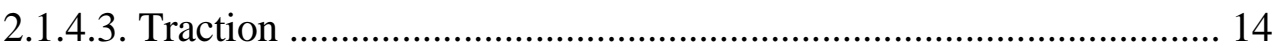

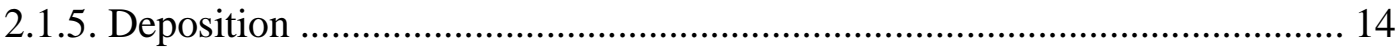

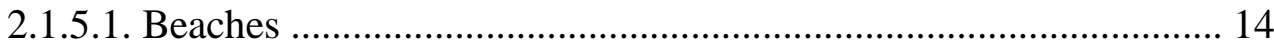

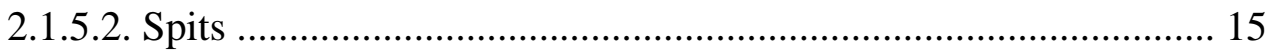

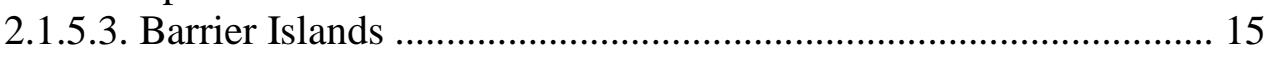

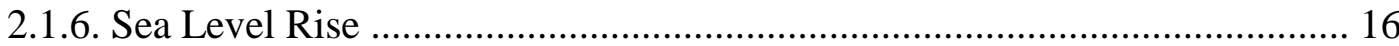

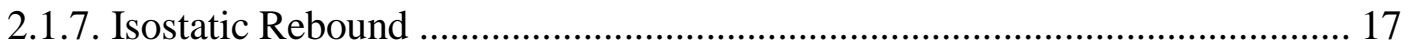

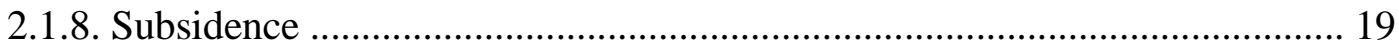

2.2. Tuktoyaktuk and Mackenzie Delta Historical Shoreline Change ............................... 21

2.2.1. Comparable Shoreline Change Studies ..................................................... 24

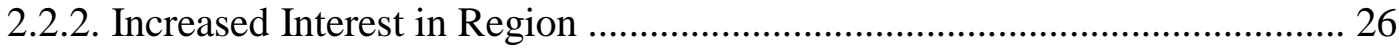

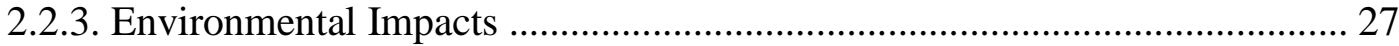

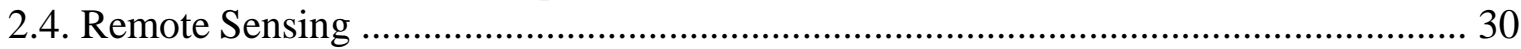

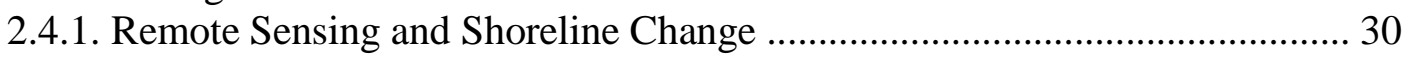

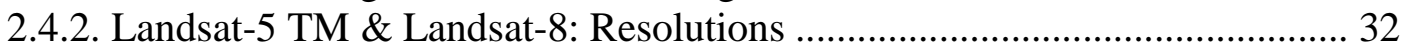

2.4.3. Landsat-5 TM \& Landsat-8: Data Cost and Availability ............................. 33

2.4.4. Change Detection Procedures .................................................................... 34 
2.4.5. Band Ratioing Technique .............................................................................. 34

2.4.6. Classification Techniques .............................................................................. 35

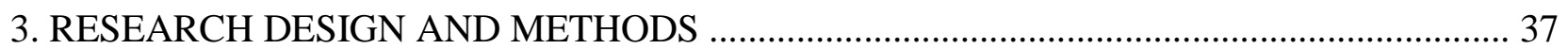

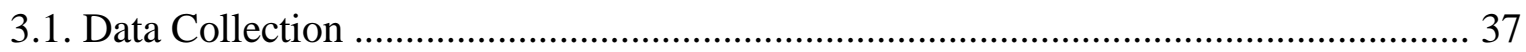

3.1.1. Earth Explorer USGS ............................................................................... 37

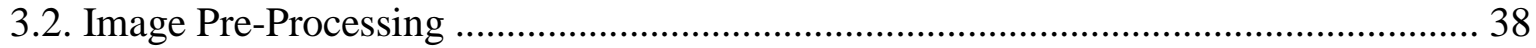

3.2.1. Radiometric Correction ............................................................................... 38

3.2.2. Subsetting ……………………................................................................ 39

3.2.3. Geometric Correction ............................................................................... 39

3.3. Image Classification .......................................................................................... 40

3.3.1. Band Ratioing .......................................................................................... 41

3.3.2. Supervised Classification ..................................................................... 41

3.3.3. Signature Separability ................................................................................. 43

3.4. Image Post-Classification ...................................................................................... 44

3.4.1. Raster to Vector Conversion ……………………....................................... 45

3.4.2. Reclassification ......................................................................................... 46

3.4.3. Map Overlay ……………………………………..................................... 46

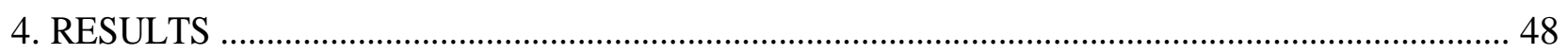

4.1. Classification Output ........................................................................................ 48

4.2. Accuracy Assessment …………………………………………………………. 50

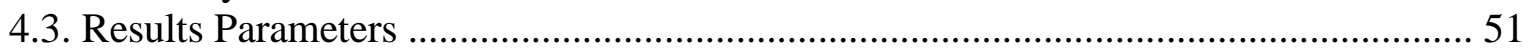

4.3.1. Temporal Change Vector 1 (1985-1990) ................................................ 52

4.3.2. Temporal Change Vector 2 (1990-1995) ..................................................... 57

4.3.3. Temporal Change Vector 3 (1995-2000) ..................................................... 61

4.3.4. Temporal Change Vector 4 (2000-2005) ....................................................... 65

4.3.5. Temporal Change Vector 5 (2005-2013) ...................................................... 69

4.3.6. Temporal Change Vector 6 (1985-2013) ………………………………..... 73

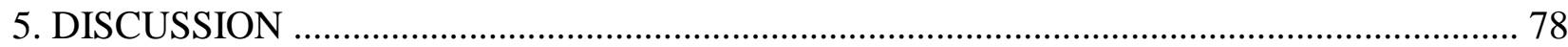

5.1. Tidal Activity Impacts ......................................................................................... 78

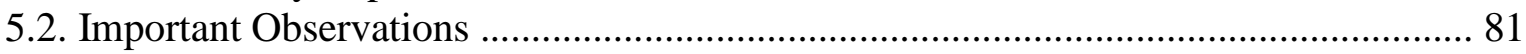

5.3. Comparative Analysis of Shoreline Changes ............................................................ 84

5.4. Linear or Cyclical Changes? ....................................................................................... 86

5.5. Implications on the Beaufort Sea Ecosystem .............................................................. 89

5.6. Implications on Shoreline Development ...................................................................... 92

5.7. Implications on Offshore Activities .............................................................................. 93

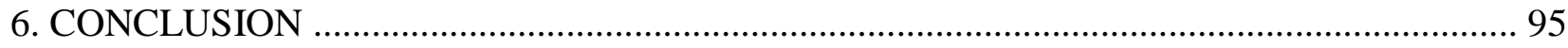

6.1. Summary of Findings ………………………………………………………….... 95

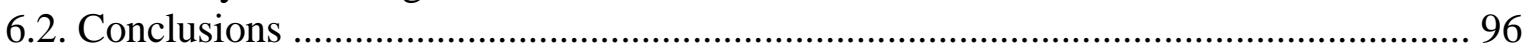

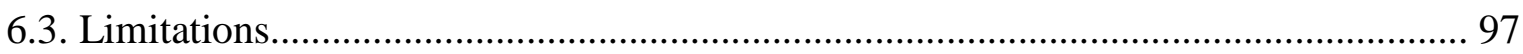

6.4. Future Research …………………………………………………………………. 98

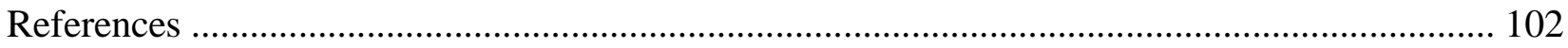




\section{List of Tables}

Table 1. Current Adaptive Strategies in Tuktoyaktuk ............................................................. 24

Table 2. Current Exposure-Sensitivities in Tuktoyaktuk ......................................................... 28

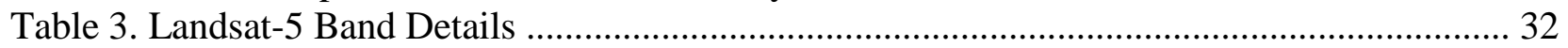

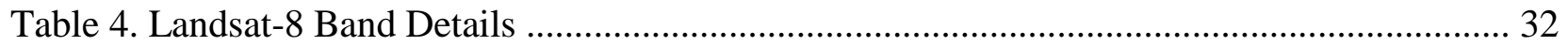

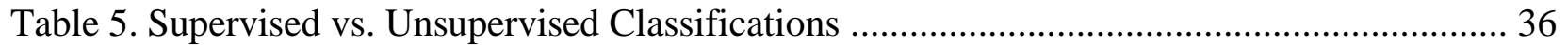

Table 6. Earth Explorer Final Images Chosen ..................................................................... 38

Table 7. RMS Values for Ground Control Points in each image .............................................. 40

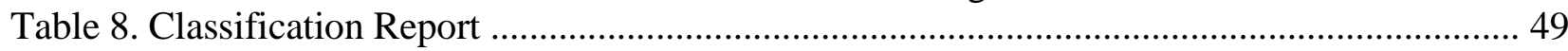

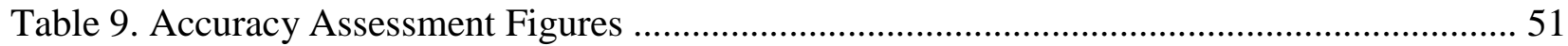

Table 10. Shoreline change classes based on area size ......................................................... 52

Table 11. Number of polygons in each area class which have undergone deposition or erosion in

temporal change Vector 1 ............................................................................................ 55

Table 12. Area size of polygons in each area class which have undergone deposition or erosion in

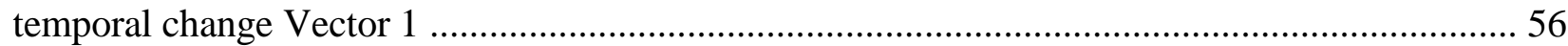

Table 13. Total rates of deposition and erosion in temporal change Vector 1 ............................ 56

Table 14. Number of polygons in each area class which have undergone deposition or erosion in temporal change Vector 2 ............................................................................................... 59

Table 15. Area size of polygons in each area class which have undergone deposition or erosion in

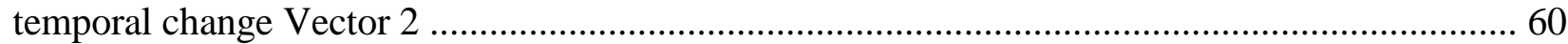

Table 16. Total rates of deposition and erosion in temporal change Vector 2 ............................ 60

Table 17. Number of polygons in each area class which have undergone deposition or erosion in

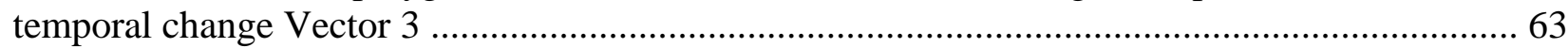

Table 18. Area size of polygons in each area class which have undergone deposition or erosion in

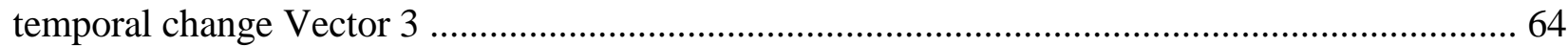

Table 19. Total rates of deposition and erosion in temporal change Vector 3 ............................ 64

Table 20. Number of polygons in each area class which have undergone deposition or erosion in

temporal change Vector 4 .................................................................................................. 67

Table 21. Area size of polygons in each area class which have undergone deposition or erosion in

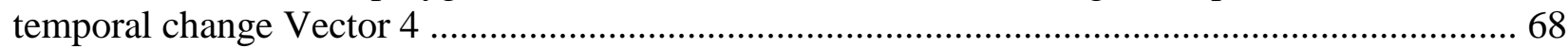

Table 22. Total rates of deposition and erosion in temporal change Vector 4 ............................ 68

Table 23. Number of polygons in each area class which have undergone deposition or erosion in

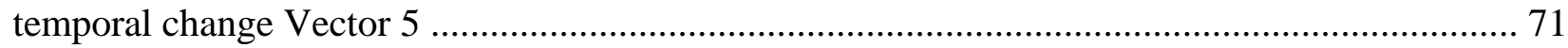

Table 24. Area size of polygons in each area class which have undergone deposition or erosion in

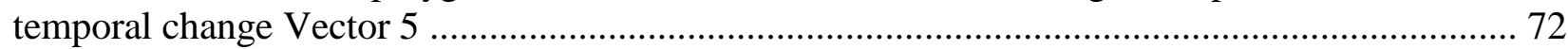

Table 25. Total rates of deposition and erosion in temporal change Vector 5 ............................ 72

Table 26. Number of polygons in each area class which have undergone deposition or erosion in

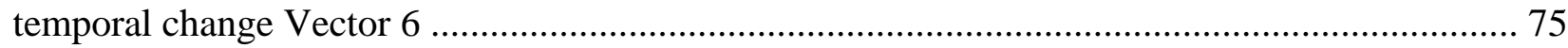

Table 27. Area size of polygons in each area class which have undergone deposition or erosion in

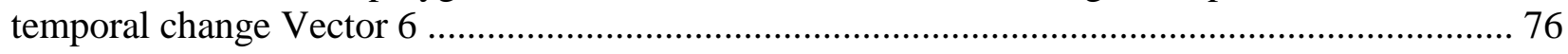

Table 28. Total rates of deposition and erosion in temporal change Vector 6 ............................ 76

Table 29. Tidal levels on date and time images were captured .................................................. 78

Table 30. The expected and actual outcomes observed due to tidal ranges .................................. 79 


\section{List of Figures}

Figure 1. Tuktoyaktuk and Mackenzie Delta Study Area Map ............................................... 2

Figure 2. Melt Onset Dates in the Arctic .............................................................................. 9

Figure 3. Coastal Zone Subsections ................................................................................. 11

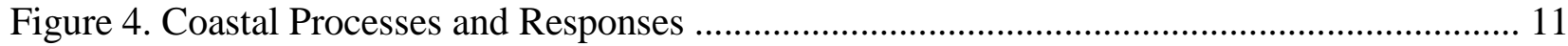

Figure 5. Transportation Processes ................................................................................ 14

Figure 6. Sea Level Rise [A] Ground Data: 1870-2000; and [B] Satellite Data: 1993-Present ..... 16

Figure 7. Postglacial Isostatic Correction in Tuktoyaktuk (inside yellow circle) and Northern

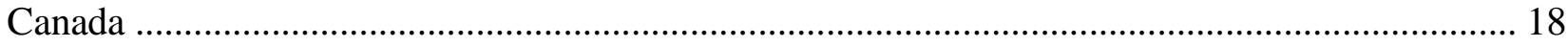

Figure 8. A Canadian Raised Beach, Cornwallis Island, Nunavut ............................................. 19

Figure 9. Shoreline progression at the study location of Tuktoyaktuk, NWT ............................. 23

Figure 10. Wells Penetrating Mesozoic Strata in the Beaufort-Mackenzie Area ......................... 27

Figure 11. Electromagnetic Spectrum Showing Reflectance for Major Land Cover Types and the

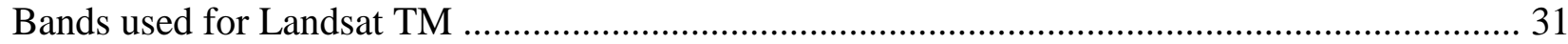

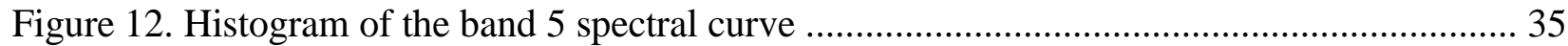

Figure 13. Basic Supervised Classification Process ................................................................ 36

Figure 14. True colour composite of the entire Landsat-5 TM image captured in 1985 including false colour composite subset where Tuktoyaktuk is located (within red circle) and surrounding

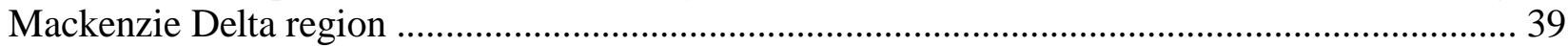

Figure 15. Probability Density Functions Defined by a Maximum Likelihood Classifier ............ 42

Figure 16. Raster versus Vector Data Formats .................................................................... 45

Figure 17. Intersection: Polygon Inputs and Polygon Output .................................................. 47

Figure 18. Shoreline change map of Tuktoyaktuk and surrounding Mackenzie Valley Delta with buffers highlighting regions of interest, temporal change vector 1 (1985-1990) ......................... 54

Figure 19. Percentage of all polygons which have undergone deposition or erosion [A].

Percentage of polygons in each area class which have undergone deposition [B] and erosion [C] in temporal change Vector 1 ....................................................................................... 55

Figure 20. Bar graph displaying the total area size in each area class which have undergone deposition and erosion in temporal change Vector 1 ........................................................... 56

Figure 21. Shoreline change map of Tuktoyaktuk and surrounding Mackenzie Valley Delta with buffers highlighting regions of interest, temporal change vector 2 (1990-1995) ........................ 58 Figure 22. Percentage of all polygons which have undergone deposition or erosion [A]. Percentage of polygons in each area class which have undergone deposition [B] and erosion [C]

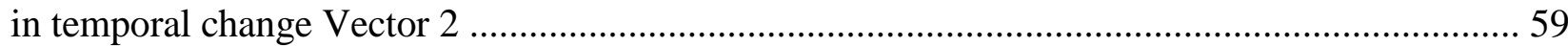
Figure 23. Bar graph displaying the total area size in each area class which have undergone deposition and erosion in temporal change Vector 2

Figure 24. Shoreline change map of Tuktoyaktuk and surrounding Mackenzie Valley Delta with buffers highlighting regions of interest, temporal change vector 3 (1995-2000) ........................ 62 Figure 25. Percentage of all polygons which have undergone deposition or erosion [A]. Percentage of polygons in each area class which have undergone deposition [B] and erosion [C] in temporal change Vector 3

Figure 26. Bar graph displaying the total area size in each area class which have undergone deposition and erosion in temporal change Vector 3 
Figure 27. Shoreline change map of Tuktoyaktuk and surrounding Mackenzie Valley Delta with buffers highlighting regions of interest, temporal change vector 4 (2000-2005) ........................ 66 Figure 28. Percentage of all polygons which have undergone deposition or erosion [A]. Percentage of polygons in each area class which have undergone deposition [B] and erosion [C] in temporal change Vector 4 67

Figure 29. Bar graph displaying the total area size in each area class which have undergone deposition and erosion in temporal change Vector 4 68

Figure 30. Shoreline change map of Tuktoyaktuk and surrounding Mackenzie Valley Delta with buffers highlighting regions of interest, temporal change vector 5 (2005-2013) 70

Figure 31. Percentage of all polygons which have undergone deposition or erosion [A].

Percentage of polygons in each area class which have undergone deposition [B] and erosion [C] in temporal change Vector 5

Figure 32. Bar graph displaying the total area size in each area class which have undergone deposition and erosion in temporal change Vector 5

Figure 33. Shoreline change map of Tuktoyaktuk and surrounding Mackenzie Valley Delta with buffers highlighting regions of interest, temporal change vector 6 (1985-2013) 74

Figure 34. Percentage of all polygons which have undergone deposition or erosion [A].

Percentage of polygons in each area class which have undergone deposition [B] and erosion [B] in temporal change Vector 6 75

Figure 35. Bar graph displaying the total area size in each area class which have undergone deposition and erosion in temporal change Vector 6 76

Figure 36. Bar area graph displaying the total polygon change areas which have undergone deposition and erosion in each temporal change vector as well as the running total 77 Figure 37. Shorelines with lower slopes [A] are more seriously impacted by tidal variations than shorelines with higher slopes [B] 80 Figure 38. The 1985 Landsat-5 image which helped form the first change vector. The arrows help identify two rivers conceivably forming 83 Figure 39. The 2000 Landsat-5 image which helped form the third change vector. The arrow helps highlight the possible location where the two previously forming rivers eventually connected, merging the inland lake with the Ocean ............................................................................ 83 Figure 40. Complete Interconnected Erosion Cycle from start (top) to finish (bottom) ............... 91 


\section{INTRODUCTION}

\subsection{Background and Overview}

As it is now widely accepted in the scientific community, the planet is undergoing a succession of environmental changes as a result of a warming global climate (NOAA, 2014). While some of these changes may seem to only affect a specific locality, the truth remains that the natural environment is not a separate and freestanding entity but rather an interrelated and complex network of biomes. These are all impacted by changes at many scales and are most clearly manifested in pristine regions of the planet such as the Canadian Arctic (ISAC, 2012).

Coastal erosion in the Canadian Arctic is one of the most serious problems facing the people of littoral hamlets such as Tuktoyaktuk, and perfectly illustrates the intricate interaction between anthropogenic activity, climate change, and geomorphology (Aré, 1988). Fortunately, with the help of satellite image analysis, researchers are able to generate images of the Earth's surface and allow this interaction to be closely analysed in order to locate, observe, quantify, and where possible, ultimately develop solutions to remedy the issue of shoreline loss or gain. Shoreline changes occur through a multitude of mechanisms that include, but are not limited to, changes in sea ice patterns, erosion, deposition, and sea level rise (IPCC, 2007). Climate change plays an integral role in many of these mechanisms often by increasing the rates at which they manifest themselves, especially in the case of sea ice loss, erosion, and deposition (NASA, 2010). In this particular study, multi-spectral imagery from LANDSAT-5 and LANDSAT-8 are employed to quantify the rate and amount of change occurring on the shorelines of Tuktoyaktuk and the Mackenzie Delta in the Northwest Territories, Canada. This change is also given a directional value in order to allow for straightforward comparison of the amount of erosion or deposition of the shoreline from 1985 to 2013.

\subsection{The Study Area: Tuktoyaktuk and the Mackenzie Delta}

Tuktoyaktuk is a small Inuvialuit hamlet located on the shores of the Beaufort Sea (Figure 1) in the Northwest Territories east of the Mackenzie Delta (Johnson et al., 2003). It is the most northern mainland community in Canada (Johnson et al., 2003). Tuktoyaktuk, like the rest of the Canadian Arctic has been deeply affected by climate change (CBC, 2009). While this research did investigate shoreline changes in a vast area of the Mackenzie Delta, Tuktoyaktuk, was chosen as the central study site for this thesis because it is located on shores where some of the most 
drastic changes have been observed in recent decades. In fact, the barrier islands around Tuktoyaktuk are extremely sensitive to environmental changes which makes data gathering simpler and conclusion drawing more meaningful. The total population of Tuktoyaktuk in 2011 was of 854 people (Statistics Canada, 2012). This hamlet has an average yearly temperature of $10^{\circ} \mathrm{C}$, with an average summer temperature of $4^{\circ} \mathrm{C}$, and an average winter temperature of $-29^{\circ} \mathrm{C}$ ” (Johnson et al., 2003). Gaining a better understanding of the history and characteristics that are unique to Tuktoyaktuk help guide the research and lead to more confident conclusions on shoreline changes and the many other natural processes at work in this region of the world.

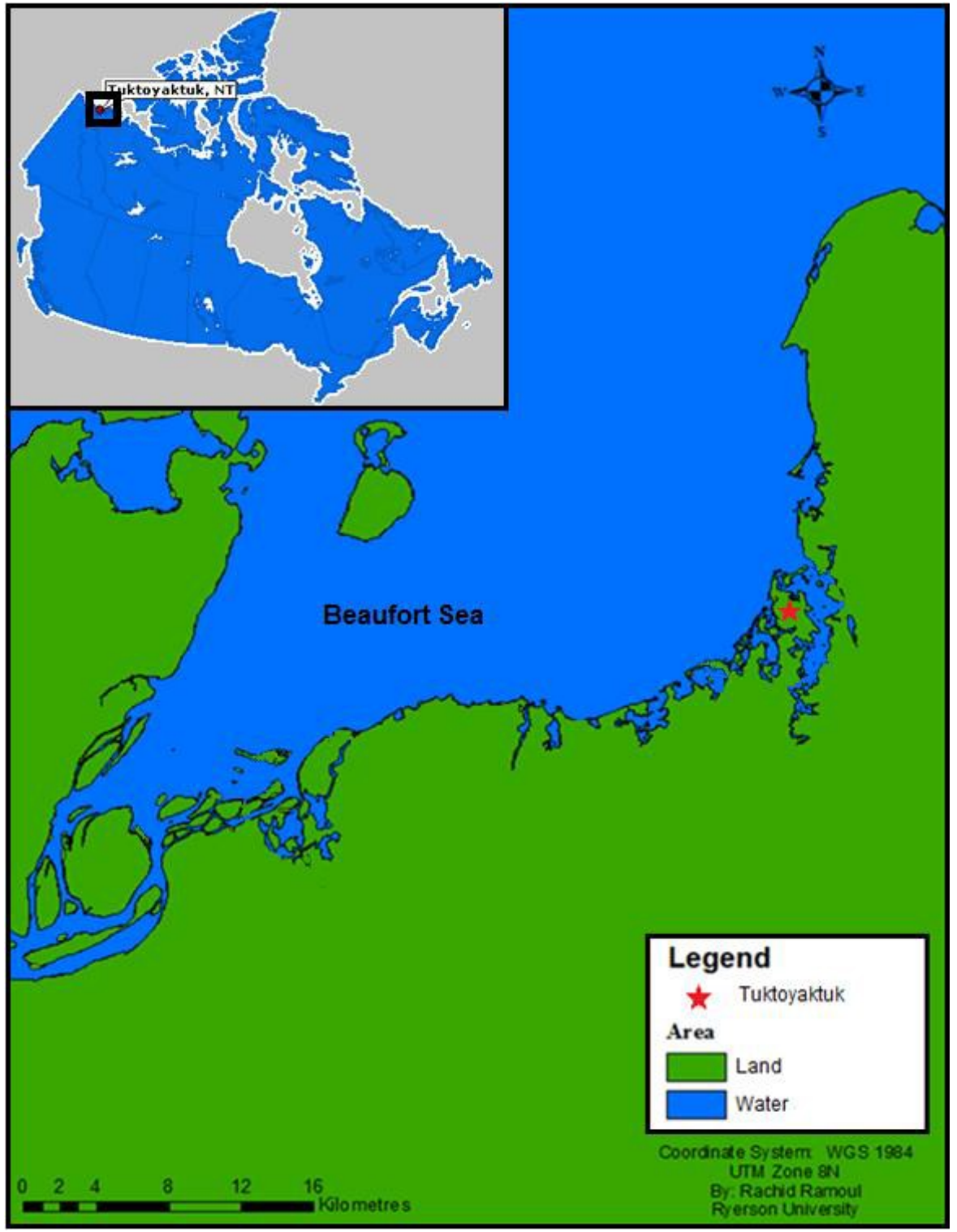

Figure 1. Tuktoyaktuk and Mackenzie Delta study area map; inset: map of Canada (EPodunk, 2007) 


\subsection{Brief History}

Traditionally, the community of Tuktoyaktuk was the home of the whale-hunting Inuvialuit who resided in the region for thousands of years. However, attracted by the potential wealth in the early 1800s, European whalers settled in the area and began establishing their own operations (The Community of Tuktoyaktuk et al., 2008). Eventually, Tuktoyaktuk developed to such an extent that it became the largest Western Arctic community on the coast (The Legislative Assembly of the NWT, 2010). This unsurprisingly led to drastic changes in Tuktoyaktuk. Intense developments in Tuktoyaktuk and the proliferation of offshore activities in the Beaufort Sea led to strong objections by First Nations communities as well as concerned environmentalists in the South (The Community of Tuktoyaktuk et al., 2008). Since then, there has been a very complicated and recurring debate on the state of resource extraction in the Arctic with deep divisions on whether to develop this region for economic aims or leave it untouched for fear of irreversible environmental harm (CFR, 2014).

\subsection{The Problem}

Developing coastlines for economic reasons has never been of greater priority than it is today (NOAA, 2012). In fact, according to Martinez et al. (2007), in 2003 more than 41\% of the world's entire population, or 2.385 billion people, lived within $100 \mathrm{~km}$ of a coast. Considering that 21 of the world's 33 megacities are located in coastal regions and with rapid global urbanisation, these numbers will continue to rise (Martinez et al., 2007). In addition, as aforementioned, by increasing the rate at which environmental changes take place, global warming has led to unprecedented pressures experienced on nearly all of the world's shorelines, whether inhabited or not (Buddemeier et al., 2002). Consequently, approximately 70\% of the world's sandy beaches were receding in 1985; the same year chosen as the commencement for this thesis's investigation (Zhang et al., 2004).

The world's shorelines have been the subject of several studies in urban centres; however, the problem of coastal erosion is an equally significant issue in more remote regions such as Canada’s Arctic (AWI, 2011). Shoreline erosion is a process affected by several factors, such as loss of sea ice, sea level rise, and thawing of ground ice which can at times be difficult to link through simple causality (IPCC, 2007). For instance, Tuktoyaktuk's shorelines which have not 
been subjected to excessive anthropogenic pressures historically, continue to experience shoreline changes much like those of large coastal metropolises (Andrachuk \& Smit, 2012). While the source of change may easily be attributed to the intensive development or overcrowding of coasts in the latter, this link is much more difficult to discern in the former. A thorough analysis of this multifaceted phenomenon in Arctic environments is imperative to understanding what is at the source of this important northern problem. Expanding the knowledge of shoreline processes which can form a cycle of land lost followed by land gained, can potentially help avoid adverse effects on coastal habitats that can in turn lead to undesirable social and economic repercussions (Center for Ocean Solutions, 2014). The loss of shoreline can reduce coastal habitats which can result in more frequent floods, compromised water supplies, and fewer beaches (Center for Ocean Solutions, 2014). On the other hand, land deposition can alter sediment equilibrium and result in changes in dissolved oxygen to the detriment of fish populations (Thompson et al., 2012).

\subsection{Research Objectives}

While there is a clear need to better comprehend the processes that lead to shoreline changes, there is perhaps an even more pressing need to quantify these variations in order to gauge the true extent of this problem. This is one of the primary objectives of this research and to accomplish this, the results of this current thesis are compared to other comparable shoreline erosion studies conducted in similar northern environments as those observed in Tuktoyaktuk.

The research objectives for this thesis are to:

1. Locate areas where shoreline changes have occurred;

2. Quantify those changes and provide their temporal vectors of change;

3. Calculate the rate of change;

4. Determine whether shoreline changes are strictly linear and in constant state of change (i.e. less ice results in more erosion); and

5. Associate rates of shoreline change and the rapidly shifting Arctic environment to offshore drilling activities and shoreline development.

It is argued that the increased human interest and presence in the Arctic attributable to the pursuit of resources such as petroleum and natural gas discovered in the region, will only intensify the rate of shoreline change in Tuktoyaktuk and lead to other potentially irreversible damage to animal species. 


\subsection{Research Questions}

This research's general objective is to assess shoreline change within the selected time frame and also to determine whether the increasingly unstable global climate, among other natural phenomena and anthropogenic activity, are resulting in said changes in the Canadian Arctic, specifically at Tuktoyaktuk. The primary research questions guiding this thesis are therefore as follows:

1. Using satellite record imagery (Landsat-5 and Landsat-8) accumulated over the past 28 years, if shoreline changes have taken place, which areas are most impacted at the regional scale of the delta region surrounding Tuktoyaktuk, NWT?

2. Are the shoreline change rates increasing or decreasing?

3. Are shoreline changes strictly linear and in constant state of change or is another trend observed?

4. Do Arctic offshore drilling activities and shoreline developments influence shoreline changes and the environment as a whole or contrariwise?

\subsection{Hypothesis}

It is hypothesised that in the delta region surrounding Tuktoyaktuk, NWT, because sea-ice concentration has been decreasing and melting earlier, this has led to more open water which in turn results in increased wave action that will increase erosion in some areas and deposition in others. It is also hypothesised that erosion is the most significant process occurring and that the areas which will see the most drastic transformations are the spits, beaches, and barrier islands surrounding Tuktoyaktuk which are extremely sensitive to environmental and anthropogenic changes. While deposition is a distinct possibility, it is anticipated to represent a minor amount of change in comparison to erosion. With this in mind, the shoreline is expected to retreat inland. It is hypothesised that the increased human interest and presence in the Arctic due to resource extraction coupled with the changing Arctic environment will only intensify the rate of shoreline change in Tuktoyaktuk and the surrounding Mackenzie Delta and lead to potentially irreversible damage to migratory animals in the region. 


\section{LITERATURE REVIEW}

This following chapter is instrumental in highlighting the work that has already been conducted in this field to simultaneously reveal the gaps in knowledge. These gaps help lead this research to grow and strengthen the current state of understanding of shoreline changes in the Arctic. It begins with a discussion of the mechanisms of shoreline change, comprising but not limited to shifting sea ice patterns, erosion, and subsidence. A description of the characteristics of remote sensing systems ensues to provide a better understanding of this science and to conclude, the study area is then introduced and examined in greater detail along with some of the prominent shoreline change studies conducted in this region of the world.

\subsection{Mechanisms of Shoreline Changes}

The process by which natural environments are transmuted is rarely a simple one. While it is true that ecosystems are fairly sensitive to most external influences, these influences must typically be quite significant in magnitude and extended in their presence to affect change on a large scale. This signifies that in order for the more than 356,000 km of global shorelines to experience consequential changes, the pressures that are applied on them must be significant (Sonune, 2014). Climate change has the potential to affect this type and level of change. The increasing average global temperature is a result of unprecedented increases of carbon dioxide $\left(\mathrm{CO}_{2}\right)$ released into the atmosphere (NOAA, 2008). Carbon dioxide levels have soared due to the excess burning of fossil fuels such as coal, oil, and natural gas to help address our energy needs (NOAA, 2014). The accumulation of this gas is forming a blanket which traps heat inside the atmosphere and consequently warms the planet through the well documented process known as the greenhouse effect. As the global temperatures climb, there is a plethora of different processes that can potentially account for the coastal changes currently observed throughout the Canadian Arctic and in particular in Tuktoyaktuk (IPCC, 2007). The most common processes are simply erosion and deposition, while sea level rise, subsidence, and isostatic rebound conclude a list of the most important mechanisms of shoreline changes (IPCC, 2007). What makes definite linkages very difficult to draw is the fact that there is often more than a single process at work (Prasetya, 2006). Therefore, the task then becomes to explore which process is most momentous

in its influence on shorelines in order to identify the root cause of this issue. In this current study the focus has remained on determining the impact erosion and deposition have on shoreline changes; however, the other main processes are explained to better frame and guide the discussion. 
Shoreline processes in urban settings of temperate climate are quite well documented; however, Arctic coastal dynamics continue to be mostly misunderstood which threatens current and future mitigation approaches (Lantuit et al., 2011). Luckily some work has already been undertaken which has helped elucidate some characteristics of Arctic shorelines. For instance, according to Lantuit et al. (2011), the average rate of erosion for all Arctic Ocean shorelines is of $0.5 \mathrm{~m}$ year ${ }^{-1}$ with some elevated local disparities. In fact, some of the highest rates are observed in the Beaufort Sea where Tuktoyaktuk is located with erosion rates of more than $3 \mathrm{~m}_{\text {year}}{ }^{-1}$ (Lantuit et al., 2011). There are many explanations for this phenomenon. Unlike coastal erosion in more temperate regions of the world, shoreline erosion in the Arctic Ocean under normal conditions, occurs primarily during the three to four months (June to mid-October) of open-water season (Lantuit et al., 2011). The other major difference is evidently the presence of ice both in the marine and terrestrial environments. Shoreline erosion rates vary greatly both geographically and temporally in relation to differences in lithology, topography, and geomorphology (Jones et al., 2008).

\subsubsection{Changes in Sea Ice Patterns}

As has now been clearly documented, climate change is taking place (NOAA, 2014). To further exacerbate this situation, studies suggest that over $97 \%$ of climate scientists actively publishing in this field agree that this phenomenon is very likely due to human activities (Anderegg et al., 2010). One of the most studied impacts has been the decline of the polar ice caps in the Arctic Circle, both in extent and thickness, over several decades (NSIDC, 2014; NASA, 2014). This pristine region of the world is highly susceptive to environmental disturbances and as a result it is continuously being studied and closely monitored due to its importance on a global scale.

Sea ice covers millions of square kilometres, and forms or melts with the changing polar seasons affecting both human activities as well as natural ecosystems (NSIDC, 2013). Sea ice melts in the summer months and reforms in the winter months; a process known as the freeze-thaw cycle. However, in the Arctic, under normal climatic conditions most of the sea ice remains intact on a yearly basis - known as multiyear ice - while in the Antarctic, it tends to melt and reform annually thus earning it the labels of "seasonal ice" or "first-year ice" (NSIDC, 2013). Multiyear ice contains less brine, a salt solution, than seasonal ice, which results in ice that contains more air pockets which makes it firmer (NSIDC, 2013). In addition, sea ice is usually covered with snow which acts as insulation and helps delay the melting process (NSIDC, 2013). The extent of sea ice 
is deeply intertwined with the notion of albedo, and this phenomenon influences heat and water transfer to the atmosphere which affects local clouds and precipitation. Albedo refers to the ability of a surface to reflect solar energy, or its "whiteness" (NSIDC, 2013). Objects and materials that have a low albedo reflect very little solar radiation and therefore absorb most of it. Sea ice has a much higher albedo than most other surfaces which means it reflects the majority (thick sea ice covered with snow reflects as much as 90 percent of the incoming solar radiation) of sunlight that comes in contact with it and this, in turn, affects the amount of energy absorbed by the Earth (NSIDC, 2011).

Unfortunately, with the global climate warming at alarming rates, the freeze-thaw cycle has been drastically altered and this has had several impacts on the surrounding region (UNEP, 2012). Arctic sea ice is not only shrinking rapidly in its geographic extent, but also in thickness (NSIDC, 2014). In past years, sea ice could reach up to 3 metres in thickness over several years of accumulation; however, today most of the sea ice is first-year ice which only has a one year growth making it much less likely to last until the next winter (NSIDC, 2014). In fact, according to Nagurnyi (2009), a yearly sea ice decrease of $10 \mathrm{~cm}$ was observed from 1970 to 1990 over the entire Arctic Basin which represents 3\% of the average thickness or roughly 3 metres. Meier et al. (2006) also reported that since 1979, Arctic sea ice extent declined roughly $3 \%$ to $4 \%$ per decade. These researchers along with many prominent studies are in good general agreement that Arctic sea ice extent has been in significant decline since the early 1950s at the very least (NSIDC, 2013). September 2012 marked a record low for Arctic sea ice extent when it reached a mere 3.41 million square kilometres which is $44 \%$ lower than the average calculated from 1981 to 2010 (NSIDC, 2013). In addition, the years 2007 to 2012 marked the six lowest minimum sea ice extents since 1979 when satellite imagery became available and in that span, the record low was set four different times; in 2002, 2005, 2007, and 2012 (NSIDC, 2013). This alarming trend is ongoing today and essentially signifies that sea ice goes out sooner in the summer months which plays a crucial role in shoreline change and the rate at which it occurs (NSIDC, 2014). While there is some yearly variability, the trend remains statistically significant towards earlier melt onset (Figure 2). 


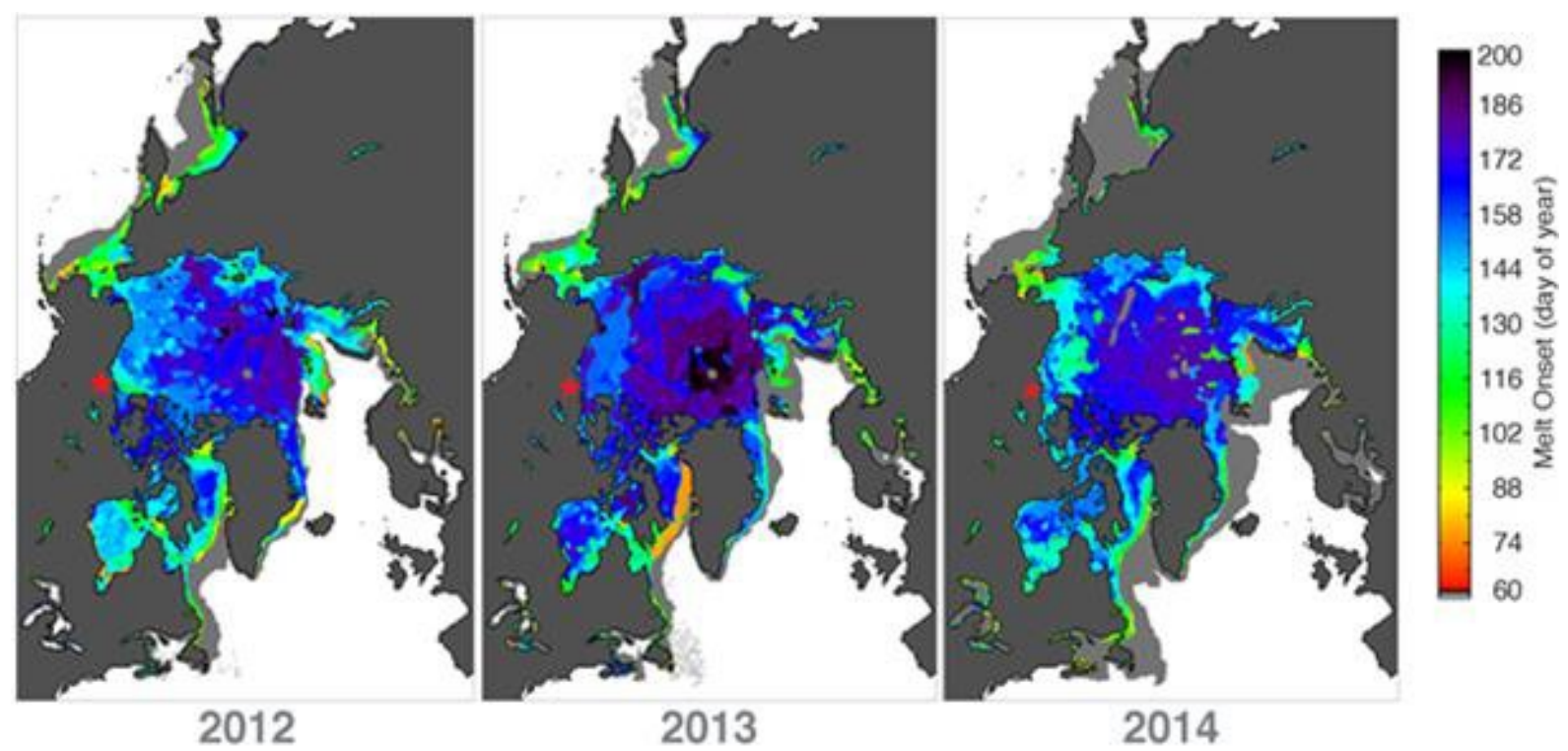

Figure 2. This figure displays melt onset dates in the Arctic (red star denotes Tuktoyaktuk) for 2012, 2013, and 2014 based on the Japan Aerospace Exploration Agency. The dates are conveyed as the day of the year (NSIDC, 2014)

Under normal conditions sea ice in the Arctic remains quite stable in its extent and thickness. Unfortunately, with the ice retreating from the coast earlier and reforming later than has previously been the case, Arctic shorelines such as Tutoyaktuk's are subjected to augmented wave activity (Overeem et al., 2011). According to Overeem et al., (2011) the trend of decline in sea ice extent across most of the Arctic has resulted in synchronously accelerated rates of erosion along Arctic shorelines which suggests a causal relationship between these two processes. In other words, the less sea ice present in the Arctic Ocean, the more rapidly shoreline erosion seems to occur. This is due to the fact that sea ice acts as a barrier for coastlines, by reducing fetch (Lantuit et al., 2011). Fetch; which is the distance travelled by waves across open water, is increasing with the lengthening open water season (Lantuit et al., 2011). More open water signifies that waves are able to travel longer distances and as they do so, they gain more energy and collide with the shores with greater force (Ardhuin et al., 2007; Carmack \& Macdonald, 2002). Each repeated wave hitting the coast, slowly contributes to its erosion (Lantuit et al., 2011; Carmack \& Macdonald, 2002).

This becomes a greater concern during storms events which is especially important in Tuktoyaktuk since it is subject to its highest frequency of storm events in the fall months (mainly October); however, the presence of sea ice helps shield the shoreline from the full impact of waves (Atkinson, 2005). Less sea ice will therefore be very problematic for the Tuktoyaktuk's natural defence from waves. While Arctic winds are usually light, strong gales that can reach hurricane strength and last several days have been observed and an increase in fetch in the Arctic Ocean can consequently also increase the rate of shoreline erosion (NSIDC, 2013). In 
addition, these storms also threaten infrastructure and can alter sediment and nutrient pathways in the near-shore zone (Dunton \& Cooper, 2005). Erosion is a well-documented process, which has a profound impact on shorelines and must be investigated in greater detail to better grasp its true influence.

\subsubsection{Ground Ice Coasts}

Historically, studies of the coastal zone (Figure 3) have not been very comprehensive because they were usually inclined to follow the approach devised by Shepard (1948) which separated the coast into two distinct categories, "primary (shaped by non-marine processes) and secondary (shaped by marine processes)” (Lantuit et al., 2011). These studies failed to mention ground ice and sea ice despite the influence isostatic rebound (isostasy) has in re-shaping geomorphology in the Arctic (Whitehouse et al., 2007). This is surprising today considering the fact that the thermodynamic interaction between ground ice and sea ice controls the geotechnical stability of coastal terrains and their susceptibility to erosion (Moorman, 2010). Arctic ground ice coastlines account for roughly $34 \%$ of all of the planet's shorelines and are, as aforementioned, greatly affected by the presence of ground ice and seasonal ice cover (Lantuit et al., 2011). While the importance of ice in the marine ecosystem will be discussed in further detail, terrestrial ice in the coastal system must also be explored due to its importance in the erosion process. Terrestrial ice, also known as ground ice, is found in the subaerial segment of the shore profile but can also be found beneath the water column as submarine ground ice (Rachold et al., 2007). Once the terrestrial ice begins to melt, coastal zones are more prone to erosion especially when the ground ice is found in large quantities (Kobayashi et al., 1999). This can be explained by the increased rate of abrasion; a process known as "thermal abrasion" which includes the kinetic action of waves as well as the thawing of ground ice (Aré, 1988). Otherwise, ground ice in normal Arctic conditions binds coastal sediments together helping stave off erosion (Forbes et al., 2004). It is therefore imperative to consider the impacts of erosion particularly when studying Arctic ground ice shorelines such as those found in Tuktoyaktuk and surrounding regions because of their heightened sensitivity. Some work has already been completed in this field and supports this assertion which includes studies by Lantuit et al (2011), Zamolodchikov (2008), and Aré (2003) which are mentioned subsequently. 


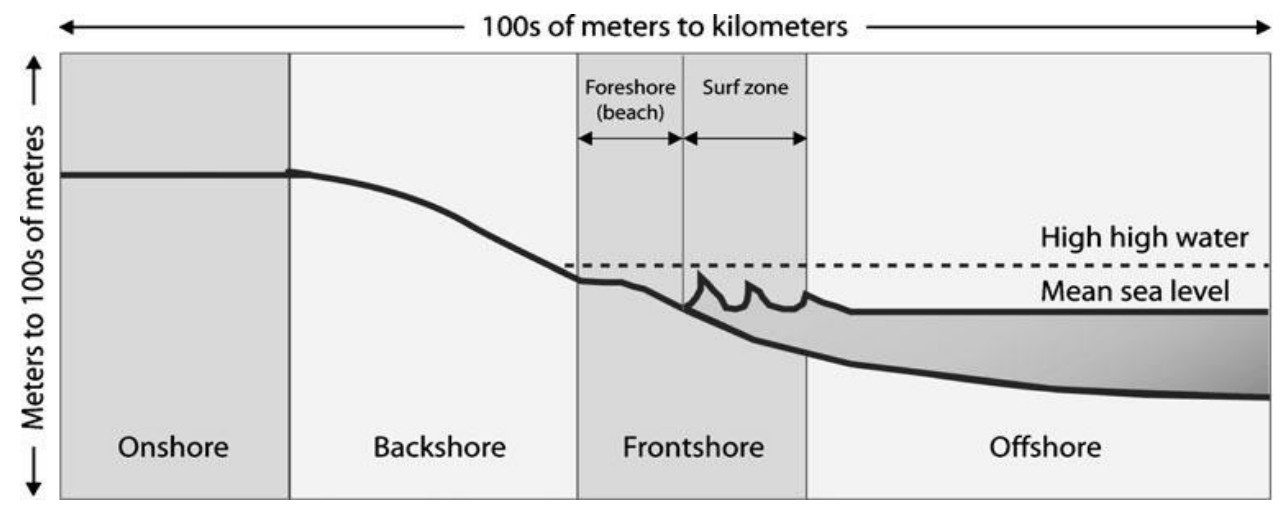

Figure 3. Coastal Zone Subsections (Lantuit et al., 2011)

\subsubsection{Erosion}

Shorelines are inherently influenced by their topography as well as their geological composition (Lantuit et al., 2011). The most looming threat to shorelines today is erosion (Newman, 2009). This is a natural process in which soil and rock are detached from the Earth's surface through a multitude of factors (including water action, wind, or changing soil fertility), transported, and ultimately deposited in different areas resulting in imbalances to coastal ecosystems and creation of new landforms (Newman, 2009). While all coasts are impacted by global warming, Arctic ground ice coasts are at a heightened risk (Figure 4) due to their unique topography and geomorphology (Lantuit et al., 2011). Shoreline change is therefore of significant importance to Tuktoyaktuk and its residents and it is important to understand the numerous processes by which erosion occurs.

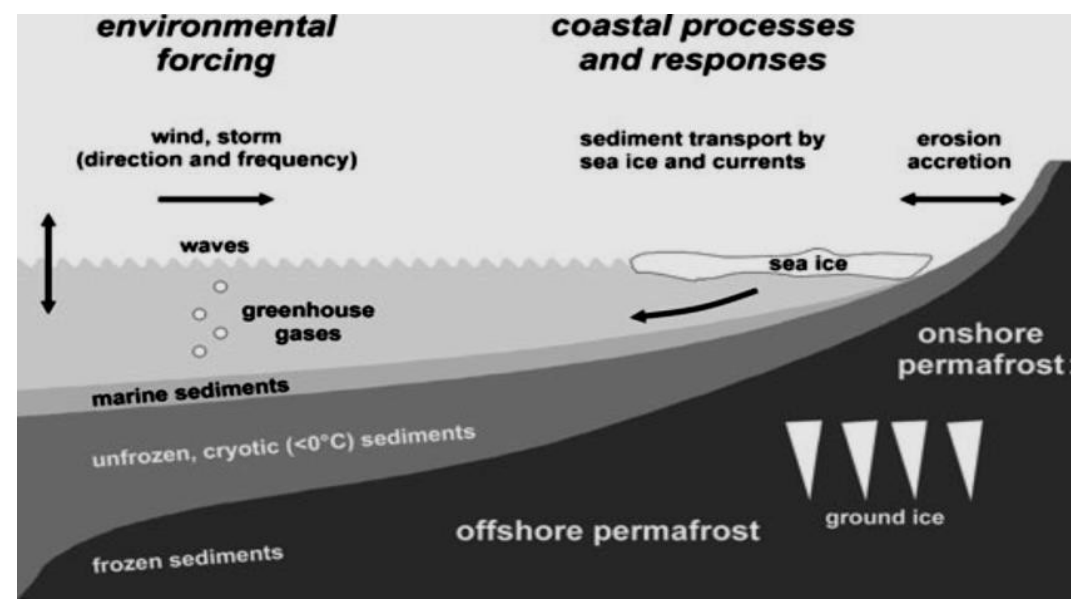

Figure 4. Arctic Ground Ice Coastal Processes and Responses (Lantuit et al., 2011) 


\subsubsection{Abrasion}

One of the most influential processes causing shoreline erosion in the Arctic is abrasion which is characterised by the grinding and wearing down of sand and larger fragments by other such particles (New Zealand Ministry of the Environment, 2014). Abrasion also occurs through the action of waves that pick up beach material such as sand and pebbles and project them at the base of a cliff (New Zealand Ministry of the Environment, 2014). The decrease in sea ice concurrently increases this process. This most frequently takes place in regions that are subjected to strong winds and loose sand particles which describes Tuktoyaktuk's environment especially in the summer months (New Zealand Ministry of the Environment, 2014). The blowing wind has a similar effect to sandblasting which leads to erosion of the shores over extended periods of time (Holt, Rinehart, \& Winston Staff, 2014). Melting ground ice that is composed of ice veins and lens ice which describes the majority of Tuktoyaktuk's coast also serves to increase the rate of abrasion (Zamolodchikov, 2008).

\subsubsection{Hydraulic Action}

Hydraulic action is a type of coastal process affecting shoreline changes in the Arctic. This occurs when waves collide with the base of a cliff which leads to air being compressed into cracks in the cliff face (New Zealand Ministry of the Environment, 2014). When the wave retreats, the trapped air is released which further weakens the cliff leading to erosion (New Zealand Ministry of the Environment, 2014). This is a form of mechanical weathering that is often experienced on the ground ice shoreline cliffs of Tuktoyaktuk in the Arctic (Aré, 2003).

\subsubsection{Attrition}

Another coastal process observed in Tuktoyaktuk which plays a key role in defining the shoreline extent is known as attrition. This occurs when the movement of waves cause sand and pebbles on the shoreline to collide with each other and as a result of this interaction, they break and become smaller and flatter (New Zealand Ministry of the Environment, 2014). This process is similar to abrasion; however, much less impactful on erosion than the former (New Zealand Ministry of the Environment, 2014).

\subsubsection{Transportation}

Once shoreline erosion has taken place, the following natural process is known as 
transportation. Transportation is most generally defined as the movement of material or sediment in the ocean and along the coastline by waves (New Zealand Ministry of the Environment, 2014). While there are three main types of transportation processes which will be described (Figure 5), they all fall within the overarching category of longshore drift which is more precisely used to define the movement of sediment along the shoreline (New Zealand Ministry of the Environment, 2014). This occurs when waves move towards the coast (i.e. swash) at a given angle and carry sediment alongside the coast. The backwash then carries the material back down the shore at a $90^{\circ}$ angle as a result of gravity (New Zealand Ministry of the Environment, 2014). This process is then repeated over time while slowly progressing along the coast (New Zealand Ministry of the Environment, 2014). Longshore drift is the link that connects erosion and deposition and grasping this relationship can help predict how Arctic shorelines may react in the face of increasing erosion rates (Lantuit et al., 2011).

\subsubsection{Suspension}

The foremost method of transportation present in all coastal environments is suspension (Figure 5). Suspension is described by a situation wherein small sediment particles; most notably silts and clays, are carried through water bodies (Jinga \& Riddb, 1997). This contributes to increasing turbidity by making water appear cloudy. During storm events, currents collect large amounts of material in suspension and transport them elsewhere depending on their directional vectors (Jinga \& Riddb, 1997). This process is ubiquitous along the Tuktoyaktuk shoreline and in the Arctic in general (Lantuit et al., 2011). The increasing erosion rates in this region of the world signify that suspension will continue to occur and possibly at an increasing rate as well (Lantuit et al., 2011).

\subsubsection{Saltation}

Saltation is a transportation process affecting the movement of sediments in Tuktoyaktuk (Figure 5). This is described as the movement of sand-sized particles or various

other sediments of similar size by short "jumps" and "bounces” along the swash zone as a result of winds that lead to strong waves (New Zealand Ministry of the Environment, 2014). These sediments follow the direction of the wind and currents cannot maintain the heavier sediment suspended for extended periods of time (Holt, Rinehart, \& Winston Staff, 2014). 


\subsubsection{Traction}

The final major transportation process taking place in the Arctic is traction (Figure 5) which can be described as the rolling of pebbles and larger sediments along the sea floor (New Zealand Ministry of the Environment, 2014). In doing so, these sediments interact with the substratum (New Zealand Ministry of the Environment, 2014). This process shares many similarities with saltation.

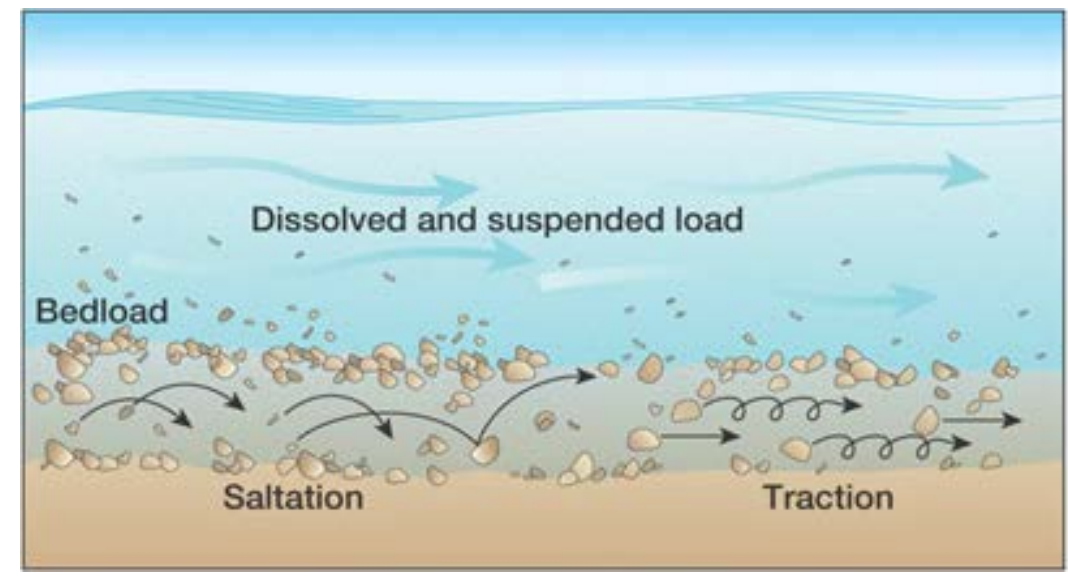

Figure 5. Transportation Processes (Newman, 2009)

\subsubsection{Deposition}

The final link in the coastal processes cycle is known as deposition. This is the method by which waves and tides eventually lose kinetic energy, hence, ending the transportation phase and releasing the eroded sediment (Tape et al., 2011). This process is completed when the ocean drops or deposits the material which builds layers of sediment (Tape et al., 2011). Deposition creates several different landforms; however, for the purposes of this thesis the ones described are beaches, spits, and barrier islands. This final process in the cycle is of extreme importance since shoreline changes can only be determined with confidence once eroded sediment is deposited. Failure to include the deposition phase in a shoreline change study will result in inaccurate estimates of the amount of change truly occurring at a given study site.

\subsubsection{Beaches}

The ubiquitous outcome of sediment deposition in the Arctic is undoubtedly the formation of beaches (St-Hilaire-Gravel et al., 2010). Simply put, a beach is defined as the area between the lowest tide level in the spring and the highest point reached by storm waves when the tide is at its zenith (St-Hilaire-Gravel et al., 2010). While each beach is inherently different, they share a common characteristic in that they are typically made up of sediment that was deposited on a wave-cut platform 
(St-Hilaire-Gravel et al., 2010). Beaches are dynamic environments that act as buffers between water bodies and land masses (New Zealand Ministry of the Environment, 2014). They are divided into four distinct zones (Lantuit et al., 2011) that include the; onshore, backshore, frontshore, and offshore (Figure 3). While studies indicate that the number of beaches has been diminishing globally in past years, the increased erosion observed in the Arctic may result in new but not defined beaches forming (Shaw et al., 1998).

\subsubsection{Spits}

Another type of landform resulting from sediment deposition is a spit. A spit is a narrow ridge of sand and shingle which projects from the shoreline out towards and into the ocean (Shaw et al., 1998). Longshore drift moves sediment along a shoreline and when a lack of kinetic energy occurs in the ocean caused by low or no waves, this leads to that sediment being deposited (New Zealand Ministry of the Environment, 2014). Over time, this sediment tends to build up leading to the formation of a long ridge, and this landform is called a spit (Shaw et al., 1998). The main cause of spit formations is a change in the direction of a coastline and with a combined change in the dominant wind direction; the end of spits can become hooked (Shaw et al., 1998). Sand dunes can develop on spits and allow vegetation to grow until deposition ceases (Shaw et al., 1998).

\subsubsection{Barrier Islands}

The final landform resulting from the deposition of sediment load is known as a barrier island. Barrier islands are described as "elongated accumulations of sand" that are detached from the mainland and separated by open water most often by lagoons or estuaries (NOAA, 2002). In regions characterised by low lying coastal plains such as those found in Tuktoyaktuk and the surrounding Mackenzie Delta, barrier islands are omnipresent. This is explained by the many channels or distributaries in the delta that cut through the coastal plain and flow slowly to the Arctic Ocean where their sand-sized sediment is deposited in bays and estuaries prior to reaching the coast (USGS, 2008). Over time, and with enough deposition, barrier islands are formed (USGS, 2008). Barrier islands play an imperative role in shoreline protection by sheltering the coast from the repeat action of waves; however, when they themselves succumb to erosion, the mainland coast is left very vulnerable (USGS, 2008). Barrier islands are common in the Arctic and their importance cannot be overstated. 


\subsubsection{Sea Level Rise}

While it is true that Arctic ground ice shorelines are experiencing significant changes due to the effects of shifting ice patterns and increased erosion, one of the most concerning factors is the increase in water levels across the globe. Sea level rise will not only undoubtedly threaten current infrastructure and ways of life in the Arctic, it will also affect the future development of shorelines (UMA, 2001). The primary cause of sea level rise is unequivocally the warming global temperatures in the past century (IPCC, 2007). In fact, "under most scenarios, the Arctic is predicted to experience the strongest air and sea temperature increase at the Earth’s surface” (Kattsov \& Källén, 2005). This strongly contributes to sea level rise through two mechanisms: thermal expansion and the melting of sea ice (IPCC, 2007). Thermal expansion refers to the chemical properties of water that allow it to expand in volume in response to increases in temperature through the transfer of heat (NOAA, 2013). When water is heated, its particles move more rapidly and consequently maintain more average separation between them which is manifested in water expanding (NOAA, 2013). The IPCC's near-global ocean temperature data sets have made it possible to fairly accurately determine the impact thermal expansion has had, and could foreseeably have on a global scale. According to their calculations, it is estimated that from 1961 to 2003, thermal expansion was responsible for roughly one quarter of the observed sea level rise while the melting of land ice contributed to just under half (IPCC, 2007). The remaining quarter was not specifically attributed to any single source although it could be explained by other processes such as isostatic rebound (IPCC, 2007).
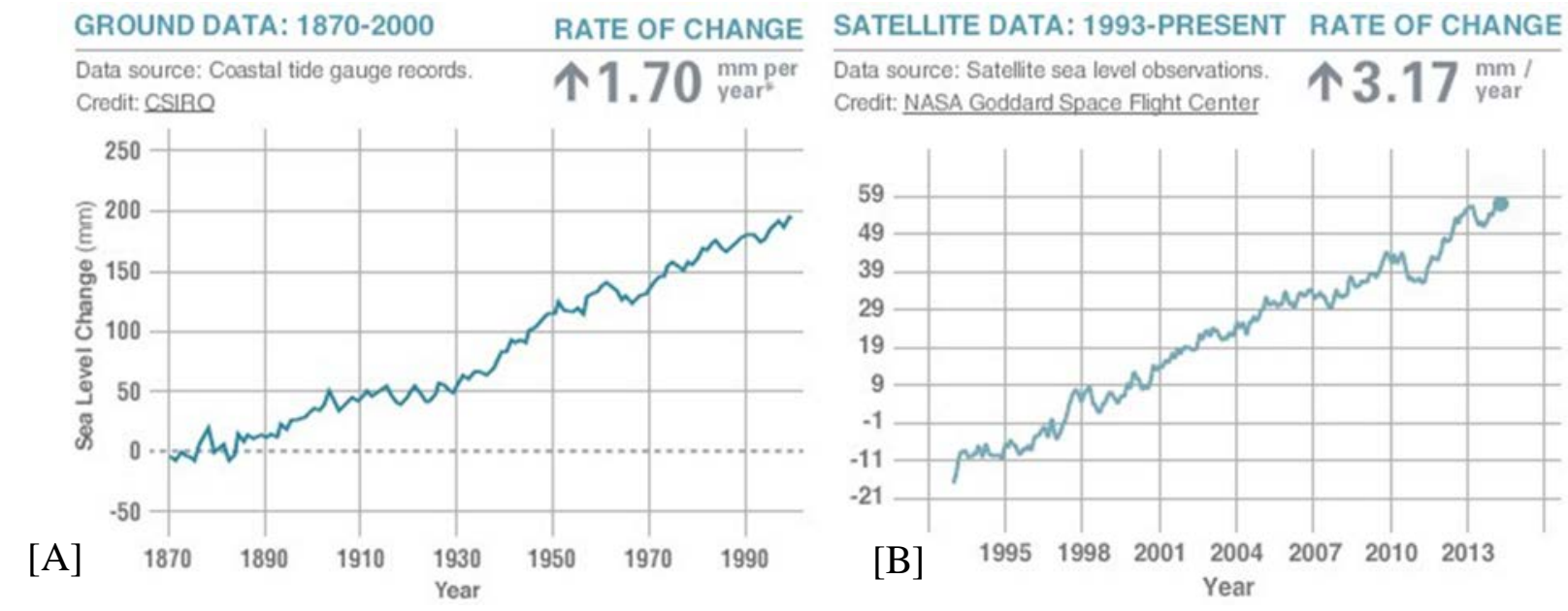

Figure 6. Sea Level Rise [A] Ground Data: 1870-2000; and [B] Satellite Data: 1993-Present (NASA, 2014)

Records indicate that global sea levels have steadily risen (Figure 6) at a rate of 1 to 2.5 millimetres annually since 1870 but are now at over 3 millimetres per year since 1993 (NASA, 
2014). In the late twenty first century; however, relative sea level rise in the Arctic is anticipated to be roughly $0.2 \mathrm{~m}$ higher than that of the global average; that is to say a rise of roughly 23 centimetres annually (Meehl et al., 2007). A data record of water level gauge accumulated over a 45 year span at Tuktoyaktuk also shows a similar trend with the relative sea level rising at a rate of more than $3.5 \mathrm{~mm}$ per year (Szostak-Chrzanowski \& Chrzanowski, 2013). To exacerbate the situation, relative sea level rise will not affect Arctic coasts evenly (Lantuit et al., 2011). In fact, the Arctic shores of the Canadian Archipelago will see a much more radical coastal retreat which is an alarming trend for coastal hamlets such as Tuktoyaktuk (Lantuit et al., 2011).

\subsubsection{Isostatic Rebound}

Another important factor that must be considered in shoreline change studies is the role of isostatic rebound in the calculation of coastal variations through time. Isostatic rebound is based on the concept of isostasy which is itself founded on the opposing influences of two primary planetary forces: buoyancy and gravity (Joseph, 2004). For the Earth, "it is the reason that the relatively rigid lithospheric plates float at certain levels in the underlying ductile asthenosphere. Blocks, or plates, will adjust themselves vertically until the forces of buoyancy and gravity are balanced.” (Joseph, 2004). When these two opposing forces are balanced, the blocks are said to be in isostatic equilibrium and consequently there will be no vertical movement (Joseph, 2004).

Isostatic rebound is a quite interesting natural geological phenomenon which was discovered in part by studying the last glacial age that occurred roughly 20,000 years ago during which most of Northern Europe, Asia, North America, Greenland and Antarctica were covered by ice sheets (glaciers) as thick as three kilometres in some regions (Kumar, \& Singh, 2012). The weight of this ice was so substantial that it caused the "deformation of the Earth's crust; pushing it downward and driving the visco-elastic mantle material to flow away from the loaded region” (Kumar, \& Singh, 2012). Once this glacial period ended and the glaciers retreated, the loss of the enormous weight on the depressed land led to slow, and still continuing, elevation or "rebound" of the continental shelf (Kumar, \& Singh, 2012). It also led to the "return flow of the mantle material back under the deglaciated area" (Kumar, \& Singh, 2012). As a result of the high viscosity $\left(3 \times 10^{21} \mathrm{P}\right)$ of the mantle, the land will not reassume its natural equilibrium level for thousands of years (Anderson \& O’Connell, 1967). 


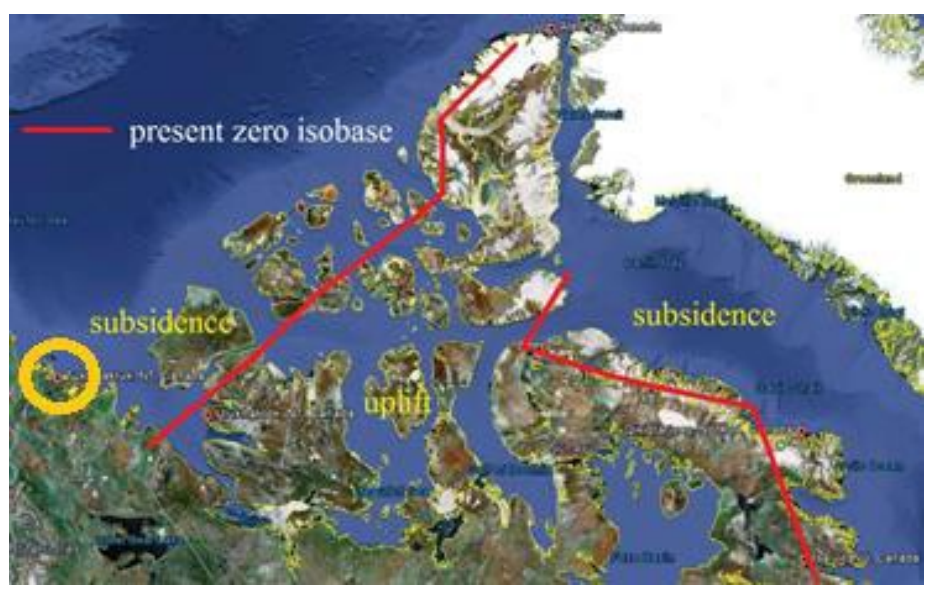

Figure 7. Postglacial Isostatic Correction in Tuktoyaktuk (inside yellow circle) and Northern Canada (SzostakChrzanowski \& Chrzanowski, 2013)

This phenomenon has been studied in greater detail in recent years, and studies have indicated that the rebound process occurs in two distinct phases (Kumar, \& Singh, 2012). The first one is almost immediate because of the elastic response of the land as the ice retreated, and the second phase is much slower due to the viscous flow and the rate of uplift which decreases exponentially (Kumar, \& Singh, 2012). At present, typical isostatic rebound rates are of the order of $1 \mathrm{~cm}$ per year or less (Kumar, \& Singh, 2012). While the total uplift can vary greatly depending on the local ice thickness at the time of the glacial retreat, it can account for several hundred metres of uplift near the centre of the rebound (Kumar, \& Singh, 2012). This process leads to the formation of raised beaches (Figure 8) which were once believed to be the product of decreasing sea levels rather than the rebounding of the Earth's crust (University of Guelph, 2002). It is predicted that the rebound process will carry on for at the very least another 10,000 years and that some regions will experience uplifts of as much as $1 \mathrm{~m}$ per century (Kumar, \& Singh, 2012; NRC, 2013). Isostatic rebound is therefore exceedingly important when calculating shoreline change because it is said to influence coastal environments by increasing shoreline extent (Peltier, 1998). In other words, as the land slowly but steadily continues to rise, the continental shelf will no longer be submerged to the same degree which means that once-immersed land will resurface (Peltier, 1998). Unfortunately, according to studies, the Beaufort Sea region where Tuktoyaktuk is located- is believed to be less greatly affected by isostatic rebound as it is by subsidence (Figure 7). This process counters the progression of rebound and this therefore places shorelines under more pressure. 


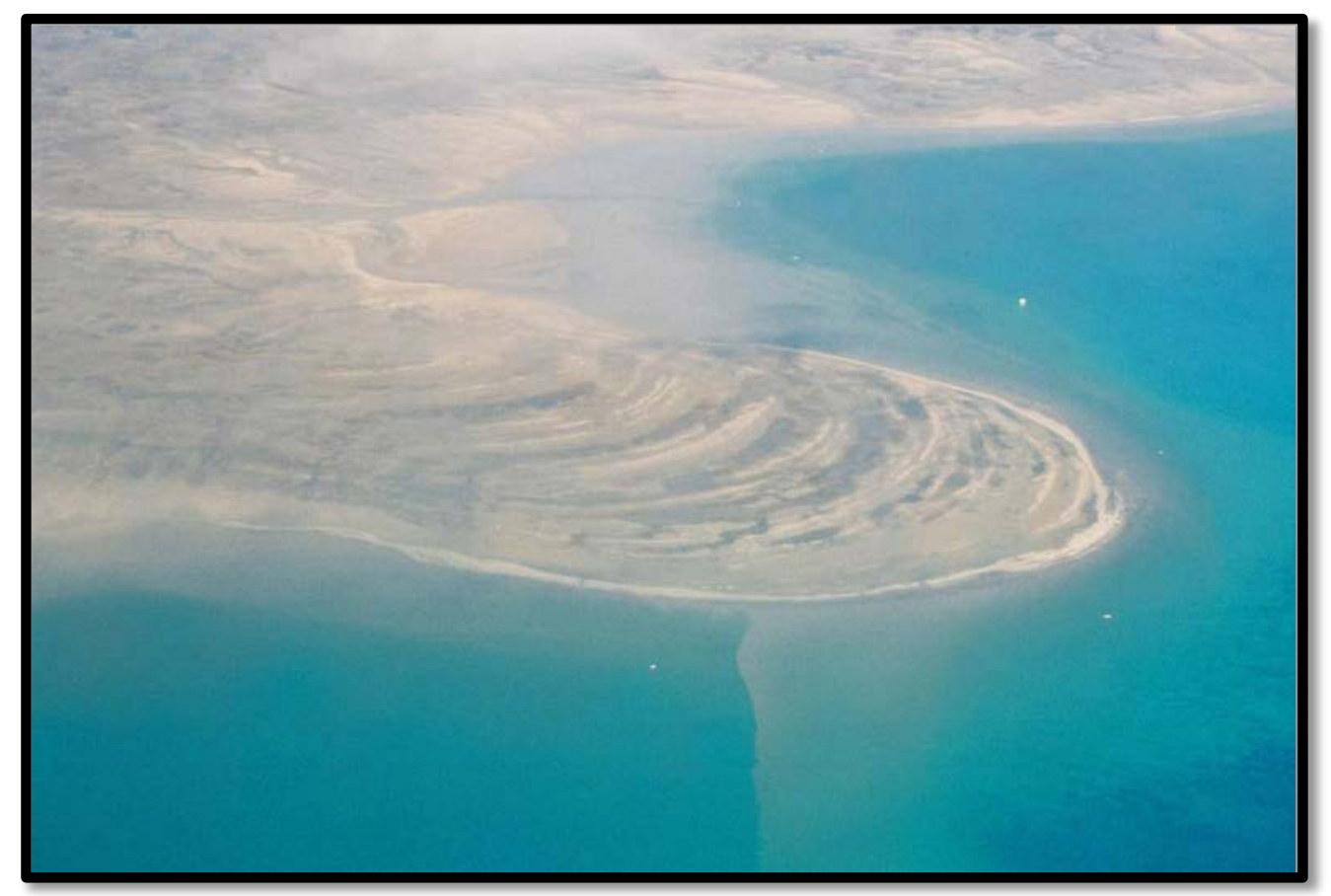

Figure 8. A Canadian Raised Beach, Cornwallis Island, Nunavut (Atkinson, 2004)

\subsubsection{Subsidence}

Another major mechanism of shoreline change in the Arctic is subsidence. While it is true that isostatic rebound did, and continues to strongly affect the Canadian Arctic, especially Tuktoyaktuk's shores, scientific evidence points to subsidence as a being a much more significant element in the changing coastal landscape (Forbes et al., 2004). Whereas its contrasting force (isostatic rebound) is defined by the upwards movement of land masses, subsidence is the downward movement of the lithosphere due to various factors (British Geological Survey, 2014). These include natural causes such as increased mass from water, ice, or sediments, a change in drainage patterns, heavy rain or water abstraction; however, subsidence can also result from man- made disturbances (British Geological Survey, 2014). This mechanism cannot be overlooked when analysing shoreline changes.

In the Beaufort Sea and Mackenzie Delta, natural ground deformation known as subsidence (Figure 7) has been occurring for thousands of years and one of the primary causes is tectonic activity and faulting (Szostak-Chrzanowski \& Chrzanowski, 2013). Studies of the Canadian Arctic show a distinct pattern of postglacial isostatic correction which continues to be in effect today (SzostakChrzanowski \& Chrzanowski, 2013). While relative sea levels at Tuktoyaktuk have been rising by more than $3.5 \mathrm{~mm}$ annually, recent studies of long term GPS observations at the Tuktoyaktuk Active Control Point (ACP) have indicated "relative land subsidence at a rate of $+2.8 \mathrm{~mm}$ per year $\pm 1.1 \mathrm{~mm}$ (Szostak-Chrzanowski \& Chrzanowski, 2013). This, with respect to the Inuvik ACP, which 
is monumented in bedrock about $130 \mathrm{~km}$ south of Tuktoyaktuk" (Szostak-Chrzanowski \& Chrzanowski, 2013). The combination of the two processes amounts to a change of approximately $6.3 \mathrm{~mm}$ yearly. This signifies that the variation between rising sea levels and subsiding land "may be within the errors of measurements or could indicate a combined effect of both" (SzostakChrzanowski \& Chrzanowski, 2013). Similarly, according to Forbes et al. (2007), considering that sea level rise in the Beaufort Sea has been similar to the global trend, subsidence in Tuktoyaktuk today could account for a change of $+2 \mathrm{~mm}$ per year $\pm 2 \mathrm{~mm}$. This is consistent with a five year GPS estimate gathered at Inuvik (Forbes et al., 2007). These figures are evidently quite comparable and fairly elevated which supports the claim that subsidence is a very influential phenomenon taking place in Tuktoyaktuk (Forbes et al., 2004). Although studies seem to support tectonic activity and faulting as the major causes of Arctic subsidence, there is also evidence that sediment compaction is also to blame (Szostak-Chrzanowski \& Chrzanowski, 2013).

Deformation of ground ice is promoting the subsidence process. The freeze-thaw cycle of ground ice which can in some cases reach decimetre levels, and the settlement of the surface in large part due to global warming, also play key roles in ground deformation (Szostak-Chrzanowski \& Chrzanowski, 2013). In the region surrounding Tuktoyaktuk, non-homogenous permafrost can be detected at depths exceeding 700 metres and the thawing of ice-rich permafrost has drastic impacts on subsidence (NRC, 2005). In the Arctic, hydraulic terrestrial processes are governed by the ice content in the soil and the depth of the top active layer of soil which is involved in the freeze-thaw cycle (Szostak-Chrzanowski \& Chrzanowski, 2013). Compaction in this top layer is restricted; however, the process does occur at lower depths. If the warming climate trend continues, permafrost in the Arctic could degrade in the following decade or so which can potentially result in uneven settlement of ground surface (Forbes et al., 2007). This can directly affect shoreline changes in Tuktoyaktuk since sinking land evidently signifies increasing relative sea levels and thus retreating coasts. With the increased interest in the Arctic as a result of the discovery of natural resources, subsidence is also progressively attributed to the withdrawal of natural gas and oil, and these only contribute to accelerate the already occurring subsidence of the land. While it is challenging to pinpoint the root cause of shoreline changes, Hulme et al., (2002) suggested "that impact analysis should explore additional sea-level rise scenarios of $+50 \%$ the amount of global mean rise, plus uplift/subsidence, to assess the full range of possible change”. Gaining a better understanding of the mechanisms that influence shoreline change can help steer future coastal planning and promote better decision making. 


\subsection{Tuktoyaktuk and Mackenzie Delta Historical Shoreline Change}

Tuktoyaktuk and the Mackenzie Delta are the interesting sites for a shoreline change study to be conducted because they are located within the Arctic Coastal Plain where elevations are low, there are numerous lakes and coastal bays present, and ground ice depressions magnify changes. There are many contrasting earth features including dense layers of sand found under most of the area, beds of coarse and pebbly sands, and on occasion, silty layered beds (Johnson et al., 2003; Solomon, 2003). Sands and gravels are found on the top layer of the finer materials along the region (Johnson et al., 2003). In short, coastlines in this entire region are predominantly composed of deltaic deposits of sand and gravel and this explains their propensity to erode (Solomon, 2003). This is due to the fact that smaller non-cohesive bank material (i.e. lacking binding properties) erode more easily than larger earth materials (BCMOE, 2006). For instance, sand erodes more readily than gravel, which in turn is more rapidly eroded than boulders (BCMOE, 2006). This geomorphology is actually comparable to that which forms the Mississippi Delta in the southern states of the United States since unconsolidated sand is found in both deltas (USGS, 2014). Unsurprisingly, coastal erosion is therefore a serious concern in both regions (USGS, 2014). If these shorelines were formed with rocky or solid bedrock, erosion would be a much slower and less urgent issue; unfortunately, this is not the case in Tuktoyaktuk (BCMOE, 2006).

Considering the geography of the hamlet of Tuktoyaktuk as the most northern mainland coastal community in the Canadian Arctic, it comes as no surprise that the majority of the natural materials have been inundated for several hundreds of years and therefore, contain excessive ice (Johnson et al., 2003). Today, ice is still present for 8 to 9 months a year in the coastal areas of the Beaufort Sea, including Tuktoyaktuk where the ocean freezes in late October, and does not break up until late June (Johnson et al., 2003). In the summer months of open water; however, the ice- free distance from shore is typically more than 100 kilometres (Johnson et al., 2003). This is in part due to the impacts of climate change and as previously discussed, unfortunately allows for strong summer storms to negatively affect the coastal regions of Tuktoyaktuk. Strong winds can at times create maximum storm surge tides of roughly 2.5 metres above average water levels which typically range from 35 to 60 centimetres (Johnson et al., 2003).

While there are many other factors to consider, erosion and deposition, prior to modern settlement and development have always played an important role in shaping Tuktoyaktuk's shorelines as well as those of other areas in the Mackenzie Delta (Solomon, 2003). Shoreline erosion 
particularly affects several communities in northern Canada and none has experienced more considerable impacts over such a consistent period than Tuktoyaktuk (Solomon, 2003). These impacts have had various environmental, social, and economic costs (CBC, 2009). In fact, in Tuktoyaktuk's relatively short history since 1937 as the official main harbour of the Hudson's Bay Company, erosion was the main cause for the destruction of a popular curling rink (Figure 9), the closure and eventual demolition of an elementary school, as well as the relocation of the RCMP detachment building (Wolfe et al., 1998). The study of coastal environments in Tuktoyaktuk originated in 1974 from an urgent need to address the hamlet's main school's proximity to the eroding coast (Johnson et al., 2003). After consulting technical specialists and environmental engineers, the first study concluded that experimental mitigation strategies and data collection procedures had to be devised in order to be better prepared for future coastal erosion trends (Johnson et al., 2003). In 1986 another study investigated the potential use of beach nourishment, longshore protection, groin construction, Longard tubes, and an offshore breakwater (Johnson et al., 2003). Beach nourishment is a technique in which sediment lost through a number of erosion processes is replaced by external sources (USGS, 2013). While somewhat successful, this technique has proven to be too costly, and must be repeated every three to four years which is unsustainable environmentally as well as economically (USGS, 2013). Longshore protection encompasses the development of various artificial landforms to attempt to curb erosion (Goudas et al., 2003) with limited success in Tuktoyaktuk, where the rates of erosion are simply too elevated to stave off. 


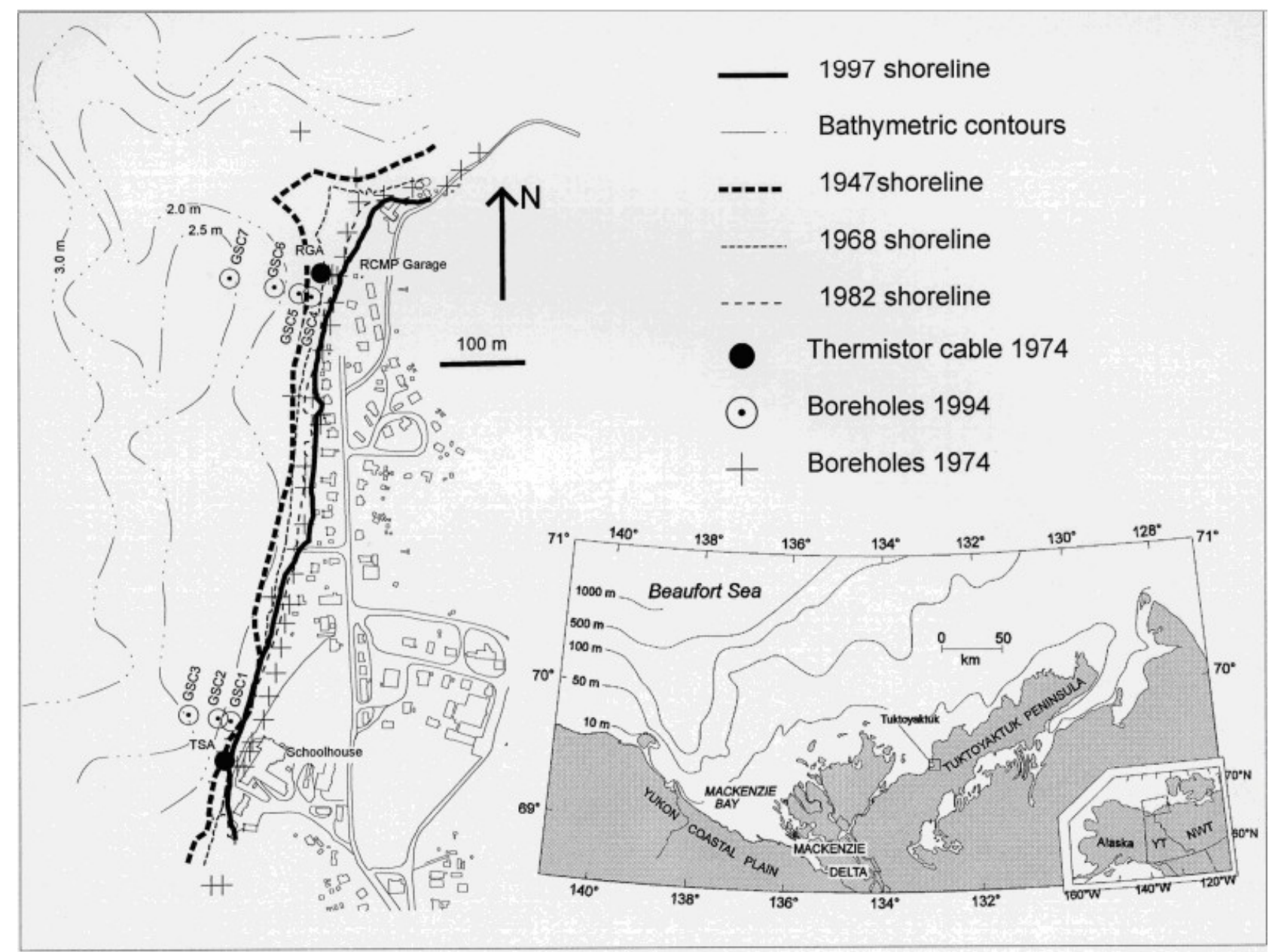

Figure 9. Shoreline progression at the study location of Tuktoyaktuk, NWT (Wolfe et al., 1998).

Most other efforts to stem coastal erosion in Tuktoyaktuk have been largely unsuccessful (Table 1) and in the interim global warming has accelerated the natural process. For instance, a sandbag system that had been implemented in 1987 was destroyed in a single storm event in 1993 when over $50 \%$ of all sandbags were washed away resulting in 4 to 8 metres of shoreline erosion in a matter of days (Johnson et al., 2003). Researchers grew more concerned with the rapidly increasing rates of erosion and this even resulted in some considering the progressive and systematic relocation of the Tuktoyaktuk town site as the most appropriate solution (Johnson et al., 2003). 


\begin{tabular}{|c|c|c|}
\hline \multicolumn{3}{|c|}{ Current Adaptive Strategies in Tuktovaktuk } \\
\hline Current Exposure Sensitivities & $\begin{array}{c}\text { Seasonal or Year to Year Adaptive } \\
\text { Strategies }\end{array}$ & $\begin{array}{c}\text { Permanent or Long Term } \\
\text { Adaptive Strategies }\end{array}$ \\
\hline \multirow[t]{2}{*}{$\begin{array}{l}\text { Risks for infrastructure and } \\
\text { municipal services }\end{array}$} & $\begin{array}{l}\text { Stockpile aggregate during winter } \\
\text { months (for shoreline protection and } \\
\text { to supplement protection under } \\
\text { building foundations) }\end{array}$ & $\begin{array}{l}\text { Shoreline protection (past: Longard } \\
\text { tubes, sandbags; present: boulders, } \\
\text { concrete slabs) }\end{array}$ \\
\hline & $\begin{array}{l}\text { Relocate/remove buildings with } \\
\text { immediate damage risk }\end{array}$ & $\begin{array}{l}\text { Construction of inland road to } \\
\text { gravel source }\end{array}$ \\
\hline \multirow[t]{2}{*}{$\begin{array}{l}\text { Stresses for livelihoods and } \\
\text { local economy }\end{array}$} & $\begin{array}{l}\text { Take advantage of (sometimes } \\
\text { spontaneous) opportunities in } \\
\text { subsistence harvesting or seasonal } \\
\text { employment }\end{array}$ & $\begin{array}{l}\text { Uptake of new technologies to } \\
\text { make harvesting more efficient }\end{array}$ \\
\hline & $\begin{array}{l}\text { Seek employment outside of the } \\
\text { community }\end{array}$ & \\
\hline \multirow[t]{3}{*}{$\begin{array}{l}\text { Stresses for health and } \\
\text { wellbeing }\end{array}$} & $\begin{array}{l}\text { Shift location, timing and/or } \\
\text { frequency of harvesting certain } \\
\text { species }\end{array}$ & $\begin{array}{l}\text { Management plans for protecting } \\
\text { important species (e.g., protected } \\
\text { areas for beluga whales; quotas or } \\
\text { moratoriums on hunting species } \\
\text { with declining populations) }\end{array}$ \\
\hline & $\begin{array}{l}\text { Food substitution (e.g., switching to a } \\
\text { different species or buying more from } \\
\text { store foods) }\end{array}$ & $\begin{array}{l}\text { Altered food preparation practices } \\
\text { (e.g., more care during hot summer } \\
\text { days; use of freezers to store meats) }\end{array}$ \\
\hline & $\begin{array}{l}\text { Small entrepreneurial enterprises } \\
\text { (e.g., tour operators, artisanal crafts) }\end{array}$ & \\
\hline
\end{tabular}

Table 1. Current Adaptive Strategies in Tuktoyaktuk (Andrachuk \& Smit, 2012)

\subsubsection{Comparable Shoreline Change Studies}

In order to gain a better understanding of the extent of coastal changes in the Arctic, it was very important to examine the works of other prominent researchers in the environmental and remote sensing fields. This could subsequently allow for comparisons to be made with the results of this current thesis which also provides a good sense of reliability and reproducibility if there was a consensus amongst different studies. If no consensus could be established, then this would not be perceived as a failure, but rather as an opportunity to learn more about the factors that may bring about these different results. For the purposes of this research, two important studies that followed the general parameters that guided this present work were explored. The results observed would provide great indications on the current state of shoreline changes in the Artic and would be further discussed in the fifth chapter.

Mars \& Houseknect's (2007), study was one of the most telling. Their research was framed in a very similar vein to this current paper by conducting an image analysis of topographic maps along a $130 \mathrm{~km}$ segment of coastline in the Beaufort Sea north of Teshekpuk Lake in Alaska. The study area was over 2,000 $\mathrm{km}^{2}$ in total size. The data collected spanned a period of fifty years beginning in 1955 and ending in 2005. While this period is significantly longer than that observed in the current 
thesis, it was divided into two shorter periods including one from 1985 to 2005 which significantly overlaps this paper and therefore allows for comparisons to be drawn. Mars \& Houseknect determined that while the spatial patterns of shoreline erosion for both time increments are mostly comparable, there is a significant increase in the rate of erosion over time. In the second time period (1985 to 2005) which better mirrors the time frame followed in this current paper, land loss accredited to shoreline erosion was of roughly $21.6 \mathrm{~km}^{2}$ (Mars \& Houseknect, 2007). This represents an average erosion rate of $1.08 \mathrm{~km}^{2}$ per year.

A similar study which was used as a base for comparative analysis with the work and results described in this current thesis is Overeem's (2014) article. This work, was interested in determining if the rate of coastal erosion could be determined by measuring several components of the coastal system including physical properties of the ground ice, atmospheric conditions, water levels, and wave activity (Overeem, 2014). The study site was a 3,000 kilometre segment of the northern shoreline of the Beaufort Sea near Alaska’s Drew Point (Overeem, 2014). The environmental characteristics of this study are very similar to the ones observed in Tuktoyaktuk and so was the time period chosen (28 years) which make comparisons between these two studies even more significant. Using a Landsat image captured in 1979, the coastline was established and mapped. Once this was completed, measurements were taken in 2007 with the use of time-lapse cameras which were placed at several locations along the study site. These provided measurements of the receding coast which were used to compare with the shoreline mapped from the basemap of 1979. Through this comparison, a rate and total amount of erosion were determined. According to Overeem, accelerating shoreline erosion rates in the region resulted in roughly $27 \mathrm{~km}^{2}$ of total land lost by 2007 at the study site which were represented by an erosion rate of roughly $0.96 \mathrm{~km}^{2} /$ year (Overeem, 2014). Both Mars \& Houseknect (2007) and Overeem's (2014) studies provided some invaluable base material for comparison in the discussion chapter.

If the results of this current research mirrored those found in these other studies it would certainly help build a strong case for the relocation of the community of Tuktoyaktuk further inland. However, this seemed less likely moving forward considering the increased interest in Tuktoyaktuk and its surrounding region resulting from the presence of prized natural resources, namely oil and natural gas. 


\subsubsection{Increased Interest in Region}

As the petroleum era begins to steadily decline due to the lack of available sources, oil tycoons have amplified their efforts to discover new deposits before the planet's reserves are entirely and perpetually exhausted (The Guardian, 2013). While there are still some new discoveries of natural and shale gas made (recently in Pennsylvania and Ohio) the overall crude oil trend remains in decline (The Globe and Mail, 2012). This frantic pursuit of petroleum, has led oil companies to brave more dangerous physical terrains and conditions than ever before to obtain the resource (The Legislative Assembly of the NWT, 2010). Unfortunately, some of the last known major deposits are often found in regions of the world where shorelines are most susceptible to anthropogenic changes (WWF, 2014; Ahmed, 2013; IPCC, 2007). In Canada, one of these areas where deposits have been identified are marine ecozones in the Arctic Ocean as well as the Beaufort Sea, known as the Arctic Basin and Arctic Archipelago; the latter, where Tuktoyaktuk is located (GNT, 2014). As previously mentioned, while oil and gas exploration in this region was once at a very promising stage, these endeavours were soon halted by strong opposition in the scientific community as well as from First Nations people (AANDC, 2011). The Berger Report (1977) was primarily responsible for reporting the feasibility as well as the social, economic, and environmental impacts associated with the construction of a pipeline down the Mackenzie Valley was a focal component in slowing the oil industry.

While the 10-year moratorium he proposed on pipeline construction served an imperative purpose in the 1980s, with this ground-breaking ban no longer in effect, the oil and gas industry has returned to the region and has increased their exploration ventures (AANDC, 2012). What may seem somewhat surprising today, is that the Canadian government in conjunction with some First Nations people support economic developments proposed by northern oil and gas multinationals as outlined in the Government's Northern Strategy (AANDC, 2012). The potential in the region surrounding Tuktoyaktuk is very promising (Figure 10); in fact, offshore continental shelves have potential of a scale similar to several other active exploration regions around the globe (AANDC, 2011). It is estimated that the Canadian Arctic contains a third of all potential remaining oil and natural gas in the country (AANDC, 2012; Sustainalytics, 2012). In the past few years, resources in excess of one billion barrels of petroleum and ten trillion cubic feet of natural gas were discovered in the Mackenzie

Delta and Beaufort Sea region surrounding Tuktoyaktuk (AANDC, 2012). The industry has also identified more than six trillion cubic feet of marketable natural gas in three separate onshore locations as well as 200 million barrels of oil in the Amauligak field (AANDC, 2012). Unfortunately, while these 
discoveries will certainly be monetarily stimulating to the Canadian economy, there are several environmental issues associated with oil and gas exploration in the North (UNEP, 2013). These must be meticulously considered in order to avoid potentially irreversible environmental damage including shoreline loss.

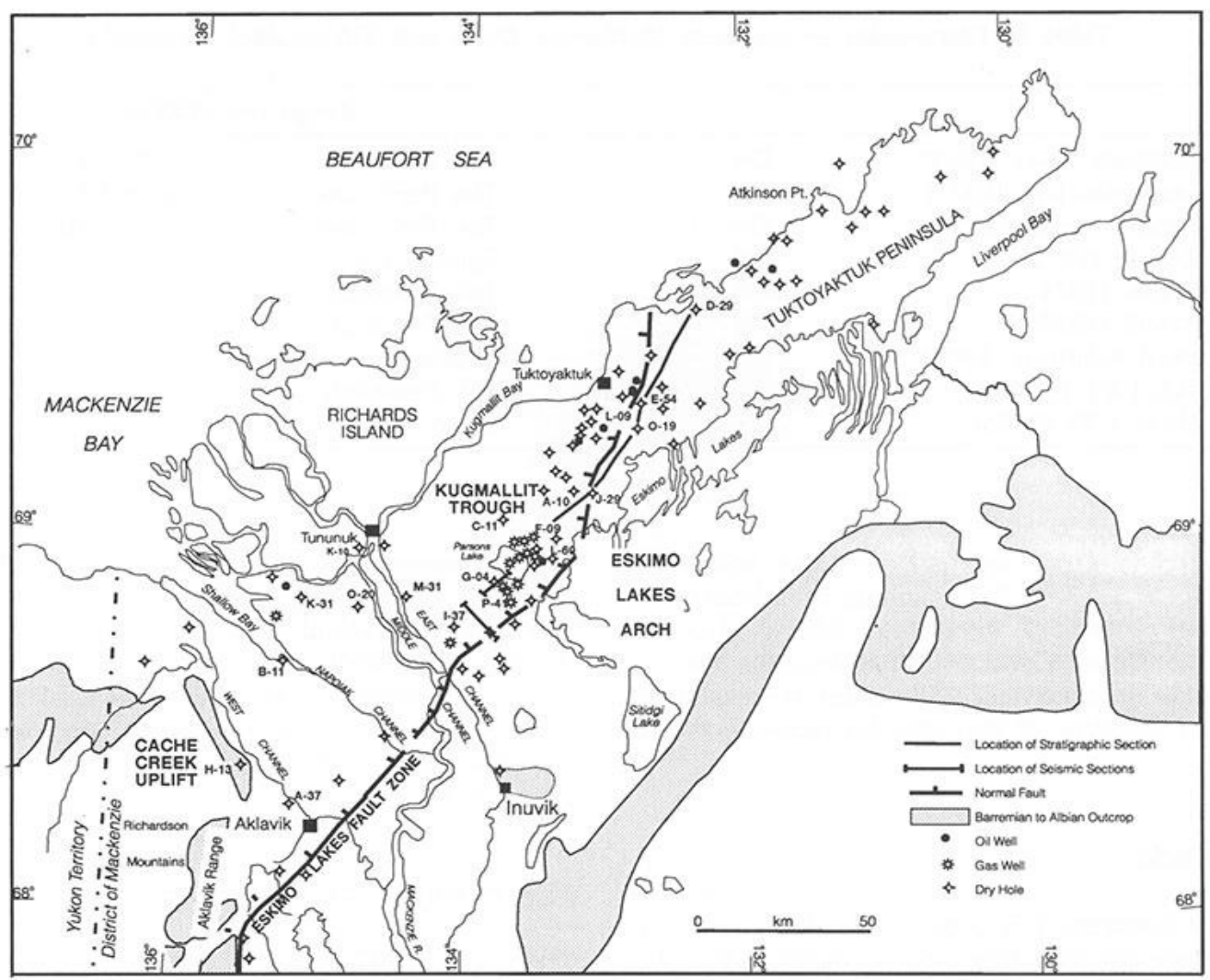

Figure 10. Wells penetrating Mesozoic strata on Tuktoyaktuk Peninsula and south Mackenzie Delta (AANDC, 2011).

\subsubsection{Environmental Impacts}

While the renewed interest in the Arctic has some clear economic benefits, what is much less evident and addressed are the potential environmental impacts associated with this shift (UNEP, 2013). Some of the most prominent research in this still-lacking field suggests that oil and gas exploration in the Arctic, especially in the region surrounding Tuktoyaktuk drastically increases the risks of oil spills and increases coastal development, both of which have potentially far-reaching implications on coastal change (UNEP, 2013).

It is very important to gain a full understanding of the numerous factors which lead some scholars to oppose offshore drilling projects (Table 2). Those who dispute this practice most often cite the precautionary approach as their main argument because it has considerable implications in the context of resource extraction in the Arctic (Scharper, 2010). In the scientific community, the 
precautionary principle is an imperative concept which was first introduced in June 1992 at the Declaration of the Rio Conference on Environment and Development, which stated that:

"In order to protect the environment, the precautionary approach shall be widely applied by States according to their capabilities. Where there are threats of serious or irreversible damage, lack of full scientific certainty shall not be used as a reason for postponing cost-effective measures to prevent environmental degradation.” (UN, 1992)

In layman's terms, the precautionary principle simply denotes that when there are risks of harmful environmental or health impacts possibly linked to a given practice, the lack of irrefutable evidence linking the practice to the harm will not be an adequate reason for delaying necessary actions to negate the damage. This is very important because the environment is very fragile and once harm has occurred, it is often irreversible (UNESCO, 2005). Bearing in mind the lack of certainty that exists when it comes to the safety of offshore drilling projects, the precautionary principle must therefore be applied. This is especially true in light of recent offshore drilling catastrophes around the globe and the inability of corporations to react appropriately despite the safeguards that were supposedly in place (Kingston, 2002).

\begin{tabular}{|ll|}
\hline \multicolumn{2}{|c|}{ Current exposure-sensitivities in Tuktoyaktuk } \\
\hline Community attribute & Stressors \\
\hline $\begin{array}{l}\text { Infrastructure and municipal } \\
\text { services }\end{array}$ & Space constraints \\
& Coastal erosion \\
& Permafrost degradation \\
Livelihoods and local & Income from tourism \\
economy & Viability of sport hunting \\
& Employment opportunities \\
& Availability and access to wildlife \\
& Nutrition in traditional food versus \\
Health and wellbeing & store foods \\
& Availability and access to wildlife \\
& Alcohol and substance abuse \\
& Young and growing population \\
& Disconnect between generations \\
& Less time spent on land (school, \\
& employment) \\
\hline
\end{tabular}

Table 2. Current Exposure-Sensitivities in Tuktoyaktuk (Andrachuk \& Smit, 2012)

History has shown that oil contamination may persist in aquatic ecosystems several years following a spill (Kingston, 2002). This is evidently quite problematic since oil pollution will not simply dissipate, but will rather remain in the sea and continue to affect the organisms that populate the region (Kingston, 2002). Once oil has entered an aquatic environment, there are impacts at all levels of the ecosystem; however, for the purposes of this thesis, the aspect which is of greatest concern is 
the effect on shoreline erosion. Oil spills negatively contaminate and degrade shorelines which are already receding around the globe (Clark, 1994). With the wind and wave activity of water, oil slicks begin to spread and travel great distances eventually colliding with the coastline (Rosal \& Triguis, 2007). This adds an entirely new dimension to the previously described aquatic problems because land organisms are now also impacted. This is most true of coastal plants that are the first line of protection for coastlines against erosion by tides and winds (Danchuk \& Willson, 2010). The algae near the shorelines are first damaged by the oil slick and are soon followed by other land species of plants. Their roots help stave off erosion by binding the soil around them and once they are no longer present this natural defense is lost and shorelines then begin to recede more rapidly (Danchuk \& Willson, 2010). This also affects the human activities located in the surrounding areas as well as the other organisms that rely on vibrant and healthy shorelines (Danchuk \& Willson, 2010). Considering these potential impacts resulting from oil spills, it would be most appropriate to apply the precautionary principle and study all the components of offshore drilling before engaging in these projects which may permanently and irreversibly damage the environment.

Coastal development associated with the oil and gas industry's exploration plans will certainly also have serious impacts on northern coastlines as well as a multitude of other aspects (Table 2). Shipping is expected to increase significantly in the Arctic as a result of longer ice-free seasons (CFR, 2014). Although Tuktoyaktuk does have a 4 metre deep sheltered harbour that is able to act as a re-supply station for small barges travelling to other surrounding communities, it is not deep enough for the requirements of larger vessels (Andrachuk \& Smit, 2012). This natural characteristic will fortunately act as a barrier to larger shipping operations; however, the lengthening ice-free season will signify that more barges will visit Tuktoyaktuk’s harbour (Andrachuk \& Smit, 2012; Smith \& Levasseur, 2002). Despite the smaller size of these vessels, their repeat travel through the community's harbour will inevitably result in necessary coastal developments to accommodate the influx of traffic which may consequently adversely influence the shorelines (Andrachuk \& Smit, 2012). As oil and gas companies discover new resource deposits near Tuktoyaktuk’s shores, they will also require infrastructure to maintain and increase their operations (Andrachuk \& Smit, 2012). Considering that all of Tuktoyaktuk is built on ground ice, the amplified development of the coastal area places the community at an elevated risk of disturbances to the thermal regime which can result in liquefying soils and ultimately in shoreline loss (Andrachuk \& Smit, 2012). In addition, sand mining which is often required when developing the coastline, can have deeply harmful impacts on the erosion-deposition balance in the region depending on the scale of given projects (IPCC, 
2007; FAO, 2013). It is therefore evident that this hamlet has already, and will continue to experience unprecedented pressures from industry which will have adverse environmental impacts. While some of these are well documented, others will only become more palpable with time and further research. The problem is that environmental changes will continue to be observed in Tuktoyaktuk, and the hamlet's residents cannot afford to be reactive when risks such as shoreline loss can potentially be irremediable. The use of remote sensing will be imperative in attempting to determine whether the shoreline change impacts discussed in this paper are truly occurring or at risk of manifesting themselves or if they are overstated throughout the literature.

\subsection{Remote Sensing}

Remote sensing is most aptly described as "the science and art of obtaining information about an object, area, or phenomenon through the analysis of data acquired by a device that is not in contact with the object, area, or phenomenon under investigation” (Lillesand et al., 2007). In the framework of Earth science, remote sensing refers to the task satellites have of identifying electromagnetic radiation emitted by various objects or surfaces in order to allow for interpretable results on their current composition as well as their possible change over periods of time (NSIDC, 2011). Modern satellites can easily measure the presence of land and water in the visible, infrared, and microwave regions of the electromagnetic spectrum. This is of great importance when selecting a satellite and sensor because they each sense specific types of radiation and have their distinct advantages and disadvantages. Remote sensing is therefore a powerful tool in contemporary science studies which can help investigate natural phenomena such as shoreline change in order to accurately determine whether change is actually taking place, and if so, how much. It is important to grasp the intricacies of this tool to ensure that it is employed appropriately in such studies.

\subsubsection{Remote Sensing and Shoreline Change}

In the past few decades, remote sensing technology has undergone great advancements and is now a true staple in geographical and environmental research. These data are quite practical because they allow the gathering of information about the environment from a distance without ever having to come in contact with it over huge areas simultaneously. This enables researchers to approach problem resolution spatially from a greatly different perspective then they would otherwise with on-site data gathering. As a result remote sensing has a vast array of applications and for the purposes of this thesis, the focus was on the applications of remote sensing in coastal resources management. 
One of the most important functions of remote sensing within the coastal resources field has been the delineation and mapping of shoreline changes as well as the tracing of beach erosion (USGS, 2013; Yang, 2009). This is due to the fact that it is much simpler, accurate, and cost effective to map shoreline changes through this tool rather than on site analyses which would be very timeconsuming and hence, costly (USGS, 2013; Yang, 2009). In addition, remote sensing is ideal for shoreline change studies because of the natural characteristics and interactions between land and water. All objects on the Earth's surface interact with the electromagnetic spectrum by means of reflection, absorption, or transmission of incoming solar radiation. These materials all have differing spectral signatures which allow for classifications to be made between surfaces (USGS, 2013). When mapping coastal changes the two most important earth features required; land (soil and vegetation) and water, have vastly dissimilar spectral signatures (Figure 11) and are thus very easily distinguished one from another (Bulman, 2000). This allows for relatively simple delineation of the land-water interface which can subsequently serve to quantify the amount of coastal change taking place, if any (USGS, 2013).

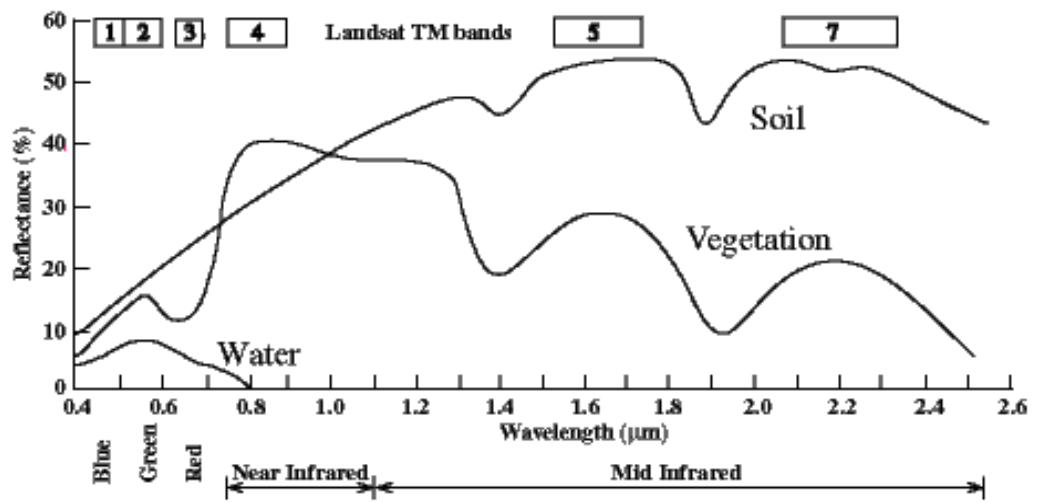

Figure 11. Electromagnetic Spectrum Showing Reflectance for Major Land Cover Types and the Bands used for Landsat TM (Bulman, 2000)

Remote sensing researchers have therefore employed these natural characteristics of land and water to help discriminate them from each other as well as other earth surfaces in order to determine the area where these two meet, effectively forming the shoreline (Boak \& Turner, 2005). Since remote sensing sensors such as Landsat-5 and Landsat-8 are only able to detect given features in specific bands, the most important task is determining which band is best suited to absorb the information required. While multiple techniques have been explored throughout the years, band ratioing remains one of the most successful. This method, which is discussed further subsequently, utilises current knowledge of spectral reflectance to determine the extent of the land-water interface. What is well known today is that the absorption of the infrared wavelength spectral region by water and its 
strong reflectance by vegetation and soil are the ideal combination for mapping the spatial distribution of land and water (DeWitt \& Weiwen Feng, 2002). Since 1972, the Landsat sensors have accumulated and provided digital imagery in infrared spectral bands which are ideal for defining the land-water interface (DeWitt \& Weiwen Feng, 2002). Shorelines can be extracted with very little information. In fact, they can be determined from a single band image since water has a reflectance close to zero in the reflective infrared bands and almost all other Earth surfaces have a reflectance greater than water (DeWitt \& Weiwen Feng, 2002). Of the six reflective TM bands of Landsat-5, the nearinfrared band 5 rationed against the green band 2 provide the best ratio for extracting clear shoreline extent (Kelley, et al., 1998). As previously mentioned, in the Landsat-8 program there were several new bands added which differed than those in the former version of the satellite (NASA, 2013). As a result, the ratio that had to be produced for the first set of images was no longer band 2 (green) divided by band 5 (NIR), but rather band 3 (green) divided by band 6 (Short-wave Infrared - SWIR) (USGS, 2013). The development of this ratioing technique as well as other procedures, has allowed remote sensing technology to be employed to measure shoreline locations.

\subsubsection{Landsat-5 TM \& Landsat-8: Resolutions}

When selecting which remote sensing instrument to employ, there are several components to consider most importantly, the sensor's four types of resolution. A sensor's imagery detail is entirely dependent on its spatial resolution and refers to the size of the smallest feature that can be distinguished (NRC, 2012). Landsat-5 and Landsat-8's 30 metre pixel spatial resolution (Tables 3 and 4) signifies that the smallest unit that maps to a single pixel in an image is roughly 30 metres by 30 metres (Lillesand et al., 2007). Unfortunately for this thesis, it signifies that only shoreline changes greater than 30 metres in size can be accurately sensed. This does; however, also signify that only the major changes will be analysed which are the starkest indicators of true shoreline change.

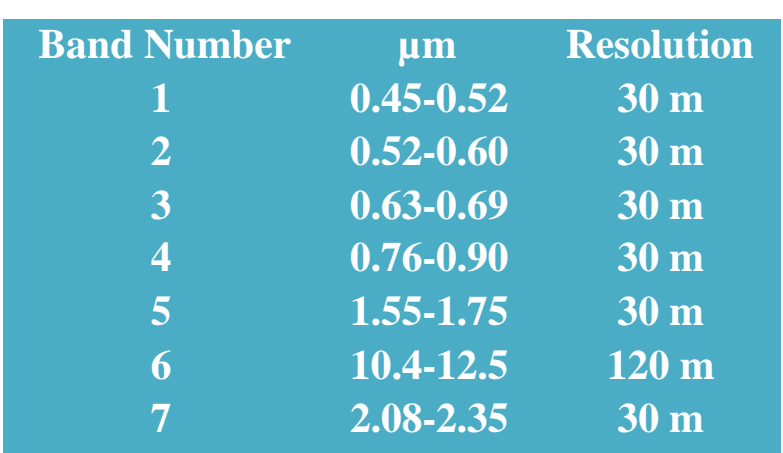

Table 3. Landsat-5 Band Details (NASA, 2014)

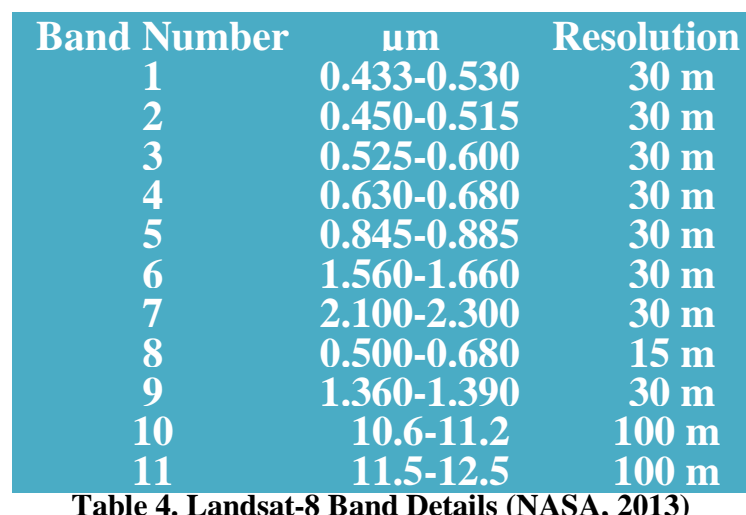

Table 4. Landsat-8 Band Details (NASA, 2013) 
Spectral resolution refers to the segments of the electromagnetic spectrum which can be measured or "sensed" by the sensor chosen (NRC, 2013). In other words it describes the ability of a sensor to sense fine wavelength intervals (NRC, 2013). The Landsat-5 thematic mapper has a sharper spectral separation (Table 3) and a spectral range from $0.45 \mu \mathrm{m}$ to $12.5 \mu \mathrm{m}$ (NASA, 2014). The Landsat-8 also has a sharp spectral separation and a nearly identical spectral range from $0.433 \mu \mathrm{m}$ to $12.5 \mu \mathrm{m}$ (NASA, 2013). In this thesis, spectral reflectance was not of very high importance because the only truly important earth features that had to be delineated in order to extract the shoreline were land and water.

Radiometric resolution describes a sensor's “ability to discriminate very slight differences in energy” (NRC, 2013). The Landsat-5 thematic mapper sensor uses 8 bits to record the data it gathers while Landsat-8 which possesses a 12 bit resolution (Lillesand et al., 2007). The fairly advanced and high radiometric resolution of Landsat-5 and Landsat-8 respectively, allows them to detect even small changes in radiometric magnitudes in any given band which in turn provides greater sensitivity to changes in relationships among bands (Lillesand et al., 2007). This also helped reduce errors in classifications, which is addressed in later sections of this thesis.

The fourth resolution -temporal resolution- is often of greatest importance in the satellite selection process. It refers to the frequency at which images are accumulated for a given area (NRC, 2011). In remote sensing, temporal resolution is imperative because shoreline changes can only be perceived and quantified by comparing the location of the coast at a given time and place to its location in succeeding years at the same site. Both, Landsat-5 and Landsat-8 satellites have a revisit time of 16 days, which means they will capture an image at a given location every 16 days which is quite suitable (NASA, 2014). While this project was not time sensitive considering the data was gathered several years ago, it was important to select images that were taken at roughly the same time, day, and month each five year (and one eight year) interval.

\subsubsection{Landsat-5 TM \& Landsat-8: Data Cost and Availability}

In 2008 the United States Geological Survey opened a Landsat archive at no charge through the Internet allowing for free data flow (USGS, 2012). Considering shoreline change was calculated over a 28 year span on a five year interval in this study, five images were required to extract the coastline. These scenes were obtained in April of 2012 and upon further investigation, two images were later acquired in July of 2013 to replace images too strongly hindered by cloud cover. A single Landsat-8 
image was also acquired in December of 2013 to ensure this thesis included the most recent imagery possible. Due to monetary constraints in this study, the USGS free Landsat archive was therefore the best option available.

\subsubsection{Change Detection Procedures}

The chief goal of this thesis is to locate and quantify shoreline changes at the regional scale of Tuktoyaktuk and the surrounding Mackenzie Delta, which can be more fundamentally summed up as undertaking change detection. Change detection "involves the use of multitemporal data sets do discriminate areas of land cover change between dates of imaging” (Lillesand et al., 2007). In order to ensure consistency, change detection should ideally involve data acquired at the same time of day, by the same sensor, and recorded using identical spatial, spectral, radiometric, and temporal resolutions (Lillesand et al., 2007). There are several change detection procedures available including: postclassification comparison, classification of multitemporal data sets, principal components analysis, temporal image differencing, temporal image ratioing, change vector analysis, change-versus-nochange binary mask to guide multidate classification (Lillesand et al., 2007). It was determined that a post-classification comparison combined with an image ratioing would be most ideal and was therefore carried out.

The post-classification comparison is undertaken by selecting two images captured on different dates then georectifying and classifying them independently. In this thesis, six images were selected, georectified, and independently classified. Once this is done, an algorithm was applied to compare the images pixel by pixel and identify pixels with a change in classification between the two dates (Lillesand et al., 2007). Statistics and change maps can be assembled to visually describe the nature of the changes from one image to the next. Evidently, this technique is strongly reliant on the accuracy of each initial independent classification, because errors present from the first phase are compounded throughout the process of multiplying their negative impact (Lillesand et al., 2007). Therefore, in order to increase the accuracy of the classifications, a band ratioing was undertaken. This

process involves dividing a measure of reflectance for pixels in one image band by those in a different band to enhance feature contrast (ESRI, 2014).

\subsubsection{Band Ratioing Technique}

Possessing a firm understanding of the basic principles of remote sensing was instrumental in this thesis. For instance, realising that the absorption of the infrared wavelength region by water and its 
strong reflectance by vegetation and soil, can assist in mapping the spatial distribution of land and water. Coastline can even be extracted from a single band image since the reflectance of water is nearly equal to zero in reflective infrared bands and reflectance of the absolute majority of land covers is greater than water (DeWitt \& Weiwen Feng, 2002). Research has proven that the near-infrared band 5 rationed against the green band 2 are best suited for extracting the land-water interface because they exhibit a strong contrast between land and water features due to the high degree of absorption of near-infrared energy by water and strong reflectance of near-infrared by vegetation and natural features in this range (Kelley, et al., 1998). The histogram, of band 5 (Figure 12) visually represents this through a double peaked curve where the transition zone between land and water resides between the peaks (Chen, 2003). This transition zone can play an instrumental role in delineating the land from water prior to the classification process in order to improve the accuracy of this process. It is for this reason that a simple band ratio operation was carried out in the methodology for each true colour image. Ratio images are enhancements brought to the image as a result of a division of the digital numbers in one spectral band by the corresponding values in a second band (Lillesand et al., 2007). They are useful for discriminating understated spectral variations in a scene that are concealed by brightness variations (Lillesand et al., 2007).

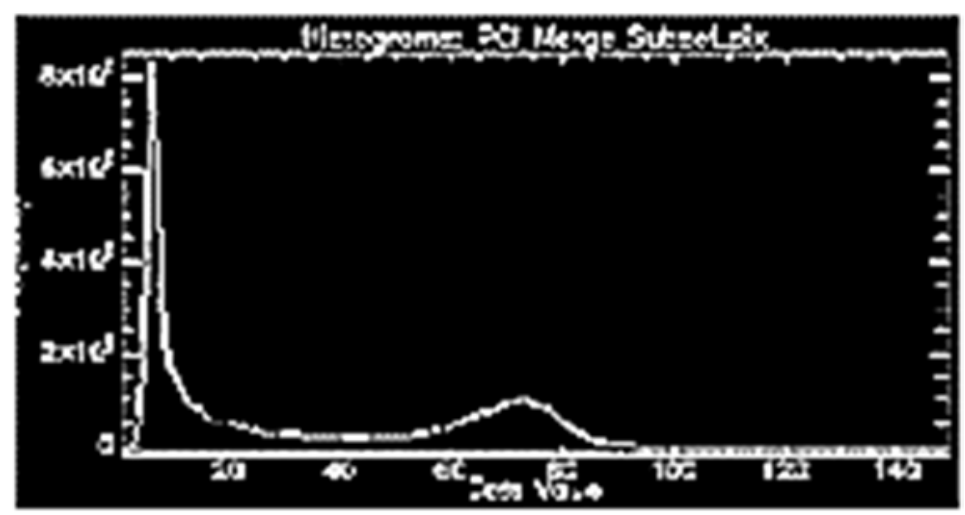

Figure 12. Histogram of the band 5 spectral curve (PCI, 2013)

\subsubsection{Classification Techniques}

Supervised and unsupervised classifications are prominent classification techniques and while they both have their own distinct benefits and drawbacks which were carefully weighed (Table 5), it was decided that a supervised classification would be most suitable here. It is carried out in three major steps (Figure 13). The first step involves locating specific sites in the remotely sensed data based on spectral responses that characterise homogeneous land cover types (Jensen, 2005). These regions are known as training sites because their unique spectral characteristics are used to 
“train” the classification algorithm to which it is later applied (Jensen, 2005). All pixels that fall within or outside the created training sites are then assessed and allocated to the class they have the greatest likelihood of belonging to which comprises the second step (Jensen, 2005). The final step is the output stage, when results are presented in the form of maps, tables, and GIS data files (Lillesand et al., 2007). The supervised classification process employed in this research is further detailed in the following chapter.

\section{Supervised}

- Pre-defined classes

- Serious classification errors detectable

- Defined classes may not match natural classes

- Classes based on information categories

- Selected training data may be inadequate

- A priori class training is time consuming and tedious

- Only pre-defined classes will be found

\section{Unsupervised}

- Unknown classes

- No classification errors

- Natural classes may not match desired classes

- Classes based on spectral properties

- Derived clusters may be unidentifiable

- A posteriori cluster identification is time consuming and tedious

- Unexpected categories may be revealed

Table 5. Supervised vs. Unsupervised Classifications (Atkinson, 2011)

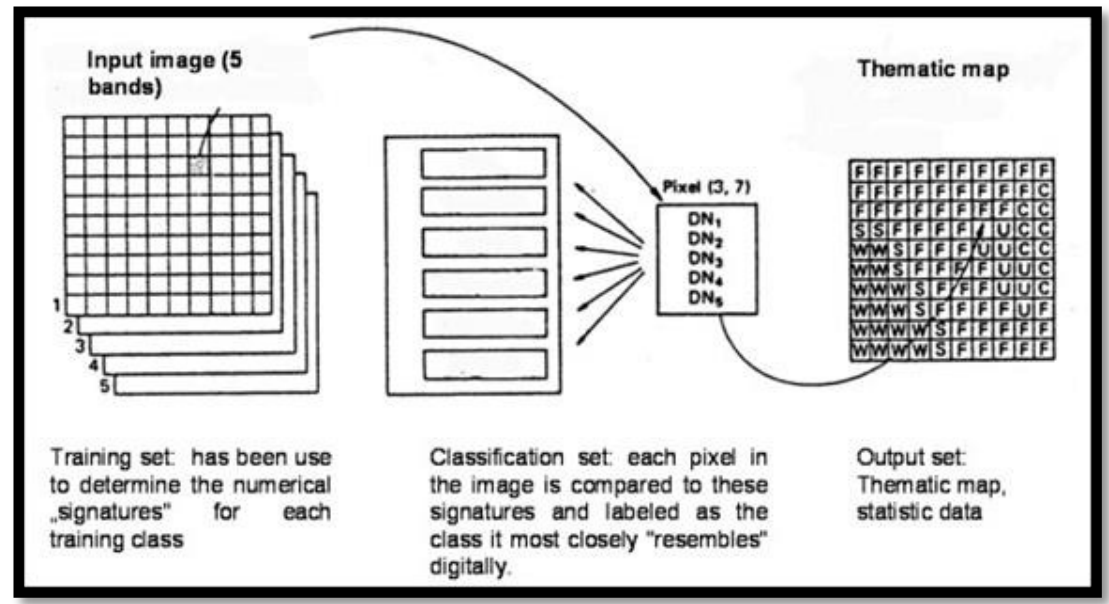

Figure 13. Basic supervised classification process (Malgorzata, 2010). 


\section{RESEARCH DESIGN AND METHODS}

This third chapter begins by describing the data collection logic followed in this thesis. It continues by enumerating the methods of data collection and processing operations undertaken which include the pre-processing, image classification, and post-classification phases. It ends by addressing the accuracy of some of the steps undertaken to ensure that rigid parameters are maintained throughout the research.

\subsection{Data Collection}

When structuring studies, there are several different methods of inquiry available to follow; however, the scientific method is widely recognised as the single most practical manner of conducting research in order to obtain verifiable information. It is arguably most successful when employing quantitative, measureable data and functions by asking and answering pertinent questions through observations and experiments. It is primarily for this reason that this particular thesis was designed and undertaken through a quantitative lens. Similarly to other remote sensing shoreline change studies, the present research did not require a lengthy data collection phase. The reason for this is that the satellite sensors employed automatically gathered the necessary information in the form of images which were required to produce the final change maps. However, much planning and thought was given in the images' selection and this affected the manner in which this research was conducted.

\subsubsection{Earth Explorer USGS}

It was decided that shoreline change would be best extracted by collecting Landsat images over a 28 year span dating from 1985 to 2013 at five year intervals. One 8 year interval was also carried out from 2005 to 2013 attributable to difficulties in acquiring reliable Landsat-5 and Landsat-7 imagery following equipment failures with both satellites (NASA, 2014; USGS, 2013). Therefore it was not until Landsat-8 was launched in 2013 that new dependable imagery was available (NASA, 2013). These images had to be captured geographically in the Tuktoyaktuk region according to the Worldwide Reference System (NASA, 2011). This was ensured by selecting images whose coordinates fell within the same or adjacent paths and rows (Table 6). It was also essential to only select imagery captured during the three to four months (June to mid-October) of open-water season (Lantuit et al., 2011). The next step was to filter the search to strictly include

images with less than $10 \%$ cloud cover to reduce noise and potential erroneous classification in 
later steps. Only the sixth and final image captured by Landsat- 8 had more cloud cover than anticipated at, 13\%; however, this was the best image available during this chosen time frame (Table 6).

\begin{tabular}{ccccccc} 
Image & Satellite & $\begin{array}{c}\text { Landsat Scene Identifier } \\
\text { Path }\end{array}$ & $\begin{array}{c}\text { Row } \\
\text { Date }\end{array}$ & $\begin{array}{c}\text { Cloud } \\
\text { Acquired } \\
\text { Cover \% }\end{array}$ \\
\hline & Landsat-5 & LT50620111985219PAC13 & 62 & $\mathbf{1 1}$ & $\mathbf{1 9 8 5 / 0 8 / 0 7}$ & $\mathbf{0 \%}$ \\
3 & Landsat-5 & LT50620111990185PAC00 & $\mathbf{6 2}$ & $\mathbf{1 1}$ & $\mathbf{1 9 9 0 / 0 7 / 0 4}$ & $\mathbf{0 \%}$ \\
4 & Landsat-5 & LT50620111995183PAC00 & $\mathbf{6 2}$ & $\mathbf{1 1}$ & $\mathbf{1 9 9 5 / 0 7 / 0 2}$ & $\mathbf{0 \%}$ \\
5 & Landsat-5 & LE70620112000205PAC01 & $\mathbf{6 2}$ & $\mathbf{1 1}$ & $\mathbf{2 0 0 0 / 0 7 / 2 3}$ & $\mathbf{0 . 0 1 \%}$ \\
6 & Landsat-5 & LT50620112005226PAC01 & $\mathbf{6 2}$ & $\mathbf{1 1}$ & $\mathbf{2 0 0 5 / 0 8 / 1 4}$ & $\mathbf{0 . 0 1 \%}$ \\
& Landsat-8 & LC80640112013182LGN00 & $\mathbf{6 4}$ & $\mathbf{1 1}$ & $\mathbf{2 0 1 3 / 0 7 / 0 1}$ & $\mathbf{0 . 1 3 \%}$
\end{tabular}

\subsection{Image Pre-Processing}

Prior to manipulating and analysing remote sensing imagery, rectification and restoration procedures must be carried out on each image to extract specific information as well as correct the image data for distortions that inevitably occur during the image acquisition process (Lillesand et al., 2007). While the image pre-processing procedures can be very tedious and time consuming, they are crucial in the overall accuracy, reliability, and validity of any remote sensing project. This was especially true for this thesis since shoreline changes typically take place gradually so that even slight image distortions can be registered as coastal changes even if these are erroneous. In addition, due to the focus of this thesis being more specifically placed on shoreline changes in Tuktoyaktuk and its surrounding areas in the Mackenzie Delta, there was significant redundant data which served only to complicate or confuse the end results. Consequently, one of the tasks which was also completed on each image was the subsetting of each scene size to a more manageable dimension which would also serve to highlight the most pertinent data.

\subsubsection{Radiometric Correction}

Radiometric corrections are concerned with rectifying the data for sensor irregularities and unwanted sensor or atmospheric noise (NRC, 2013). This would help improve the accuracy of the supervised classification process which would in turn improve the shoreline change results. While there are manual methods of accomplishing this, they are tedious and time consuming. Fortunately, there are automated ways of achieving this in some software platforms hence radiometric correction was carried out to the top of atmosphere. This was done through a mathematical translation to convert the image into reflectance as opposed to strictly digital number, hence 
providing a more accurate reflectance value. Once these images were radiometrically corrected, the image pre- processing phase could then ensue.

\subsubsection{Subsetting}

In order to dispose of unnecessary data, the five Landsat-5 TM and one Landsat-8 scenes selected which each have a swath size of $170 \mathrm{~km}$ x $185 \mathrm{~km}$ (185 km x 185 km for the Landsat-8 image) were clipped, through a process termed subsetting. The clipping process reduced the scene size to a 2,500 x 2,500 pixel subset over the hamlet of Tuktoyaktuk (Figure 14). Considering the fact that the TM spectral bands used in this thesis have a spatial resolution of 30 metres, it was therefore possible to determine the true ground dimensions of the subset. A 30 metre resolution signifies that one pixel on the image represents an area of 30 metres by 30 metres on the ground; therefore the 2,500 x 2,500 pixel subset scene created represents (30 m x 2,500 pixels) $75 \mathrm{~km} \mathrm{x}$ $75 \mathrm{~km}$ on the ground. This area is large enough to capture the entire hamlet of Tuktoyaktuk, as well as surrounding land within the Mackenzie Delta in order to provide some perspective on the shoreline changes possibly experienced in other sites.

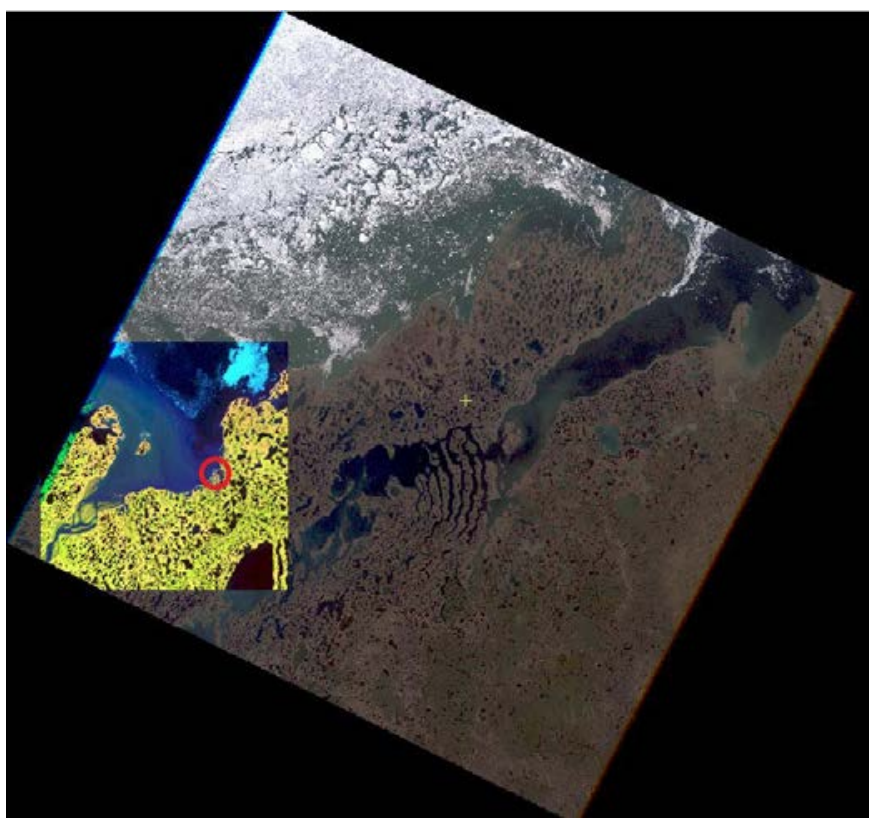

Figure 14. True colour composite of the entire Landsat-5 TM image captured in 1985 including false colour composite subset where Tuktoyaktuk is located (within red circle) and surrounding Mackenzie Delta region.

\subsubsection{Geometric Correction}

Due to the complex geometric relationship between the Earth's surface imaged, the sun, and the sensor employed, all remote sensing imagery is inherently exposed to some level of 
geometric distortion (NRC, 2013). These misrepresentations of real world data, if unaccounted for, can result in specious calculations. These can then lead to poor decisions that bring about property loss and even fatalities. In the case of shoreline loss, both of these outcomes are very possible which explains the importance of rectifying such errors prior to processing the images. Geometric corrections are intended to compensate for these anomalies and these were undertaken in this research by geometrically registering the images selected to a known ground coordinate system. Prior to beginning the geometric correction process, it was important to select the appropriate coordinate system and Datum information used in cartography to ensure accuracy. Word Geodetic System 1984, Universal Transverse Mercator zone 8 were selected because that is where Tuktoyaktuk is located. Geometric correction involved identifying a single base image's coordinates (i.e. its row and column) for several discernible points - referred to as ground control points (GCPs) - and matching them to their location on the other five images (NRC, 2013). This process is known as image-to-image rectification (NRC, 2013). The main challenge here was that there were very few manmade features in Tuktoyaktuk or its vicinity to select as unambiguous ground control points and consequently, physical features such as lakes were therefore relied on.

Once a point was selected on the initial image, and a matching point was located on the image which was being corrected, it would be accepted. Many points had to be repositioned several times in this tedious procedure due to their elevated residual value calculated as the root-meansquare (RMS). It was decided that a minimum of 20 GCPs with a total RMS of less than 15 metres for both the $\mathrm{X}$ and $\mathrm{Y}$ coordinates would be necessary to ensure that the images align well because misalignment could possibly be picked up as change (Table 7).

$\begin{array}{cccc}\text { Image } & \text { X-RMS } & \text { Y-RMS } & \text { RMS } \\ 1 & \mathbf{0 . 1 3} & \mathbf{0 . 1 5} & \mathbf{0 . 2 0} \\ 2 & \mathbf{0 . 1 5} & \mathbf{0 . 1 5} & \mathbf{0 . 2 2} \\ 3 & \mathbf{0 . 1 5} & \mathbf{0 . 1 5} & \mathbf{0 . 2 2} \\ 4 & \mathbf{0 . 1 5} & \mathbf{0 . 1 5} & \mathbf{0 . 2 1} \\ 5 & \mathbf{0 . 1 5} & \mathbf{0 . 1 4} & \mathbf{0 . 2 1} \\ 6 & \mathbf{0 . 1 4} & \mathbf{0 . 0 5} & \mathbf{0 . 1 5}\end{array}$

Table 7. RMS Values for Ground Control Points in each image

\subsection{Image Classification}

Image classification and analysis techniques are employed to recognise and classify pixels in the data (NRC, 2013). It is a crucial phase of this research and during this process, each pixel in an image is allocated to a given class based on statistical characteristics of the pixel brightness 
values (NRC, 2013). Classification can be undertaken through a multitude of techniques; however, the two most widespread approaches are supervised and unsupervised classifications (NRC, 2013). In order to improve the accuracy of these approaches which would in turn improve the accuracy of the shoreline changes detected, the previously described band ratioing image transformation technique was also employed. Once the classification was completed, accuracy statistics were produced to ensure the process was accomplished successfully according to scientific standard.

\subsubsection{Band Ratioing}

For the purposes of delineating the shoreline extent, band ratioing was undertaken in which following these expressions:

$$
\begin{gathered}
\text { Landsat-5 Images: (Green) } \div \text { (Near-infrared) } \\
\text { and; } \\
\text { Landsat-8 Image: (Green) } \div(\text { Short-wave infrared) }
\end{gathered}
$$

These expressions revealed the spectral differences between the two contrasting bands in each image to further enhance their delineation. Following this step, the six initial true colour images were transformed into binary panchromatic images displayed in grey tones scale ranging from black (digital number of 0 ) to white (highest value available). The binary panchromatic images included a single band which clearly highlighted the shoreline transition line also known as the land-water interface. The lower values depicted water while the higher values represented land. This band ratioing process reduced noise and additional information which improved the accuracy of the classification undertaken in the subsequent phase of the thesis because the less information that is included in the classification, the less complex it is.

\subsubsection{Supervised Classification}

For the purposes of this thesis, a supervised classification (Figure 13) was carried out. Training sites and sets were created; the former is an individual outline drawn on an image, and the latter is the collection of training sites drawn for a given feature (Piwowar, 2009). Considering that this thesis's parameters strictly include defining the land-water interface, the only land cover types that were of interest were evidently land and water. In order not to misrepresent or erroneously classify some areas of unnecessary data such as ice or cloud cover, a "no data" land cover class was also required. As is explained later, a fourth class titled "NULL class" was automatically generated due to the classification algorithm that was selected. The 
final four classes that were selected for the supervised classification phase were numbered 0 through 4 and represented: no data, water, land, and null. One by one for each of these classes, the classification process involved drawing polygons (i.e. training sites) on the binary panchromatic images that would capture areas of similar spectral information which represented the three classes sought (i.e. training sets). It was important to be meticulous when drawing polygons in order to avoid the inclusion of extraneous pixels that did not belong to that feature (Piwowar, 2009). When conducting the classification it is also important to check and compare training sites in search of spectral overlap because overlap within classes can cause problems in classifying. By running the spectral signature for separability measures it can be confidently stated that all classes are separable. Once these steps are completed for the water, land, and no data training sets, the following step is the selection of a classifying algorithm.

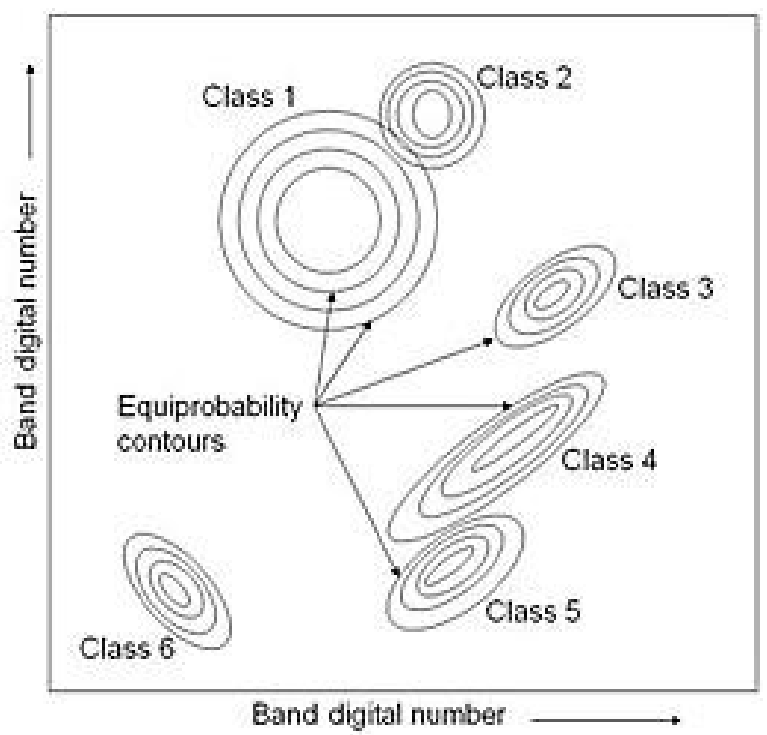

Figure 15. Probability Density Functions Defined by a Maximum Likelihood Classifier (Lillesand et al., 2007)

The unique spectral characteristics of each training site created were used to "train" the classification algorithm that is applied during the classification process (Jensen, 2005). There are several different algorithms such as the: minimum-distance-to-means classifier, parallelepiped classifier, Gaussian maximum likelihood classifier available and each serves to classify images; however, through differing approaches (Lillesand et al., 2007). For many types of image data, a Gaussian maximum likelihood classifier with a null class often results in a satisfactory classification (Piwowar, 2009). Fortunately for the purposes of this study, this technique was also the best suited because it quantitatively assesses both the variance and covariance of each training sets' spectral response patterns (Figure 15) while classifying unknown pixels (Lillesand 
et al., 2007). However in order to do so, a major assumption is made that the distribution of points forming each training set is Gaussian, that is to say, normally distributed (Lillesand et al., 2007). This assumption is largely reasonable for common spectral response distributions such as those employed for this research and considering these parameters, the statistical probability of a given pixel value belonging to one of the three determined land cover class can be accurately calculated (Lillesand et al., 2007). This classifier forces the algorithm to limit its extents to the threshold values defined during the training stage which keeps pixels that do not closely resemble any of the three training sets selected prior, unclassified (Piwowar, 2009). These will appear blank on the classified image. Failing to include a null class, will result in the procedure assigning each pixel to a class as it was statistically predetermined by the algorithm irrespective of how accurate this assignment may be (Piwowar, 2009). At this phase, the classification was finally run for each image and several iterations were undertaken to improve the classifications' overall accuracy.

\subsubsection{Signature Separability}

As previously mentioned, during the many iterations of the supervised classification process and prior to the output of the final classification, it is imperative that the data in each image's training site are verified for spectral overlap. In this thesis, six signature separability reports were produced to ensure that each image was classified with as much accuracy as possible (See Appendix A). There are multiple separability measures available including: Bi- and TriSpectral Plots, Divergence, Bhattacharya (B) Distance, Euclidean and Non-Euclidean Distances,

Kolmogorov-Smirnov Distance. Following careful consideration it was decided that the Bhattacharya (B) Distance would be most appropriate. This statistic represents an approximate measurement of the amount of overlap among two statistical samples (Comaniciu et al., 2000). This coefficient is calculated through a simple form of integration of the overlap between two samples (Comaniciu et al., 2000). The interval of the values between the two samples is separated into a predetermined number of dividers, and the number of members of both samples in each divider is employed in this formula:

$$
\text { Bhattacharyya }=\sum_{i=1}^{n} \sqrt{\left(\mathbf{\Sigma} \mathbf{a}_{i} \cdot \mathbf{\Sigma} \mathbf{b}_{i}\right)}
$$

(Comaniciu et al., 2000)

Where; considering the samples a and $\mathbf{b}, \mathbf{n}$ is the number of dividers, and $\mathbf{\Sigma} \mathbf{a}_{i}, \mathbf{\Sigma} \mathbf{b}_{i}$ are the number of members of samples $\mathbf{a}$ and $\mathbf{b}$ in the $\mathbf{i}$ 'th partition. Evidently, the formula is greater with 
each divider which has members of both samples, and also greater with each divider that has a significant overlap of both sample’s members within it (Comaniciu et al., 2000). Consequently, the Bhattacharya coefficient will be 0 where there is complete overlap, and 2 where there is none.

In image 1 of Tuktoyaktuk captured in 1985, the average separability was of 1.926 which is quite elevated hence indicating little overlap between each land cover class (See Appendix A for complete reports). This signifies that the land, water, and no data classes were very separable which improved the accuracy of this classification and ultimately provided more precise shoreline changes. In image 2 captured in 1990, the average separability was of 1.635. In this second image, there is considerable overlap of the no data and water classes represented by a low separability of only 0.949. This is explained by the similar low spectral signature of both of these classes. In image 3 captured in 1995, the average separability was of 1.641 which is also nearing 2 and hence represents fairly separable classes. The figure for image 4 taken in 2000 was of 1.412 which was satisfactory; however, lower than expected. Despite the perfect separability of land and water (which is most important), the no data and land classes had significant overlap at 0.240 which reduced the overall average separability. This issue was later addressed and accounted for during the reclassification stage which is subsequently explained. The average separability in image 5 captured in 2005 was of 1.818 which is a very strong Bhattacharya coefficient despite a noticeable overlap between the no data and water classes at 1.454. In the sixth and final image captured by Landsat-8 in 2013, the average separability between all classes was of 2.000 which signifies that the classes were all perfectly separable. All of the images selected for this thesis were therefore very appropriate because the classes created to extract shoreline change were mostly devoid of spectral overlap particularly between land and water. Considering that the main image classification steps were carried out successfully, the post processing stage of this thesis could then be initiated.

\subsection{Image Post-Classification}

Once the classification process was completed and verified for accuracy, the following stage was the image post-classification which would derive the shoreline changes sought. This phase evidently encompasses the crux of this thesis and it is here that the most important results were obtained. In order to truly define the extent of the land-water interface and extract the required shoreline location, several time consuming steps were undertaken. This involved the transition from remote sensing to geographical analysis. 


\subsubsection{Raster to Vector Conversion}

There are two primary approaches (Figure 16) to representing the locational component of geographical information in most GISs: a raster (grid cell) or vector (polygon) format (Lillesand et al., 2007). According to the raster data approach, the location of geographic features is defined by "the row and column positions of the cells they occupy" (Lillesand et al., 2007). The value stored in each cell denotes the type of feature that is found at that position for the entire cell (Lillesand et al., 2007). In the vector data model on the other hand, feature boundaries are converted into "straight-sided polygons that approximate the initial regions" (Lillesand et al., 2007). These polygons are created by establishing the coordinates of their vertices (referred to as intersections) that can then be joined to form arcs (Lillesand et al., 2007). Through the use of topological coding - a process that recalls which arcs share common nodes and which polygons are located to either side of a given arc - spatial operations such as overlay analysis and buffering can be streamlined (Lillesand et al., 2007). A vector model was preferred for this study primarily because they typically appear to have better spatial resolution than raster models which is essential for a shoreline change study considering changes can often be indiscernible at low spatial resolutions (Lillesand et al., 2007). In addition, vector models often have relatively lower data volumes and can preserve topological data relationships (Lillesand et al., 2007).

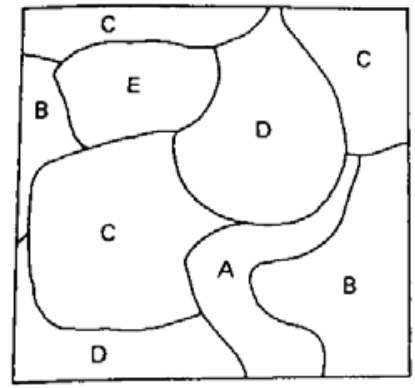

(a)

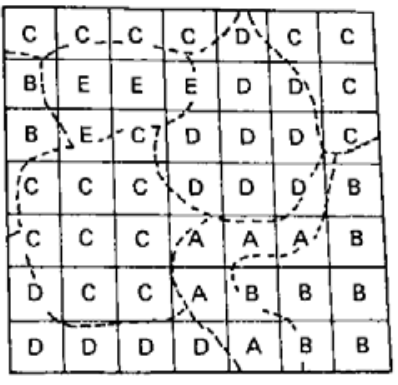

(b)

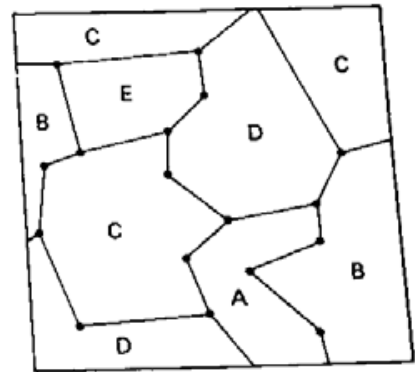

(c)

Figure 16. Raster versus Vector Data Formats: (a) map, (b) raster format, and (c) vector format (Lillesand et al., 2007)

As aforementioned, the images chosen were collected in a raster format as is the case with the majority of remote sensing imagery. While this expedites the inclusion of these images into raster-based GIS, this was not ideal for this research. Using a GIS tool, the classified raster images that were imported were then converted into polygon features. Following this translation all the point and line features became closed polygon features. Unfortunately, despite the fact that the data conversion did decrease the number of features, each image was still left with more than 130,000 polygons which was a very large number. This created a visually challenging classified 
image and in order to simplify the classification which would reveal the shoreline, a reclassification had to be undertaken. This would help reduce the images’ noise.

\subsubsection{Reclassification}

In the GIS, reclassification of the vectorised data was imperative to ensure accuracy as well as streamline the subsequent steps of the post-classification stage. The four classes that were created in the original classified images and numbered 0 through 4 representing: no data, water, land, and null classes would be further investigated using this procedure. To start, the water class (1) remained the same, while the land class (2) also maintained its classification of land. However, the null class (3) was reclassified to represent water (1) and the no data class (0) was reclassified to denote water (1). While these changes seem minor, they had a thorough impact on the images' classification. This was especially true of the fourth image captured in 2000 which had a lower average accuracy as mentioned earlier. This reclassification helped increase the initial accuracy.

\subsubsection{Map Overlay}

The final step in the image post-classification phase is the undertaking of a map overlay which is the main method of amalgamating data from two otherwise separate themes. Overlays are customarily employed when polygonal vectorised data are being manipulated and through a geometric intersection, a new layer containing the combined attributes of both preliminary layers is produced (ArcGIS, 2014). There are several different methods of completing an image overlay; however, in this thesis a map intersect was employed (Figure 17). The Intersect tool "computes a geometric joining of the output features. Features or portions of features which overlap in all layers and/or feature classes will be written to the output feature class” (ArcGIS, 2014). Intersect will also automatically determine the ideal spatial reference to be employed for all features during the image processing phase (ArcGIS, 2014). This tool will furthermore discern geometric relationships in the form of intersections between various features from every feature class and layer and will write these as point, line, or polygon features in the output (ArcGIS, 2014). 


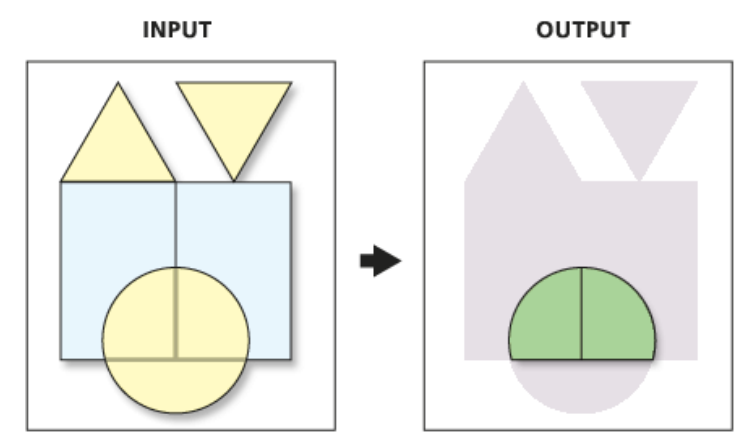

Figure 17. Intersection: polygon inputs and polygon output (ArcGIS, 2014)

There were 6 intersects carried out for this thesis. The first intersect had as input layer, image 1 and image 2 representing Tuktoyaktuk in 1985 and 1990 respectively. The second intersect was between the images captured in 1990 and 1995, the third was for images of 1995 and 2000, the fourth was between 2000 and 2005, and the fifth was carried out between 2005 and 2013. The final intersect was conducted from the very first image taken in 1985 and the last image of 2013 which allowed for an overall change analysis to be undertaken for the duration of this study. Through this procedure, only areas where input feature classes or layers intersect a polygon from the second input feature class or layer will be highlighted and consequently, the other areas are areas of change. These other areas are the regions of interest in this thesis because they represent shoreline changes whether erosion or deposition. 


\section{RESULTS}

This fourth chapter presents the study results according to the research questions that were enumerated in Section 1.6. It begins by describing the results of the supervised classification carried out as well as assessing its accuracy. It highlights the successes of this phase and addresses any anomalies discerned. This chapter then continues by quantifying the shoreline changes sought in a concrete and discrete manner prior to describing the temporal change vectors from each of the six main time periods. It ends with a presentation of the results of the change detection spanning the entire study period from 1985 to 2013.

\subsection{Classification Output}

Once a classification is completed, it is important to evaluate its results by analysing the classification report. This reveals what data is represented in each image and how they compare with the rest of the images which can in turn help provide a clearer idea of what land cover class is most prominent and which is not. It is important to note that when subsetting was undertaken in one of the very first phases of the methodology, the subsets created could not be perfectly identical for each image. While it was confirmed that Tuktoyaktuk and its surrounding region was observable in each image, the scenes are not identical. For instance, this signifies that if one of the original images was captured to the south of Tuktoyaktuk, it would include more land and if it was taken further north, it would include more of the Beaufort Sea, that is to say, water. While the subsets created attempted to reproduce the same area for each image, this was not a perfect process and could explain the slight variations in land cover classes. If the images were identical for each of the five year intervals, theoretically, any change in the land cover classes of water or land could be immediately interpreted as shoreline change; however, this is not so straightforward in application.

In the first image captured in 1985, the classification report (Table 8) indicates that of all of the pixels that comprise the image, 39.75\% represented water and 54\% land. The "no data” and "null” classes displayed low values and this is ideal because it signifies that the most relevant data (land and water) are present. Similar ratios were observed for each of the other five images classified as demonstrated throughout the classification report, excluding the fourth image. This fourth image is the only image which had a large proportion of water pixels compared to land pixels at $43.18 \%$ to $24.58 \%$ respectively. The primary reason for this is that there was a very 
significant classification of no data pixels at $32.22 \%$. This issue was previously noticed when the "no data" and "land" classes had significant Bhattacharya coefficient overlap at 0.240. By observing this final classification, it appeared that the Gaussian maximum likelihood classifier mistakably confused a significant amount of the "no data" class pixels with the "null" class which skewed the classification. This inconsistency was addressed and accounted for during the reclassification stage which was previously explained and essentially redefined the classes to more accurately represent the real world data.

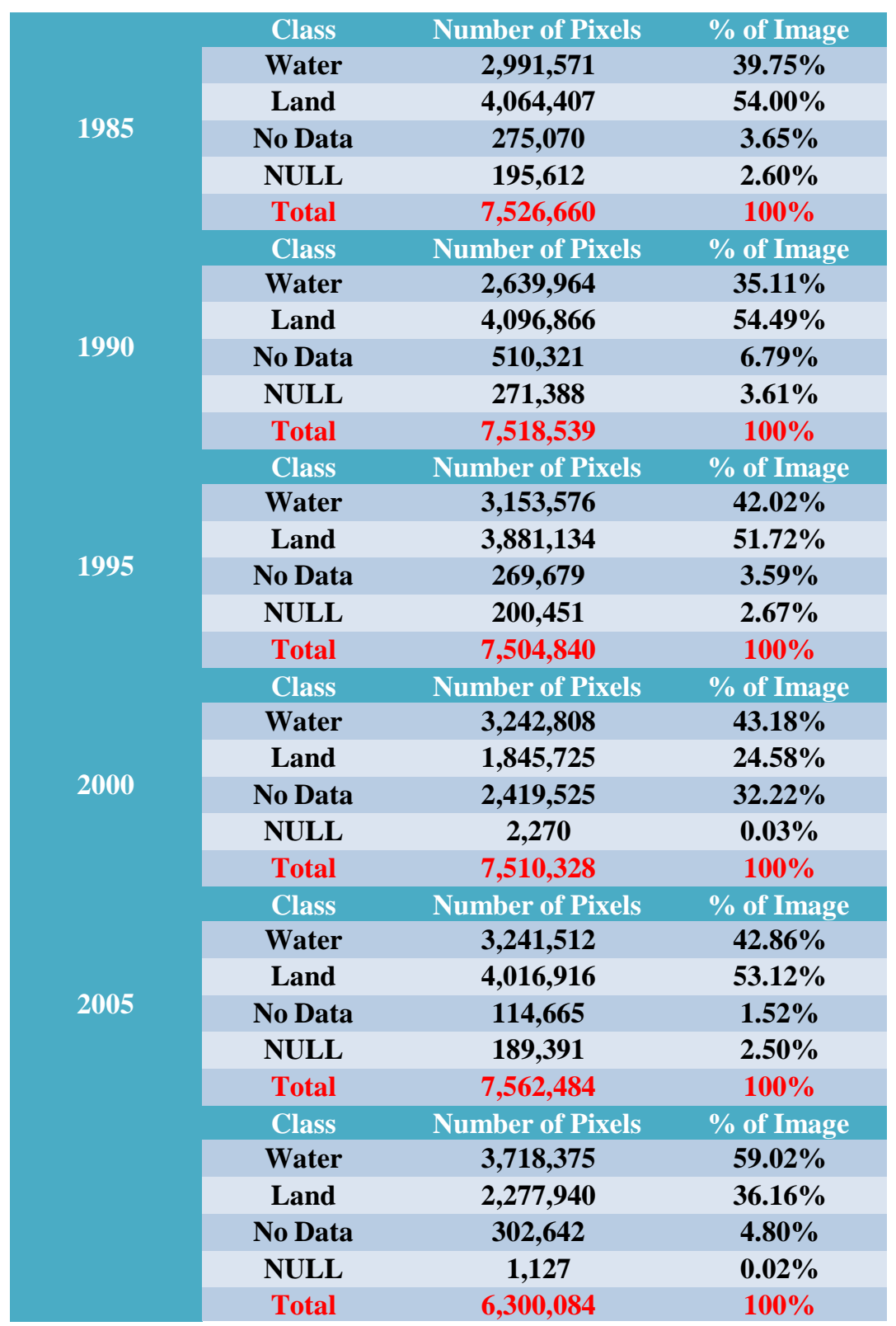

Table 8. Classification Report 


\subsection{Accuracy Assessment}

Once the supervised classification is completed, it is imperative that measures are taken to ensure that the results are accurate and indicative of the true land cover classes. Accuracy can therefore be defined as "the degree (only as a percentage) of correspondence between observation and reality” (Atkinson, 2011). Evidently, in order to investigate the accuracy of the supervised classification, this requires being aware of what reality is at some pixels through higher authority such as ground truthing (Atkinson, 2011). In this thesis, an accuracy assessment was undertaken by selecting sample points on the original reference image and these were compared to the classified image to ensure that they matched as closely as possible. In order to increase the reliability of this study, 60 sample points were selected for each image captured. These data were amalgamated into confusion matrices and their interpretation allowed for the supervised classifications’ accuracy to be established.

In the remote sensing field, the overall benchmark of $85 \%$ is held as the ideal figure for a classification to be considered accurate; however, this target is rarely achieved (Atkinson, 2011). Due to the importance of stating with confidence that shorelines are changing in Tuktoyaktuk, it was imperative that the highest possible classification accuracy be achieved. In the supervised classification of the first image of Tuktoyaktuk in 1985, the confusion matrix demonstrated that the classification was very successful since there was only one confirmed error. Excluding this error, the other 59 sample points were accurately classified for a sample accuracy of 98\%. In fact, all five other classifications had an unblemished sample accuracy of 100\%. This was confirmed in the accuracy assessment of the classification report (Table 9) for each classification carried out which all conveyed an overall accuracy greater than $90 \%$. Although the classification of the fourth image captured in 2000 displayed an overall accuracy of $98.29 \%$ which would be incredibly elevated, the average accuracy of this image was much lower than the others at merely $72.18 \%$. As previously mentioned, the fourth classification was skewed due to an error in classification; however, the reclassification which was undertaken at a later stage accounted for this anomaly to improve this fourth classification's accuracy. Considering that the overall accuracy of each classification was upheld to a high standard exceeding the $85 \%$ benchmark, the results of the subsequent change detection procedure can be confidently stated. 


$\begin{array}{ccc}\text { Image } & \text { Average Accuracy } & \text { Overall Accuracy } \\ 1 & \mathbf{9 9 . 1 9} \% & \mathbf{9 9 . 1 6} \% \\ 2 & 91.98 \% & 90.93 \% \\ 3 & 90.53 \% & 91.29 \% \\ 4 & 72.18 \% & 98.29 \% \\ 5 & 94.64 \% & 98.17 \% \\ 6 & 99.72 \% & 99.89 \%\end{array}$

Table 9. Accuracy Assessment Figures

\subsection{Results Parameters}

In order to simplify and streamline the description of the results, the specific parameters that were set and which guided this chapter had to be described. All the shoreline changes polygons were classified into four classes representing their temporal change vector; from land to water, water to land, land to land, or water to water. The only truly important polygons for this thesis were evidently the ones that represented an actual change from water to land or vice versa. This would display the nature of the change. Secondly, the quantification of the shoreline changes was carried out by calculating the total area for all polygons displaying changes. This was done for each image pairing representing the six time periods. Once this was completed, a threshold value needed to be established. This value allowed for less significant changes, or changes that could be attributed to a number of factors such as erroneous geo correction, misalignment, and overlay errors amongst many more to be overlooked. It was determined that the threshold value had to be greater than one pixel to account for possible human error during the image processing stages of the thesis, and lower than 5 pixels in order not to discount legitimate shoreline changes. The threshold value chosen was therefore of 4 pixels or $0.0036 \mathrm{~km}^{2}$ on the ground surface. This signified that any shoreline changes which fell between 0 to 4 pixels would be disregarded and attributed to potential errors. Changes greater than 4 pixels would on the other hand represent legitimate and significant shoreline changes. Every polygon representing shoreline change greater than $0.003601 \mathrm{~km}^{2}$ (4 pixels and above) was therefore included in the results, grouped, and classified into three classes based on area (Table 10). This would determine if they would represent minor, moderate, or extreme changes. This was carried out for each of the five time periods as well as the overall changes spanning the entire research period (1985 to 2013). Lastly, maps of each temporal change vector were produced and three regions of interest were selected through the application of $4 \mathrm{~km}$ buffers to better visually represent the changes observed in the data. Buffer number 3 represents the hamlet of Tuktoyaktuk more precisely. The other two buffers help display some of the changes taking place in the surrounding regions of the Mackenzie Delta. 


$\begin{array}{ccc}\text { Area Class } & \text { Pixel Range } & \text { Area Range }\left(\mathrm{km}^{2}\right) \\ \text { Extreme } & 34+ & \mathbf{0 . 0 3 2 4 1 3} \mathbf{~ k m}^{2}+ \\ \text { Moderate } & 12 \text { to } 33 & \mathbf{0 . 0 1 0 8 0 4} \mathbf{~ k m}^{2} \text { to } \mathbf{0 . 0 3 2 4 1 2} \mathbf{~ k m}^{2} \\ \text { Minor } & 4 \text { to } 11 & \mathbf{0 . 0 0 3 6 0 1} \mathbf{~ k m}^{2} \text { to } \mathbf{0 . 0 1 0 8 0 3} \mathbf{~ k m}^{2}\end{array}$

Table 10. Shoreline change classes based on area size

\subsubsection{Temporal Change Vector 1 (1985-1990)}

The first five year temporal change vector was composed of the overlay between the Landsat-5 image 1 captured of Tuktoyaktuk in 1985 and image 2 taken in 1990. By observing this resulting image (Figure 18) it was immediately evident that there was noticeable change between these two years. In this first temporal change vector, there were 133 total polygons of true interest (Table 11) since they fell above the threshold value of $0.003601 \mathrm{~km}^{2}$ on the ground which signified that they displayed significant shoreline changes much less likely attributable to processing errors. These polygons accounted for $22 \%$ of all shoreline changes (Figure 19 [A]) and represented a total land change area of deposition of $1.31 \mathrm{~km}^{2}$ (Table 12). Of these 133 total change polygons, 99 (74\%) were considered as having undergone minor changes, 25 (19\%) displayed moderate changes, and 9 (7\%) experienced extreme changes (Table 11 \& Figure 19 [B]). The most significant land change area class was that of minor changes (Table 12) which accounted for a shift of $0.55 \mathrm{~km}^{2}$, while the moderate class represented an area of $0.42 \mathrm{~km}^{2}$ followed by extreme changes which accounted for an area of $0.34 \mathrm{~km}^{2}$.

In this first temporal change vector, there were also 468 total polygons which underwent changes greater than the threshold chosen (Table 11), or more than $0.003601 \mathrm{~km}^{2}$ on the ground. These polygons accounted for $78 \%$ of all shoreline changes (Figure 19 [A]) and of these significant changes, 231 (49\%) experienced minor fluctuations, 138 (29\%) were moderate changes, and 99 (22\%) represented extreme changes which drew the most attention (Table 11 \& Figure 19 [C]). The minor changes spanned an area of $1.41 \mathrm{~km}^{2}$, the moderate changes totaled $2.34 \mathrm{~km}^{2}$, while the last class of extreme changes depicted a total change area of $9.16 \mathrm{~km}^{2}$ which is quite significant (Table 12). These polygons represented a total land change area of erosion of $12.91 \mathrm{~km}^{2}$.

By subtracting the total area change of the erosion polygons from the deposition polygons, the total remaining area is of $11.60 \mathrm{~km}^{2}$ which signifies that in this first temporal change vector there was a net loss of land from the sampled shorelines from 1985 to 1990 totaling over 11 square kilometres (Table 12). While there was some deposition or deposition taking place simultaneously, this was trivial in comparison to the amount of shoreline loss (Figure 20). The rate of deposition 
for this first temporal change vector was of $0.26 \mathrm{~km}^{2} /$ year while the rate of erosion was of 2.58 $\mathrm{km}^{2} /$ year (Table 13). 


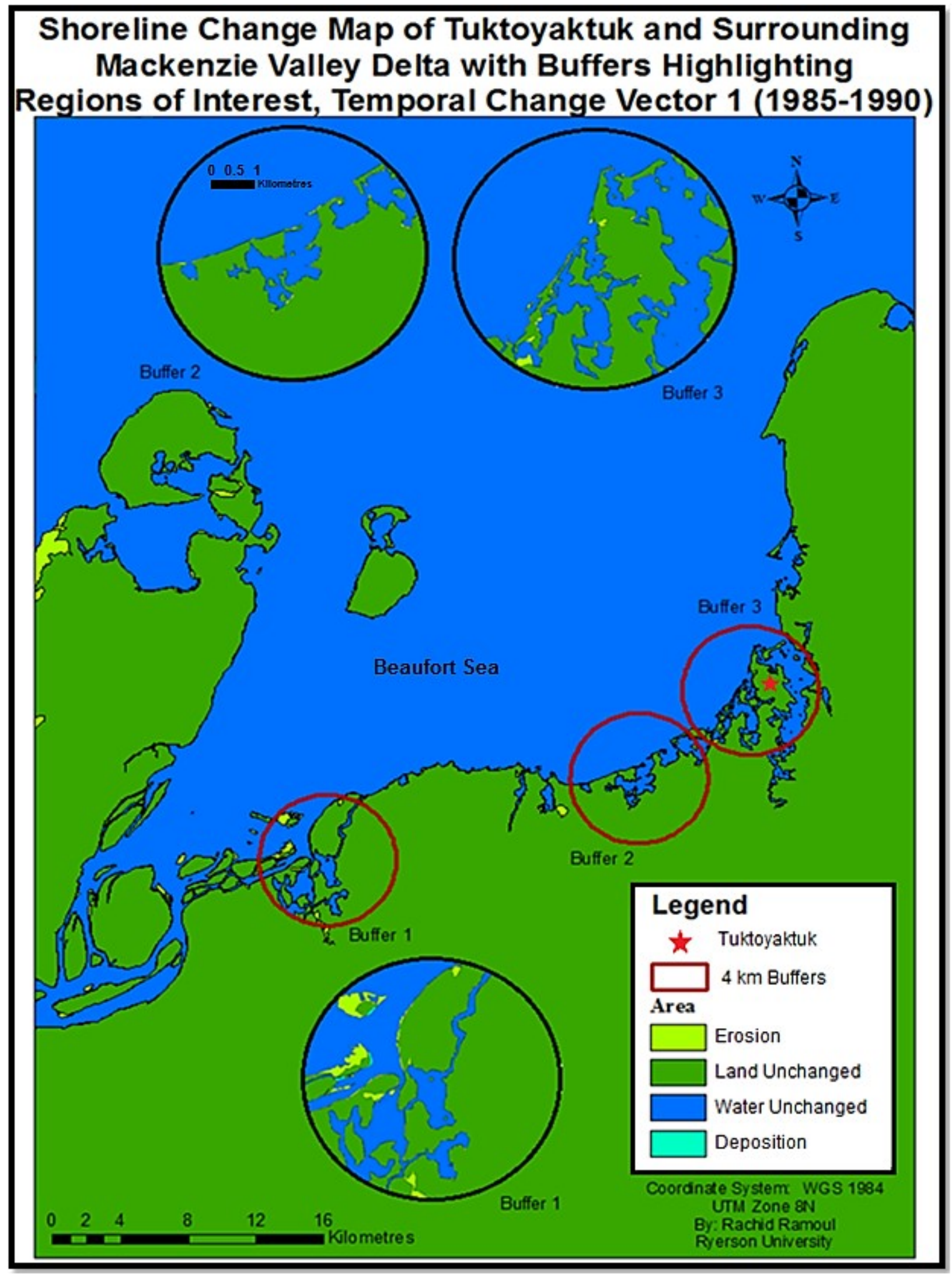

Figure 18. Shoreline change map of Tuktoyaktuk and surrounding Mackenzie Valley Delta with buffers highlighting regions of interest, temporal change vector 1 (1985-1990) 


$\begin{array}{ccc}\text { Area Class } & \text { Deposition } & \text { Erosion } \\ \text { Extreme } & \mathbf{9} & \mathbf{9 9} \\ \text { Moderate } & 25 & \mathbf{1 3 8} \\ \text { Minor } & \mathbf{9 9} & \mathbf{2 3 1} \\ \text { Total } & \mathbf{1 3 3} & \mathbf{4 6 8}\end{array}$

Table 11. Number of polygons in each area class which have undergone deposition or erosion in temporal change vector 1 (1985-1990)

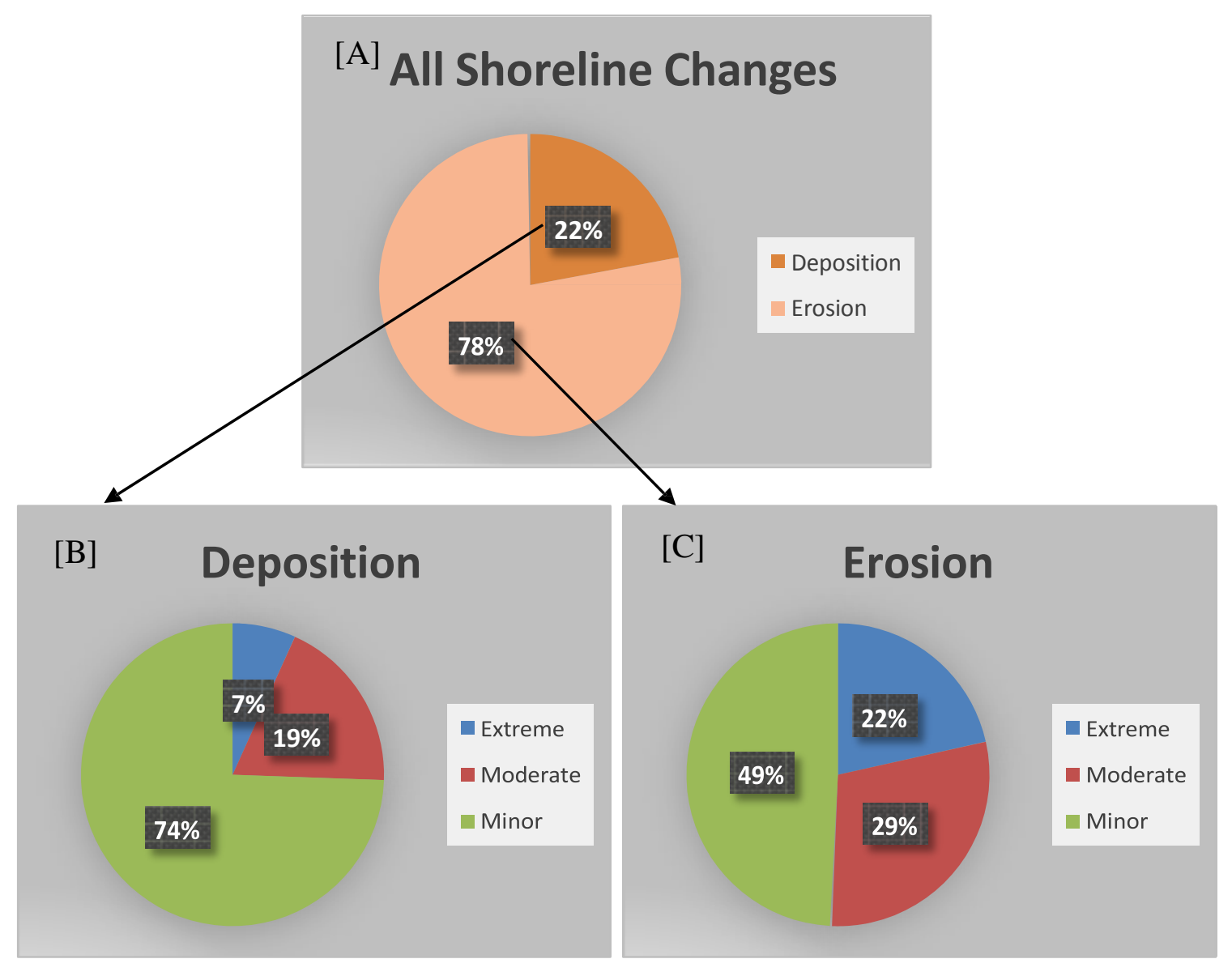

Figure 19. Percentage of all polygons which have undergone deposition or erosion [A]. Percentage of polygons in each area class which have undergone deposition $[B]$ and erosion $[C]$ in temporal change vector 1 (1985-1990) 


$\begin{array}{ccc}\text { Area Class } & \text { Deposition } & \text { Erosion } \\ \text { Extreme } & \mathbf{0 . 3 4} \mathbf{~ k m}^{2} & \mathbf{9 . 1 6} \mathbf{~ k m}^{2} \\ \text { Moderate } & \mathbf{0 . 4 2} \mathbf{~ k m}^{2} & \mathbf{2 . 3 4} \mathbf{~ k m}^{2} \\ \text { Minor } & \mathbf{0 . 5 5} \mathbf{~ k m}^{2} & \mathbf{1 . 4 1} \mathbf{~ k m}^{2} \\ \text { Total } & \mathbf{1 . 3 1} \mathbf{~ k m}^{2} & \mathbf{1 2 . 9 1} \mathbf{~ k m}^{\mathbf{2}}\end{array}$

Table 12. Area size of polygons in each area class that have undergone deposition or erosion in temporal change vector 1 (1985-1990)

\begin{tabular}{|c|c|c|}
\hline Total Rates & $\begin{array}{l}\text { Deposition } \\
0.26 \mathrm{~km}^{2} / \text { vear }\end{array}$ & $\begin{array}{l}\text { Erosion } \\
258 \mathrm{~km}^{2} / \text { vear }\end{array}$ \\
\hline
\end{tabular}

Table 13. Total rates of deposition and erosion in temporal change vector 1 (1985-1990)

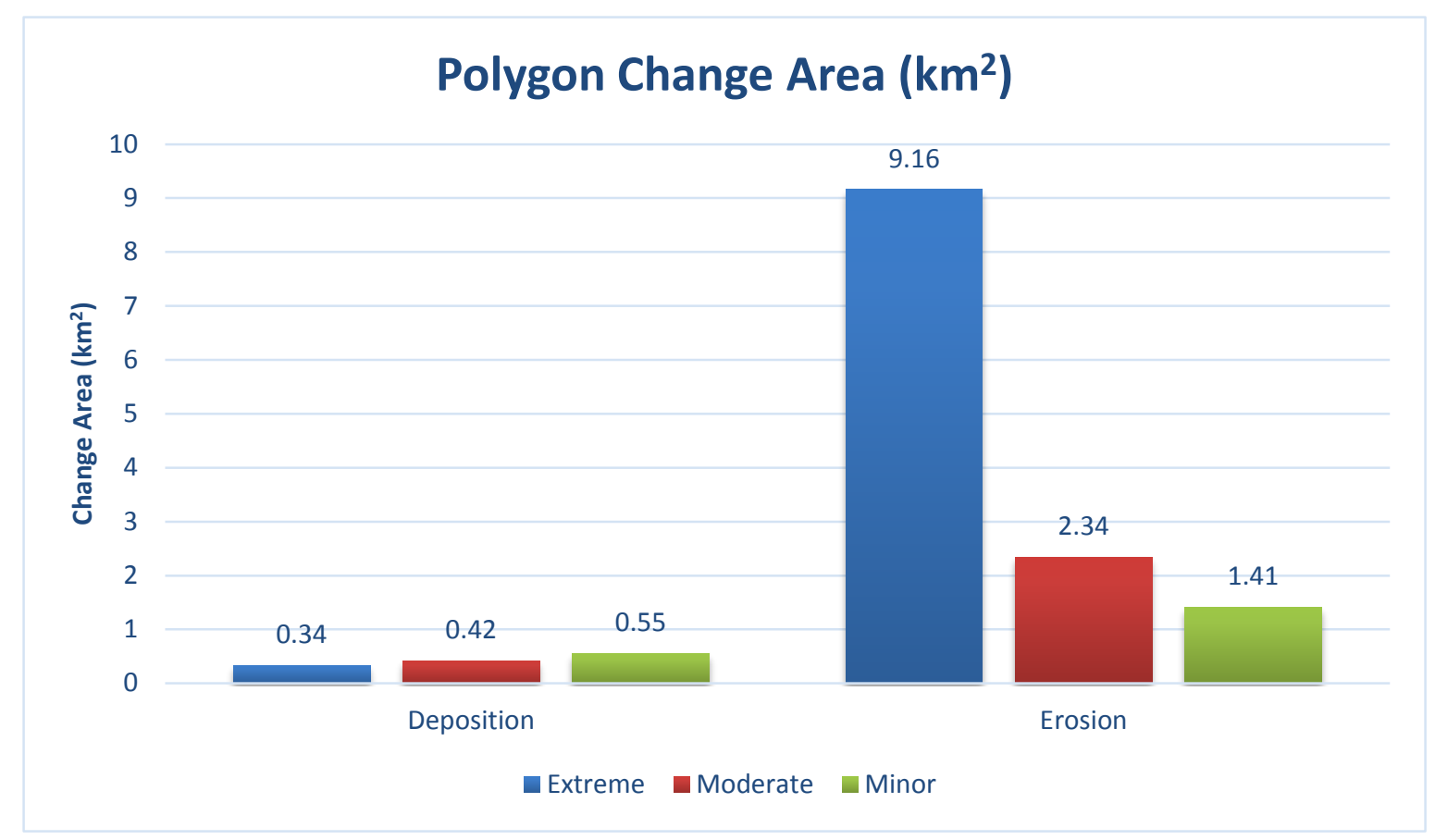

Figure 20. Bar graph displaying the total area size in each area class which have undergone deposition and erosion in temporal change vector 1 (1985-1990) 


\subsubsection{Temporal Change Vector 2 (1990-1995)}

In the second five year temporal change vector, an overlay between Landsat-5 image 2 of Tuktoyaktuk in 1990 and image 3 captured in 1995 was carried out. This overlay produced an image which displayed a different pattern than the first temporal change vector (Figure 21). In this second temporal change vector, there were 457 polygons which depicted deposition and were of significant interest since they represented areas on the ground greater than the threshold value (Table 14). These polygons accounted for $78 \%$ of all shoreline changes (Figure 22 [A]) and represented a total land change area of deposition of $14.62 \mathrm{~km}^{2}$ (Table 15). Of the 457 polygons which represented deposition (Table 14 \& Figure 22 [B]), 203 (44\%) underwent minor changes, 148 (32\%) displayed moderate changes, and 106 (24\%) represented extreme changes. The most significant land change area class was that of extreme changes which accounted for a shift of $10.85 \mathrm{~km}^{2}$, while the moderate class represented an area of $2.55 \mathrm{~km}^{2}$ followed by minor changes which accounted for a total area of $1.22 \mathrm{~km}^{2}$ (Table 15).

In this second temporal change vector, there were also 127 total polygons which underwent erosion greater than the threshold chosen (Table 14). These would therefore be less likely caused by errors or a flawed georectification but rather, by true shoreline loss. These polygons accounted for $22 \%$ of all shoreline changes (Figure 22 [A]) and of these, 84 (66\%) experienced minor fluctuations, 25 (20\%) displayed moderate changes, and 18 (14\%) represented extreme changes which were most alarming (Table 14, \& Figure 22 [C]). The minor changes spanned an area of $0.49 \mathrm{~km}^{2}$, the moderate changes totaled $0.46 \mathrm{~km}^{2}$, while the last class of extreme changes depicted a total change area of $0.77 \mathrm{~km}^{2}$ (Table 15). These polygons represented a total land change area of erosion of $1.72 \mathrm{~km}^{2}$.

In order to determine the total amount of change in this second temporal change vector, the total area of the deposition polygons was subtracted from the total area of the erosion polygons (Table 15) which resulted in a variation of $12.90 \mathrm{~km}^{2}$. Considering the amount of deposition was much greater than the extent of shoreline loss, the second temporal change vector from 1990 to 1995 displayed clear shoreline gain which is a stark contrast to the initial vector described previously (Figure 23). The rate of deposition for this second temporal change vector was of 2.92 $\mathrm{km}^{2} /$ year while the rate of erosion was of $0.34 \mathrm{~km}^{2} /$ year (Table 16). 


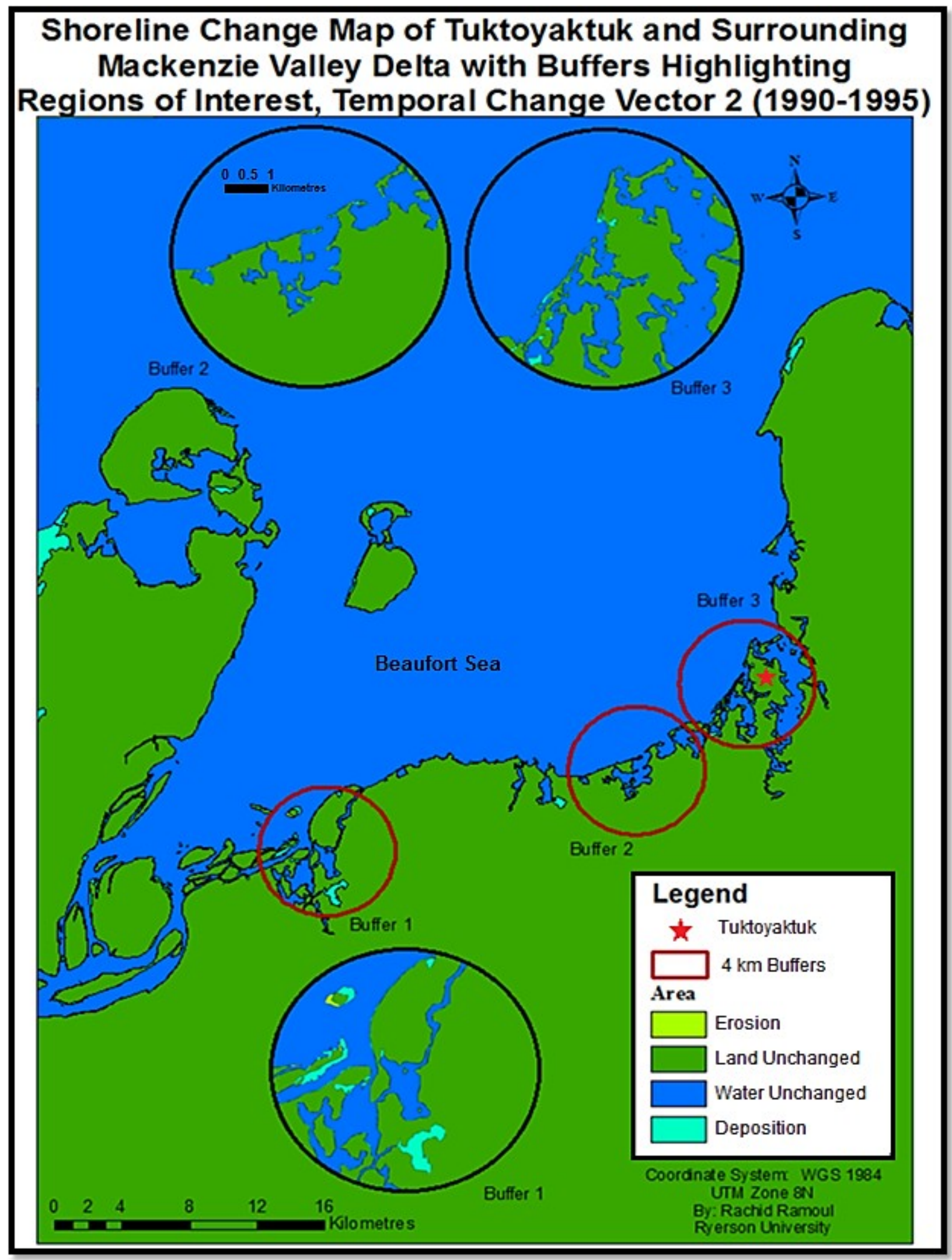

Figure 21. Shoreline change map of Tuktoyaktuk and surrounding Mackenzie Valley Delta with buffers highlighting regions of interest, temporal change vector 2 (1990-1995) 


\begin{tabular}{c|cc} 
Area Class & Deposition & Erosion \\
Extreme & $\mathbf{1 0 6}$ & $\mathbf{1 8}$ \\
Moderate & $\mathbf{1 4 8}$ & $\mathbf{2 5}$ \\
Minor & $\mathbf{2 0 3}$ & $\mathbf{8 4}$ \\
Total & $\mathbf{4 5 7}$ & $\mathbf{1 2 7}$
\end{tabular}

Table 14. Number of polygons in each area class which have undergone deposition or erosion in temporal change vector 2 (1990-1995)

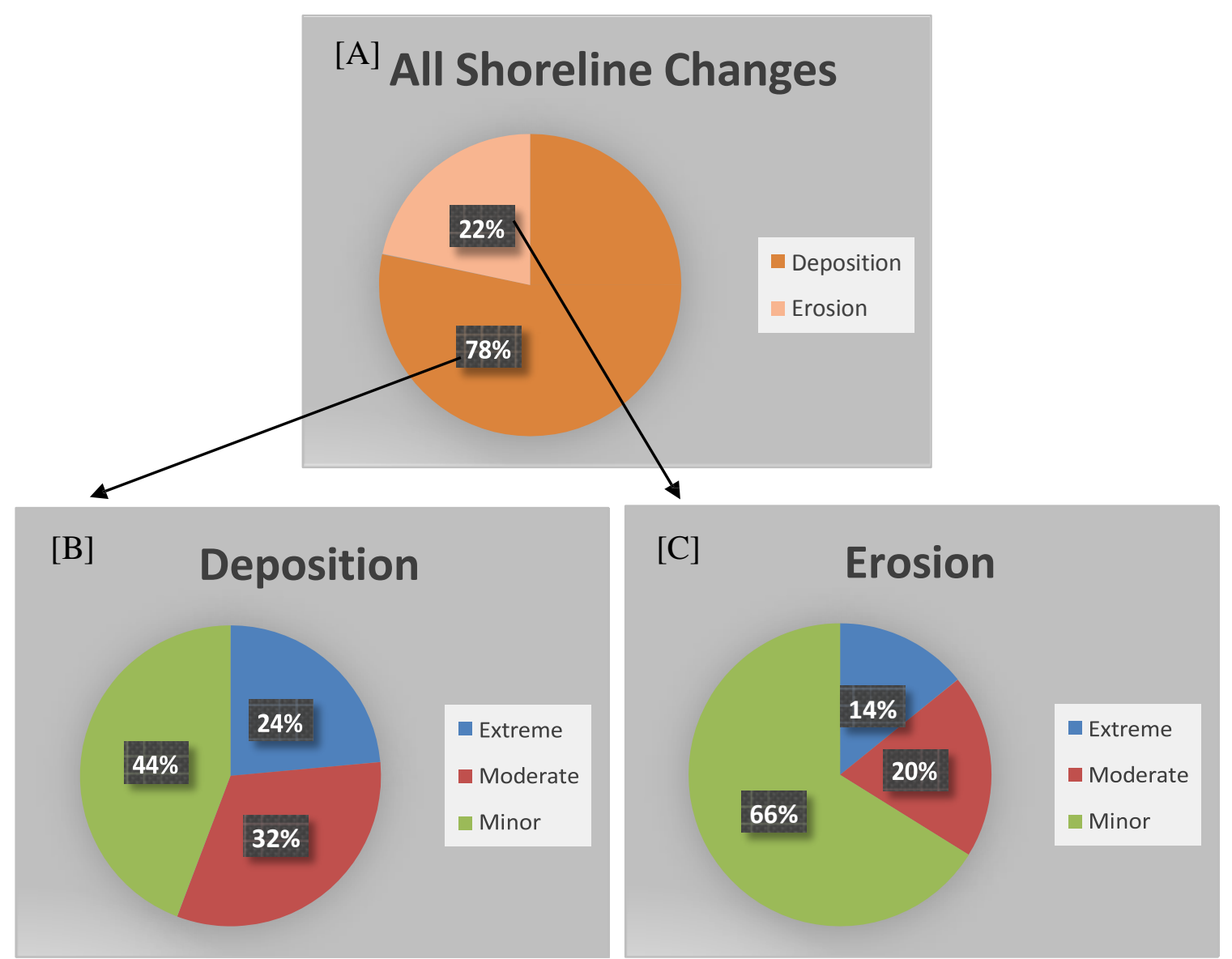

Figure 22. Percentage of all polygons which have undergone deposition or erosion [A]. Percentage of polygons in each area class which have undergone deposition $[B]$ and erosion $[C]$ in temporal change vector 2 (1990-1995) 


\begin{tabular}{|c|c|c|}
\hline Area Class & Deposition & Erosion \\
\hline Extreme & $10.85 \mathrm{~km}^{2}$ & $0.77 \mathrm{~km}^{2}$ \\
\hline Moderate & $2.55 \mathrm{~km}^{2}$ & $0.46 \mathrm{~km}^{2}$ \\
\hline Minor & $1.22 \mathrm{~km}^{2}$ & $0.49 \mathrm{~km}^{2}$ \\
\hline Total & $14.62 \mathrm{~km}^{2}$ & $1.72 \mathrm{~km}^{2}$ \\
\hline
\end{tabular}

Table 15. Area size of polygons in each area class which have undergone deposition or erosion in temporal change vector 2 (1990-1995)

$\begin{array}{ccc} & \text { Deposition } & \text { Erosion } \\ \text { Total Rates } & 2.92 \mathbf{~ k m}^{2} / \text { year } & 0.34 \mathbf{~ k m}^{2} / \text { year }\end{array}$

Table 16. Total rates of deposition and erosion in temporal change vector 2 (1990-1995)

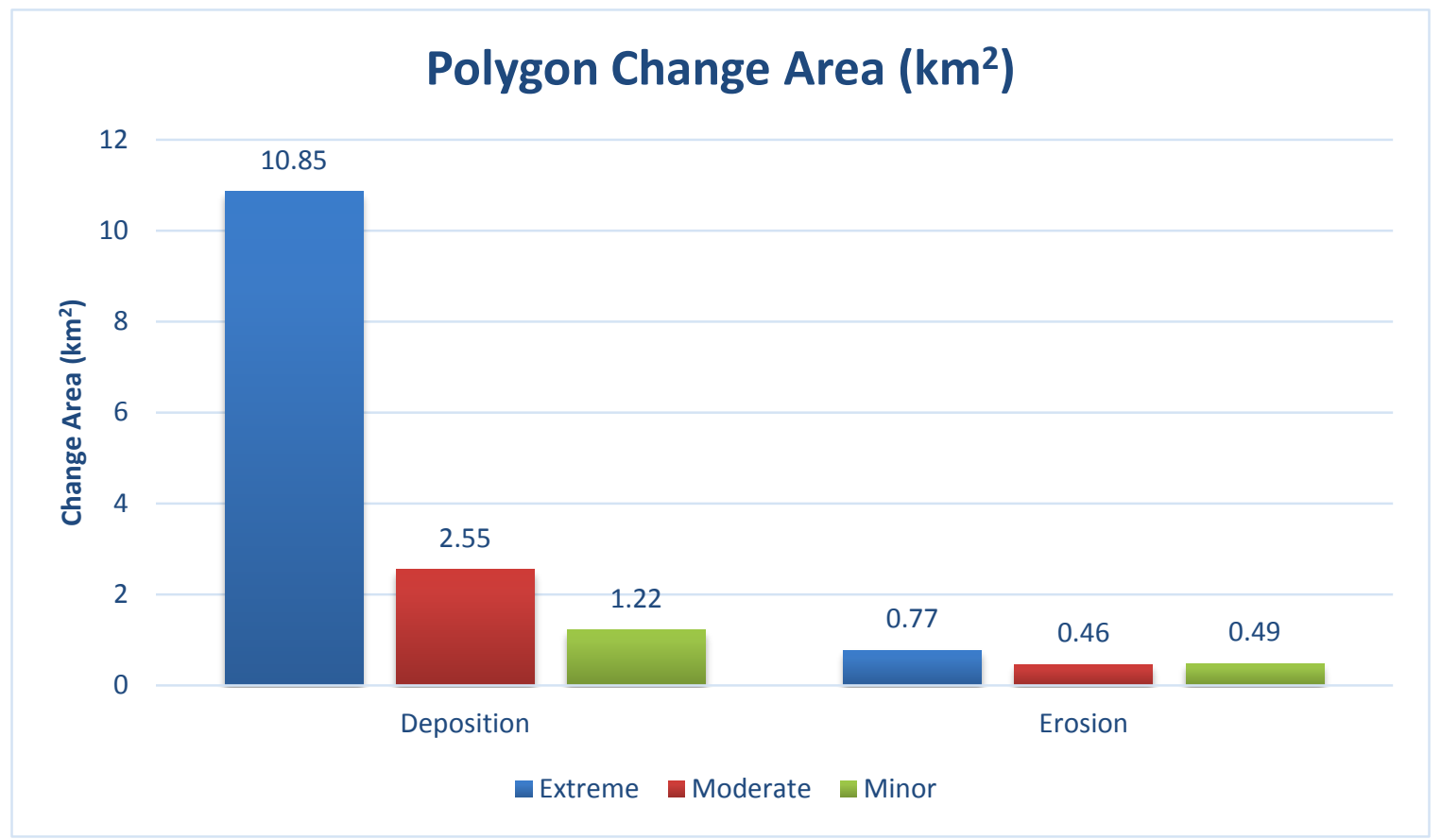

Figure 23. Bar graph displaying the total area size in each area class which have undergone deposition and erosion in temporal change vector 2 (1990-1995) 


\subsubsection{Temporal Change Vector 3 (1995-2000)}

In the third temporal change vector, an overlay was undertaken by intersecting Landsat-5 image 3 of Tuktoyaktuk in 1995 with image 4 taken in 2000. This formed an image which was discernibly dissimilar to the second temporal change vector; however, much more comparable to the first (Figure 24). In this third temporal change vector, there were 79 polygons representing areas on the ground greater than the threshold value selected which underwent deposition (Table 17). Since these polygons fell above the threshold chosen, they were more likely caused by true deposition. These polygons accounted for $16 \%$ of all shoreline changes (Figure 25 [A]) and represented a total deposition area of $1.62 \mathrm{~km}^{2}$ (Table 18). Of the 79 polygons which displayed characteristics of deposition, 63 (80\%) underwent minor changes, 11 (14\%) displayed moderate changes, and 5 (6\%) represented extreme changes (Table 17 \& Figure 25 [B]). The most significant land change area class was that of extreme changes (Table 18) which accounted for a shift of $1.08 \mathrm{~km}^{2}$, while the moderate class represented an area of change of only $0.19 \mathrm{~km}^{2}$ followed by minor changes which accounted for a total area of $0.35 \mathrm{~km}^{2}$.

In this third temporal change vector, there were also 426 total polygons (Table 17) which demonstrated shoreline loss or erosion greater than the threshold chosen. These 426 polygons falling above the threshold were chosen for the analysis since they covered larger, more statistically substantial areas of $0.003601 \mathrm{~km}^{2}$ or more. These polygons accounted for $78 \%$ of all shoreline changes (Figure 25 [A]) and of them, 171 (40\%) experienced minor fluctuations, 123 (28\%) displayed moderate changes, and 132 (32\%) represented extreme changes most probably indicative of shoreline loss (Table 17 \& Figure 25 [C]). The minor changes covered an area of $1.05 \mathrm{~km}^{2}$, the moderate changes spanned $2.11 \mathrm{~km}^{2}$, while the extreme changes depicted a total change area of $18.88 \mathrm{~km}^{2}$ (Table 18). These polygons represented a total land change area of erosion of an extensive $22.04 \mathrm{~km}^{2}$.

The total change area for the third temporal change vector was calculated by subtracting the total area change of the erosion polygons from the deposition polygons which resulted in an area of $20.42 \mathrm{~km}^{2}$. This signifies that from 1995 to 2000, there was a net loss of shoreline of more than 20 square kilometres which is evidently quite noteworthy (Table 18 \& Figure 26). The rate of deposition for this third temporal change vector was of $0.32 \mathrm{~km}^{2} /$ year while the rate of erosion was of $4.41 \mathrm{~km}^{2} /$ year (Table 19). 


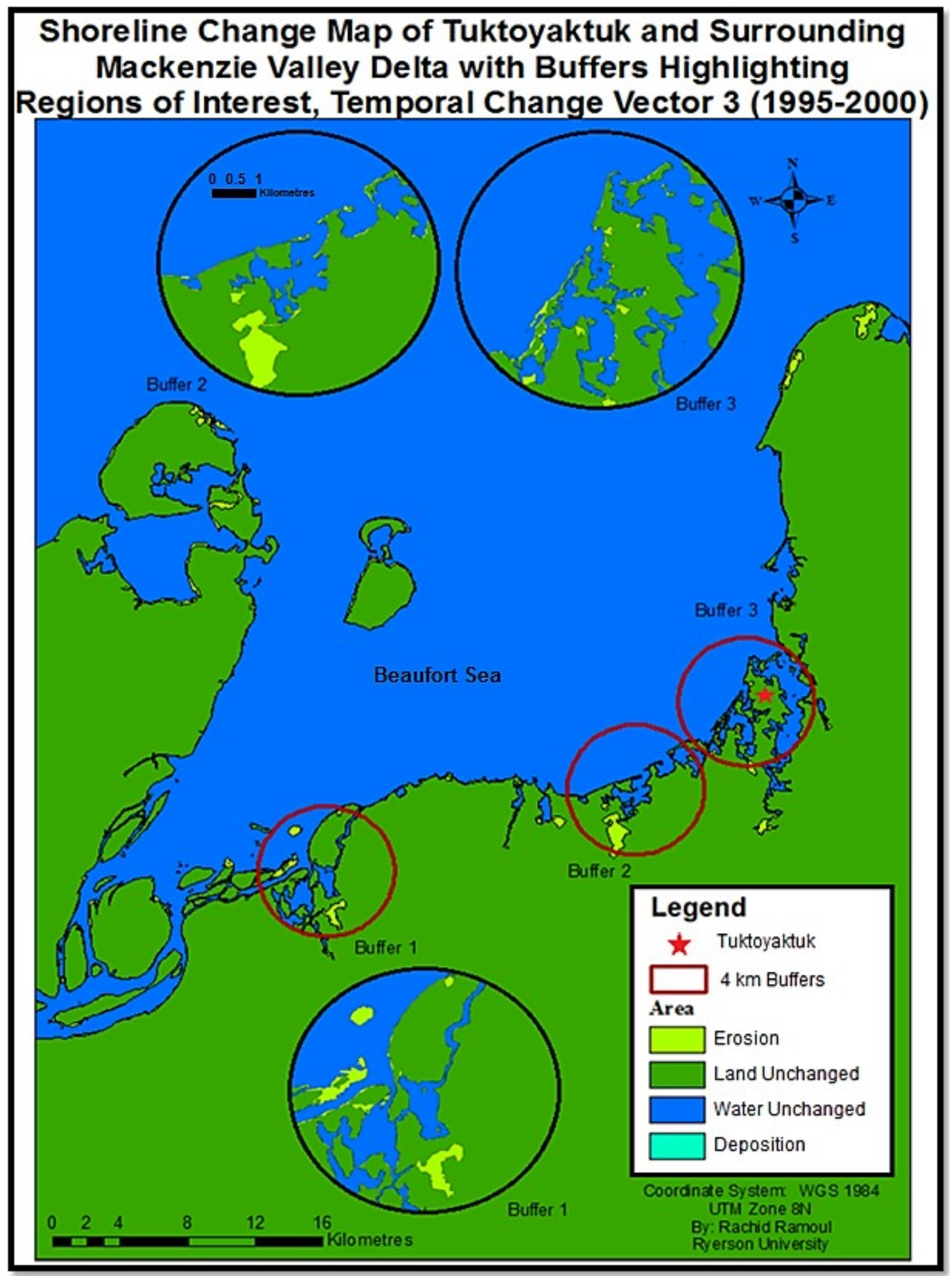

Figure 24. Shoreline change map of Tuktoyaktuk and surrounding Mackenzie Valley Delta with buffers highlighting regions of interest, temporal change vector 3 (1995-2000) 


\begin{tabular}{c|cc} 
Area Class & Deposition & Erosion \\
Extreme & 5 & 132 \\
Moderate & 11 & 123 \\
Minor & 63 & 171 \\
Total & 79 & 426
\end{tabular}

Table 17. Number of polygons in each area class which have undergone deposition or erosion in temporal change vector 3 (1995-2000)

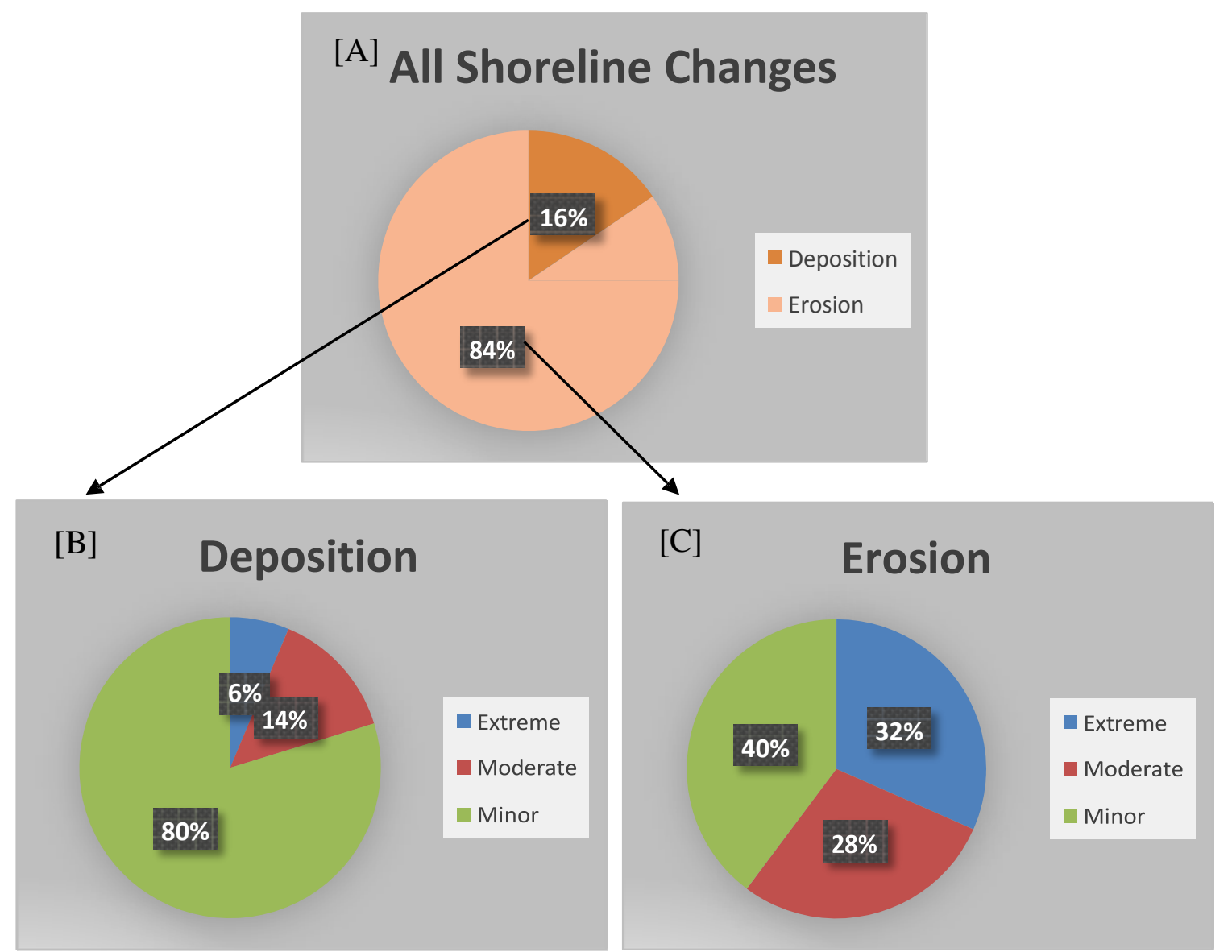

Figure 25. Percentage of all polygons which have undergone deposition or erosion [A]. Percentage of polygons in each area class which have undergone deposition $[B]$ and erosion $[C]$ in temporal change vector 3 (1995-2000) 


$\begin{array}{ccc}\text { Area Class } & \text { Deposition } & \text { Erosion } \\ \text { Extreme } & \mathbf{1 . 0 8} \mathbf{~ k m}^{\mathbf{2}} & \mathbf{1 8 . 8 8} \mathbf{k m}^{\mathbf{2}} \\ \text { Moderate } & \mathbf{0 . 1 9} \mathbf{~ k m}^{2} & \mathbf{2 . 1 1} \mathbf{~ k m}^{\mathbf{2}} \\ \text { Minor } & \mathbf{0 . 3 5} \mathbf{~ k m}^{2} & \mathbf{1 . 0 5} \mathbf{~ k m}^{\mathbf{2}} \\ \text { Total } & \mathbf{1 . 6 2} \mathbf{~ k m}^{2} & \mathbf{2 2 . 0 4} \mathbf{k m}^{\mathbf{2}}\end{array}$

Table 18. Area size of polygons in each area class which have undergone deposition or erosion in temporal change vector 3 (1995-2000)

$\begin{array}{ccc} & \text { Deposition } & \text { Erosion } \\ \text { Total Rates } & 0.32 \mathbf{~ k m}^{2} / \text { year } & 4.41 \mathbf{~ k m}^{2} / \text { year }\end{array}$

Table 19. Total rates of deposition and erosion in temporal change vector 3 (1995-2000)

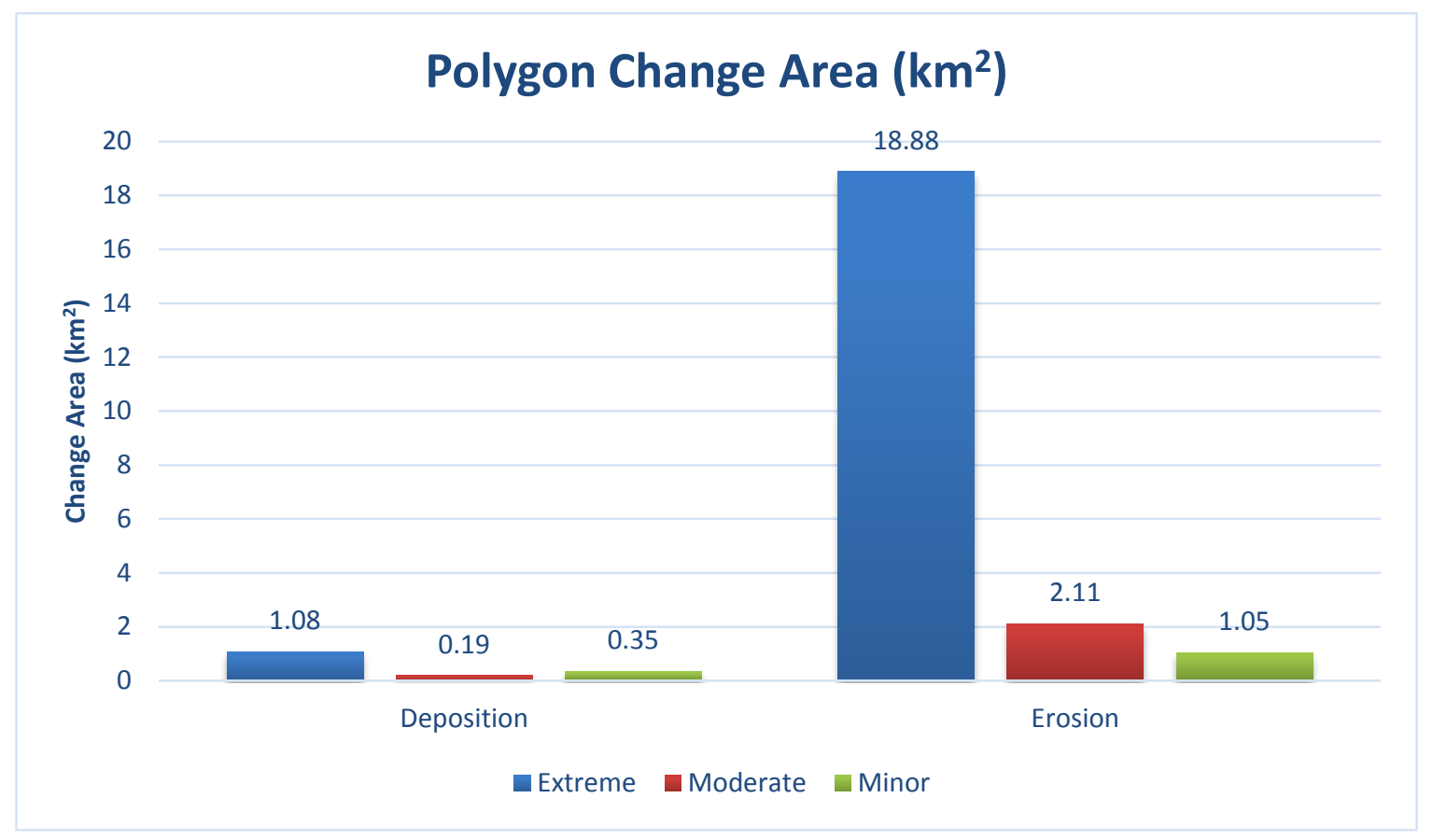

Figure 26. Bar graph displaying the total area size in each area class which have undergone deposition and erosion in temporal change vector 3 (1995-2000) 


\subsubsection{Temporal Change Vector 4 (2000-2005)}

The fourth temporal change vector was accomplished by intersecting Landsat-5 image 4 of Tuktoyaktuk in 2000 with image 5 taken in 2005. This constituted the last five year interval because there were several technical problems encountered in the following years which rendered the satellite’s imagery inadequate (USGS, 2006). This overlay once again produced a different image than the previous one in keeping with the seemingly emergent trend of deposition followed by erosion (Figure 27). In this fourth temporal vector, there were 355 deposition polygons (Table 20) which were larger than $0.003601 \mathrm{~km}^{2}$ and were therefore considered as significant and less likely attributable to potential errors. These polygons accounted for $62 \%$ of all shoreline changes (Figure 28 [A]), and they represented a total land deposition area of $8.59 \mathrm{~km}^{2}$ (Table 21). Of these 355 polygons, 205 (57\%) underwent minor changes, 102 (29\%) displayed moderate changes, and 48 (14\%) represented extreme changes (Table 20 \& Figure 28 [B]). The most substantial land changes were those falling within the extreme changes class (Table 21) which accounted for a shift of $5.59 \mathrm{~km}^{2}$, while the moderate class represented an area of change of only $1.77 \mathrm{~km}^{2}$ followed by minor changes which accounted for a total area of $1.23 \mathrm{~km}^{2}$.

There were also some change polygons which experienced erosion, and in this fourth temporal vector, 221 displayed this characteristic (Table 20). These polygons were chosen for the analysis since they covered larger, more statistically substantial areas. These polygons accounted for 38\% of all coastal changes (Figure 28 [A]) and of those, 140 (63\%) displayed minor fluctuations, 59 (27\%) were moderate changes, and 22 (10\%) represented more extreme changes most indicative of alarming erosion (Table 20 \& Figure 28 [C]). The minor changes covered an area of $0.80 \mathrm{~km}^{2}$, the moderate changes spanned $0.94 \mathrm{~km}^{2}$, while the extreme changes depicted a total change area of $1.64 \mathrm{~km}^{2}$ (Table 21). These polygons represented a total land change area of erosion of $3.38 \mathrm{~km}^{2}$.

To determine the total change area for the fourth temporal change vector, the total area change of the deposition polygons was subtracted once more by the total area change of the erosion polygons which produced an area of $5.21 \mathrm{~km}^{2}$. As a result, from 2000 to 2005 there was a clear gain of shoreline extent of more than 5 square kilometres (Table 21 \& Figure 29). The rate of deposition for this fourth temporal change vector was of $1.72 \mathrm{~km}^{2} /$ year while the rate of erosion was of $0.68 \mathrm{~km}^{2} /$ year (Table 22). 


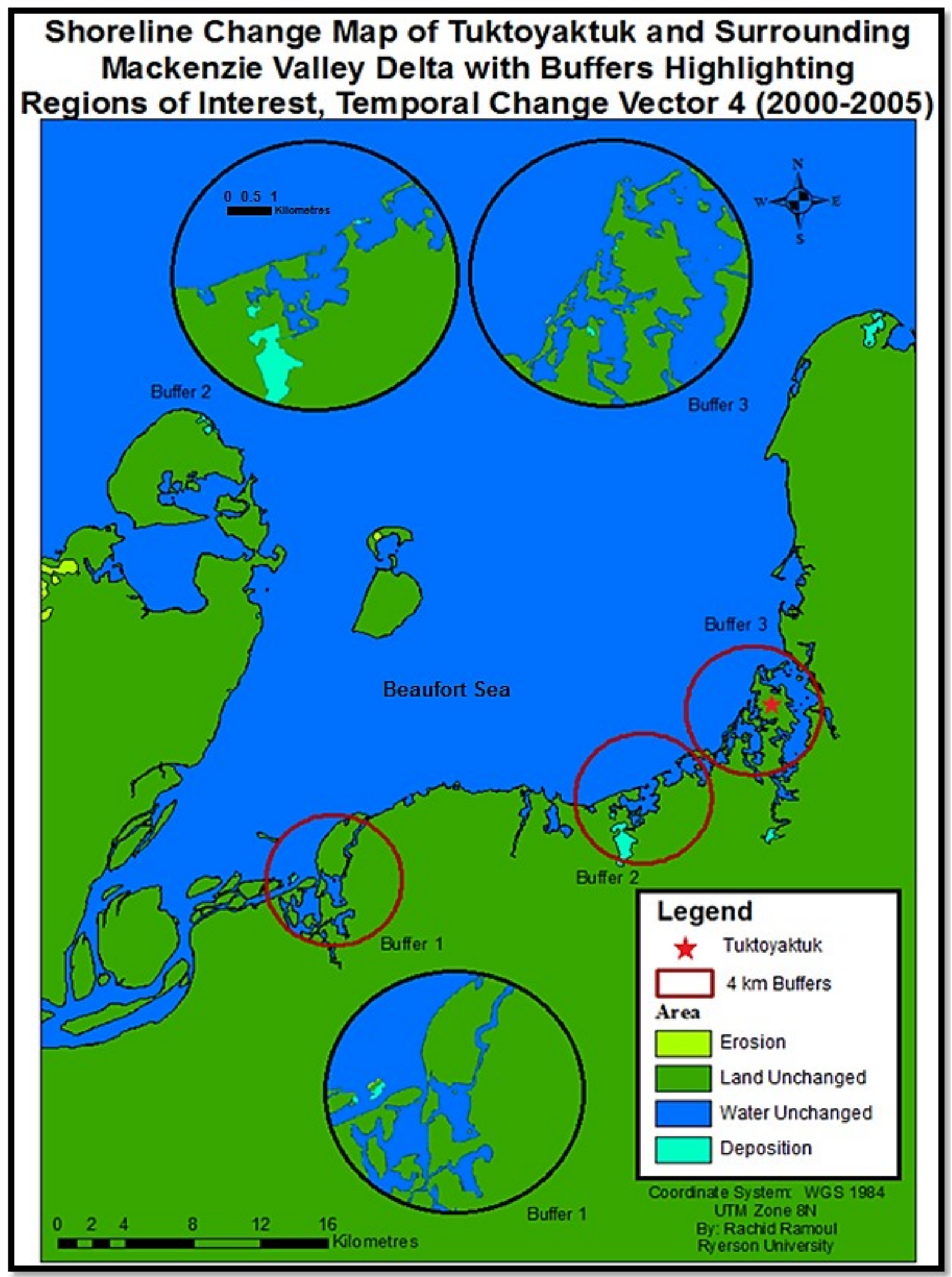

Figure 27. Shoreline change map of Tuktoyaktuk and surrounding Mackenzie Valley Delta with buffers highlighting regions of interest, temporal change vector 4 (2000-2005) 


\begin{tabular}{c|cc} 
Area Class & Deposition & Erosion \\
Extreme & $\mathbf{4 8}$ & $\mathbf{2 2}$ \\
Moderate & $\mathbf{1 0 2}$ & $\mathbf{5 9}$ \\
Minor & $\mathbf{2 0 5}$ & $\mathbf{1 4 0}$ \\
Total & $\mathbf{3 5 5}$ & $\mathbf{2 2 1}$
\end{tabular}

Table 20. Number of polygons in each area class which have undergone deposition or erosion in temporal change vector 4 (2000-2005)

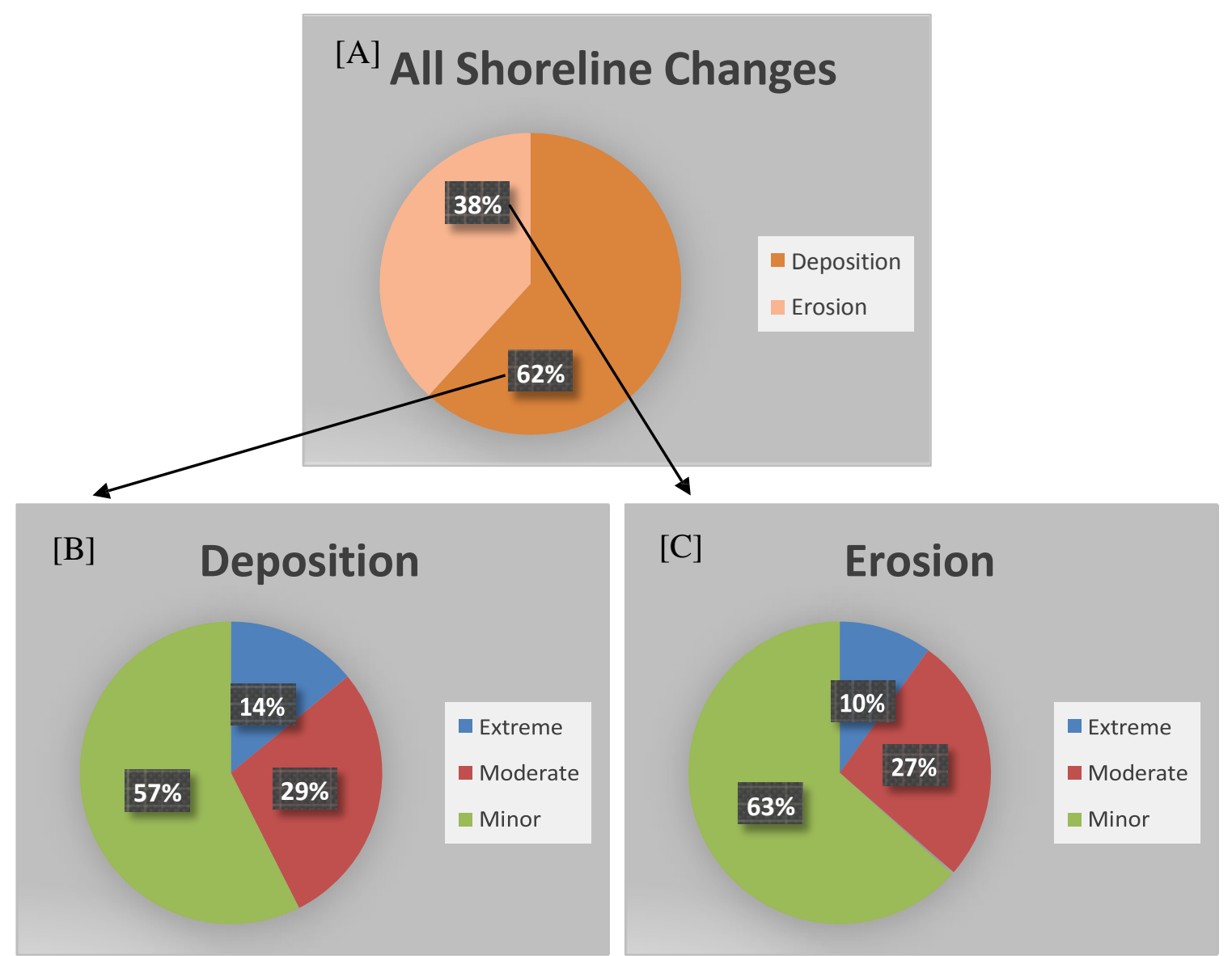

Figure 28. Percentage of all polygons which have undergone deposition or erosion [A]. Percentage of polygons in each area class which have undergone deposition $[B]$ and erosion $[C]$ in temporal change vector 4 (2000-2005) 


\begin{tabular}{|c|c|c|}
\hline Area Class & Deposition & Erosion \\
\hline Extreme & $5.59 \mathrm{~km}^{2}$ & $1.64 \mathrm{~km}^{2}$ \\
\hline Moderate & $1.77 \mathrm{~km}^{2}$ & $0.94 \mathrm{~km}^{2}$ \\
\hline Minor & $1.23 \mathrm{~km}^{2}$ & $0.80 \mathrm{~km}^{2}$ \\
\hline Total & $8.59 \mathrm{~km}^{2}$ & $3.38 \mathrm{~km}^{2}$ \\
\hline
\end{tabular}

Table 21. Area size of polygons in each area class which have undergone deposition or erosion in temporal change vector 4 (2000-2005)

$\begin{array}{ccc} & \text { Deposition } & \text { Erosion } \\ \text { Total Rates } & \mathbf{1 . 7 2} \mathbf{~ k m}^{2} / \text { year } & \mathbf{0 . 6 8} \mathbf{~ k m}^{2} / \text { year }\end{array}$

Table 22. Total rates of deposition and erosion in temporal change vector 4 (2000-2005)

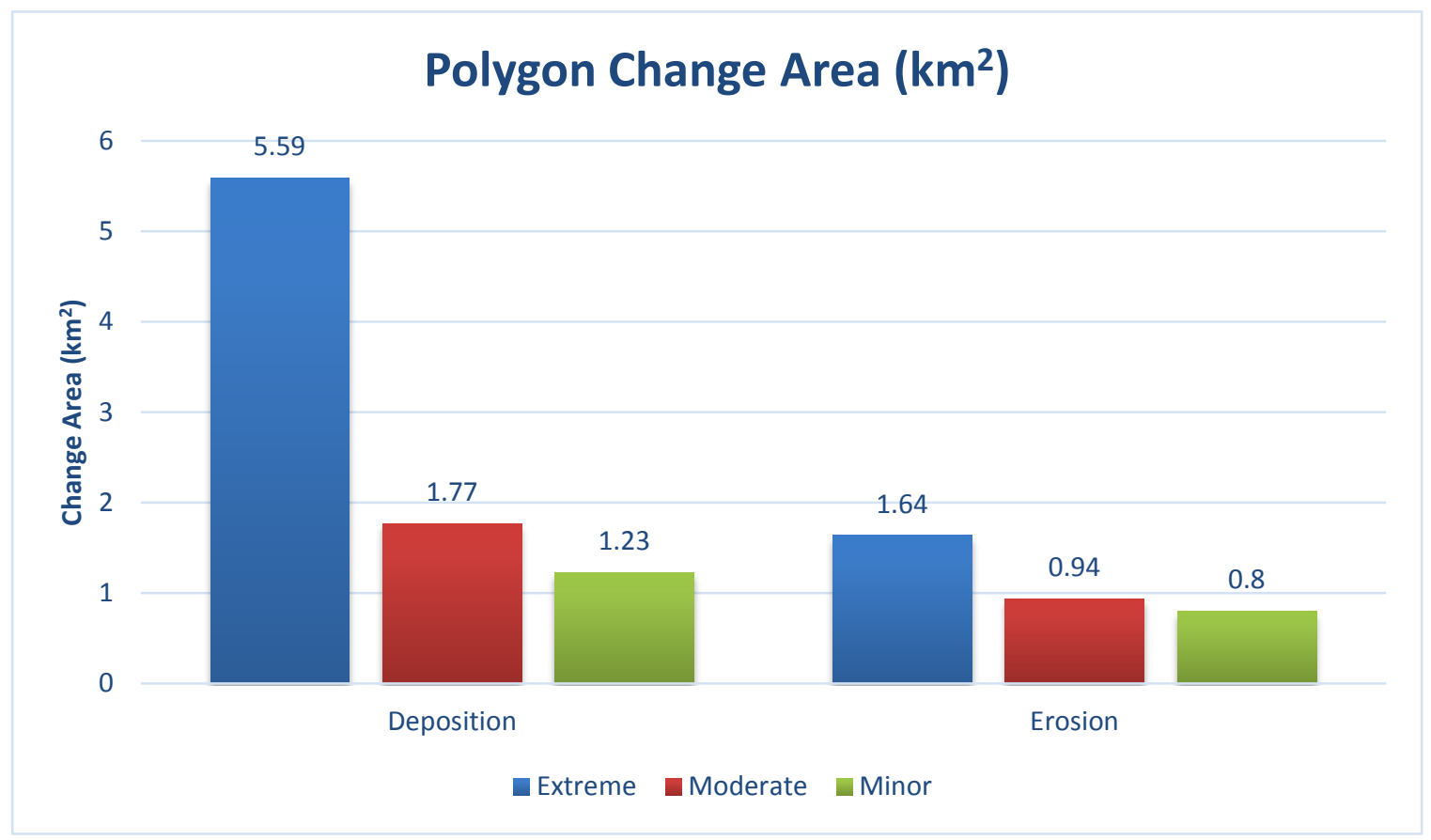

Figure 29. Bar graph displaying the total area size in each area class which have undergone deposition and erosion in temporal change vector $4(2000-2005)$ 


\subsubsection{Temporal Change Vector 5 (2005-2013)}

The fifth temporal change vector unlike the four previous ones, spanned an eight year period rather than a five year period due to the untrustworthiness of the Landsat-5 satellite which was decommissioned. By this time, the Landsat-8 satellite was already launched and delivered some very updated and dependable imagery which allowed for this thesis to be very current. The fifth vector was therefore produced by intersecting Landsat-5 image five of Tuktoyaktuk in 2005 with image 6 captured by Landsat-8 in 2013. While this time period was lengthier, the methods remained the same and the annualised results are still comparable with those achieved in the previous temporal change vectors. In this overlay, the trend previously mentioned continued as it was immediately evident that this image displayed unmistakable erosion occurring (Figure 30). There were only 46 polygons which displayed deposition (Table 23) and were larger than the threshold making them therefore considered as significant for this analysis. These polygons accounted for a mere 8\% of all shoreline changes (Figure 31 [A]) and of them, 25 (69\%) underwent minor changes, 10 (15\%) displayed moderate changes, and 11 (16\%) represented extreme changes (Table 23 \& Figure 31 [B]). The land changes that fell within the extreme changes class accounted for a shift of $1.30 \mathrm{~km}^{2}$, while the moderate class represented an area of change of only $0.15 \mathrm{~km}^{2}$ followed by minor changes which accounted for a total area of 0.14 $\mathrm{km}^{2}$ (Table 24). These polygons represented an overall deposition area of $1.59 \mathrm{~km}^{2}$ in this temporal change vector (Table 24). There were also several polygons which depicted erosion and represented striking and significant changes. In this temporal change vector, 561 polygons followed this pattern (Table 23). These polygons accounted for 92\% of all coastal variations (Figure 31 [A]) and of these, 269 (48\%) were minor fluctuations, 176 (31\%) demonstrated moderate changes, and 116 (21\%) represented extreme changes in shoreline extent (Table 23 \& Figure 31 [C]). The minor changes covered an area of $1.55 \mathrm{~km}^{2}$, the moderate changes spanned $3.00 \mathrm{~km}^{2}$, while the extreme changes depicted a total change area of $13.46 \mathrm{~km}^{2}$ (Table 24). These 561 polygons represented a total land change area of erosion of a substantial $18.01 \mathrm{~km}^{2}$.

By once again, subtracting the total area change of the erosion polygons from the deposition polygons (Table 24), the net change computed was of $16.42 \mathrm{~km}^{2}$. This evidently signified that in this final time period from 2005 to 2013, there was a pronounced loss of shoreline exceeding 16 square kilometres in total extent (Figure 32). The rate of deposition for this fifth temporal change vector was of $0.20 \mathrm{~km}^{2} /$ year while the rate of erosion was of $2.25 \mathrm{~km}^{2} /$ year (Table 25). 


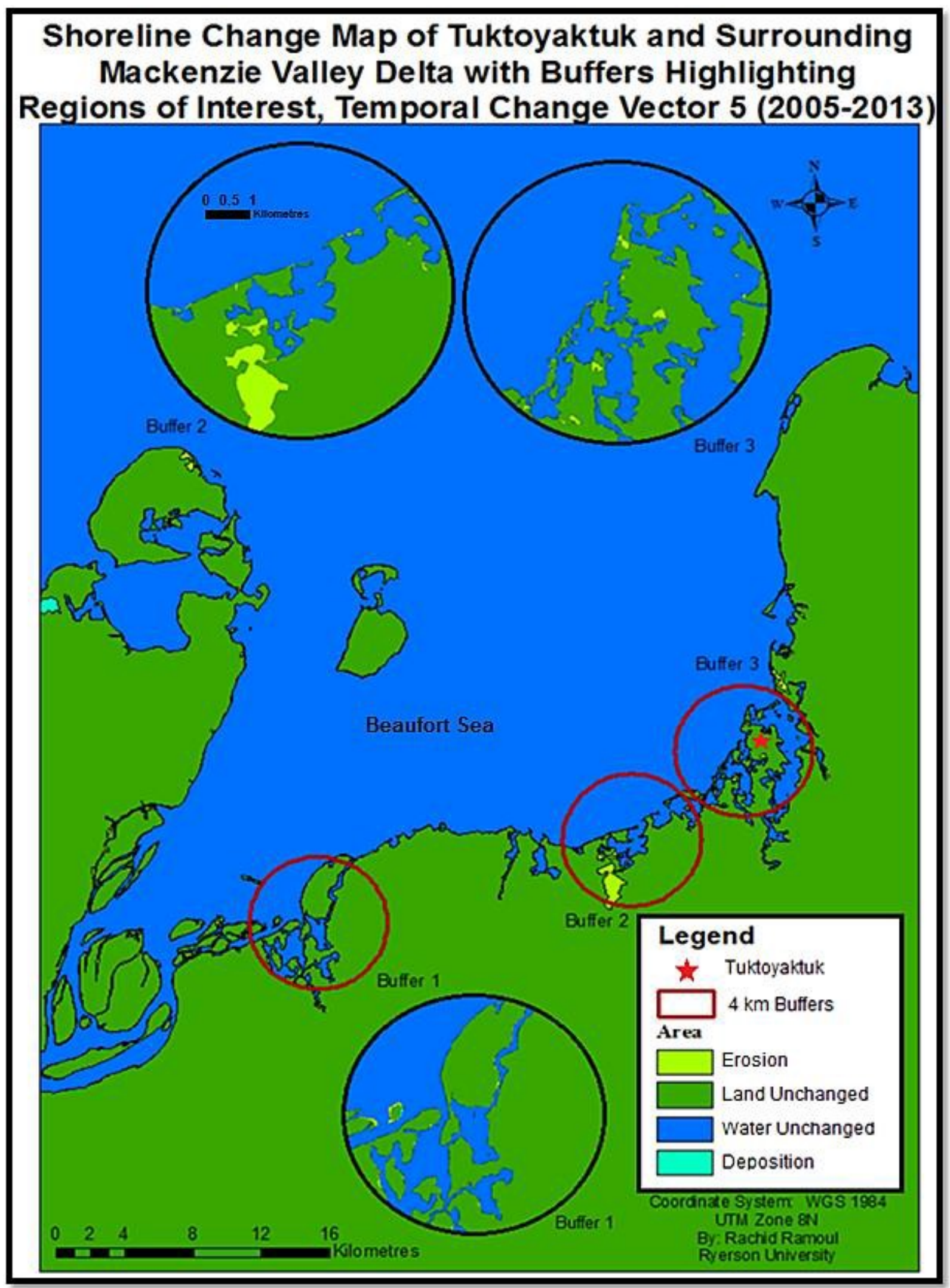

Figure 30. Shoreline change map of Tuktoyaktuk and surrounding Mackenzie Valley Delta with buffers highlighting regions of interest, temporal change vector 5 (2005-2013) 


\begin{tabular}{c|cc} 
Area Class & Deposition & Erosion \\
Extreme & $\mathbf{1 1}$ & $\mathbf{1 1 6}$ \\
Moderate & $\mathbf{1 0}$ & $\mathbf{1 7 6}$ \\
Minor & $\mathbf{2 5}$ & $\mathbf{2 6 9}$ \\
Total & $\mathbf{4 6}$ & $\mathbf{5 6 1}$
\end{tabular}

Table 23. Number of polygons in each area class which have undergone deposition or erosion in temporal change vector 5 (2005-2013)

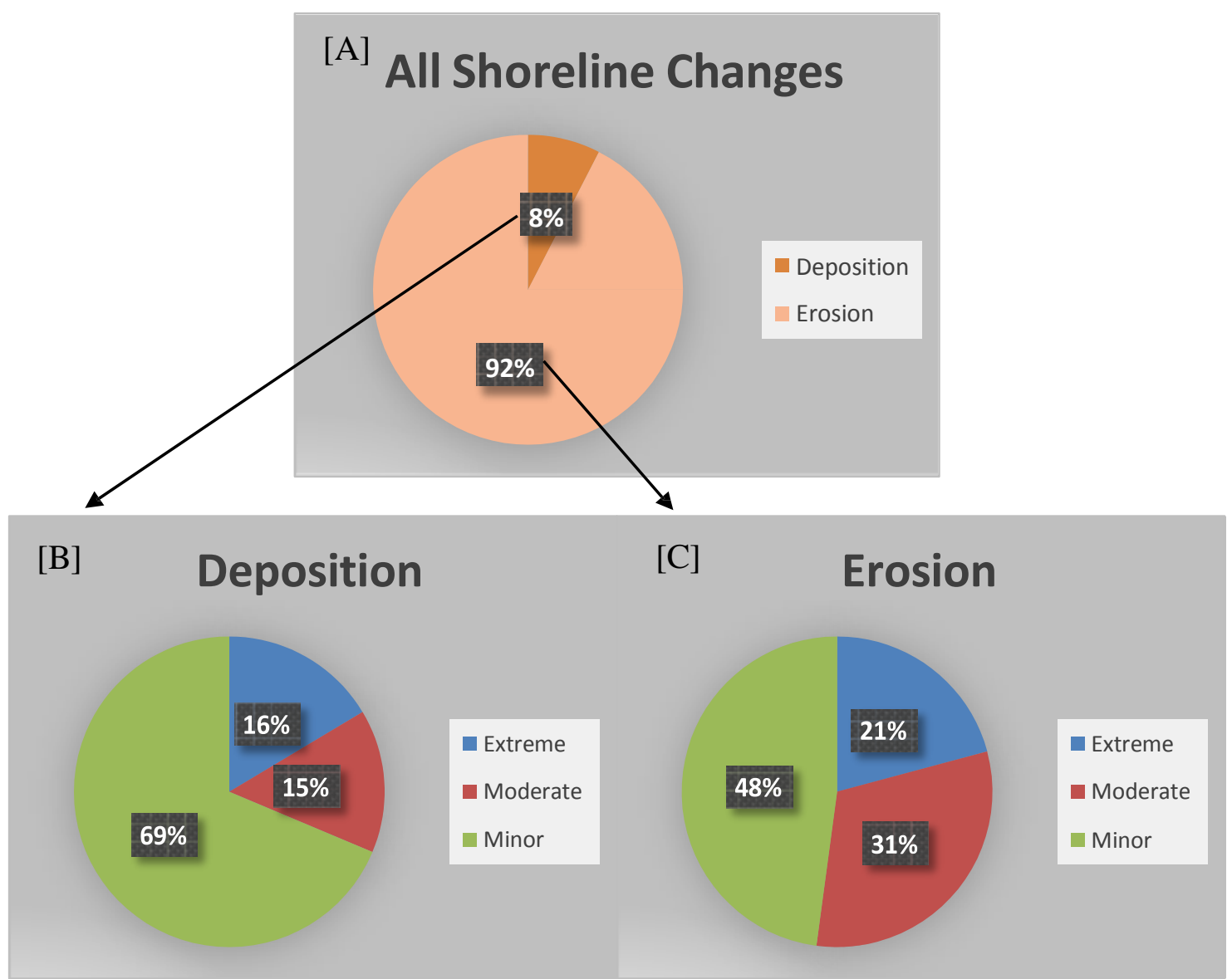

Figure 31. Percentage of all polygons which have undergone deposition or erosion [A]. Percentage of polygons in each area class which have undergone deposition $[B]$ and erosion $[C]$ in temporal change vector 5 (2005-2013) 


$\begin{array}{ccc}\text { Area Class } & \text { Deposition } & \text { Erosion } \\ \text { Extreme } & \mathbf{1 . 3 0} \mathbf{~ k m}^{\mathbf{2}} & \mathbf{1 3 . 4 6} \mathbf{~ k m}^{\mathbf{2}} \\ \text { Moderate } & \mathbf{0 . 1 5} \mathbf{~ k m}^{2} & \mathbf{3 . 0 0} \mathbf{~ k m}^{\mathbf{2}} \\ \text { Minor } & \mathbf{0 . 1 4} \mathbf{~ k m}^{\mathbf{2}} & \mathbf{1 . 5 5} \mathbf{~ k m}^{\mathbf{2}} \\ \text { Total } & \mathbf{1 . 5 9} \mathbf{~ k m}^{\mathbf{2}} & \mathbf{1 8 . 0 1} \mathbf{~ k m}^{\mathbf{2}}\end{array}$

Table 24. Area size of polygons in each area class which have undergone deposition or erosion in temporal change vector 5 (2005-2013)

$\begin{array}{ccc} & \text { Deposition } & \text { Erosion } \\ \text { Total Rates } & 0.20 \mathrm{~km}^{2} / \text { year } & 2.25 \mathrm{~km}^{2} / \text { year }\end{array}$

Table 25. Total rates of deposition and erosion in temporal change vector 5 (2005-2013)

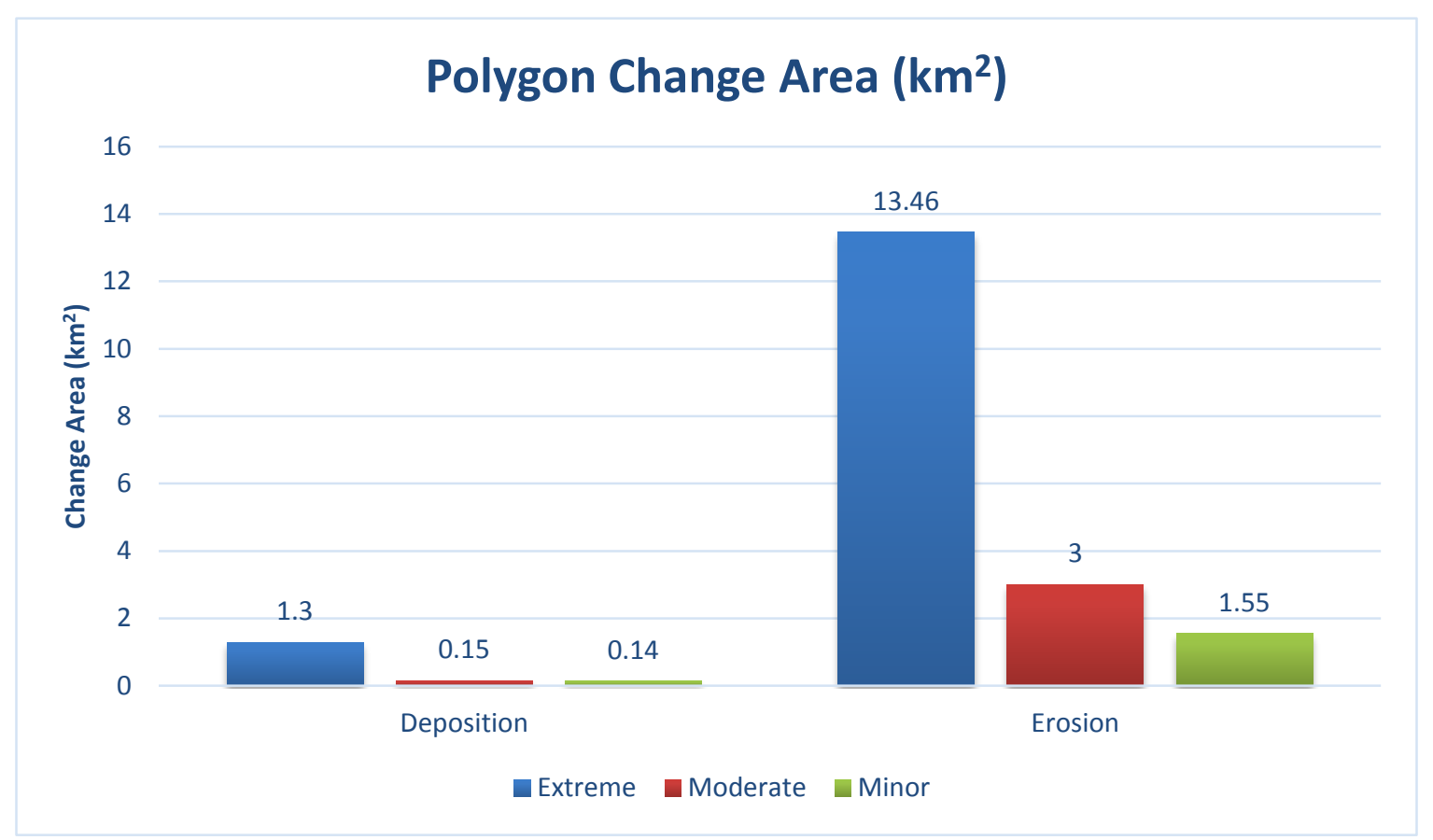

Figure 32. Bar graph displaying the total area size in each area class which have undergone deposition and erosion in temporal change vector 5 (2005-2013) 


\subsubsection{Temporal Change Vector 6 (1985-2013)}

In order to gain some perspective it was important that shoreline changes not be limited to investigations over short time intervals, but also to more overarching periods. Therefore, it was determined that in addition to the shorter time frames, a temporal change vector would be carried out over the entire study's duration from 1985 to 2013. This would provide a more generalised overview of the shoreline changes that occurred in the past 28 years (Figure 33). As with the previous five temporal change vectors, an overlay was carried out transecting Landsat-5 image 1 of Tuktoyaktuk in 1985 with image 6 captured by Landsat-8 in 2013. This would provide the necessary output which would help establish if shorelines truly changed or if they ultimately maintained equilibrium despite the trend of erosion followed by deposition. This vector included a mere 65 total polygons which were larger than the threshold and displayed a shift towards deposition (Table 26). These accounted for only 13\% of all shoreline changes (Figure 34 [A]) and of these 65 polygons, 41 (63\%) underwent minor changes, 14 (22\%) displayed moderate changes, and 10 (15\%) represented extreme changes (Table 26 \& Figure 34 [B]). The land changes that fell within the extreme changes class accounted for a change of $0.61 \mathrm{~km}^{2}$, while the moderate class represented an area of change of only $0.26 \mathrm{~km}^{2}$ followed by minor changes which accounted for a total area of $0.25 \mathrm{~km}^{2}$ (Table 27). These polygons represented an overall deposition area of 1.12 $\mathrm{km}^{2}$ in this temporal change vector. There were 422 polygons which exhibited the opposite shift; that is erosion properties (Table 26). These polygons corresponded to $87 \%$ of all coastal variations (Figure 34 [A]) and of these, 128 (30\%) were minor fluctuations, 119 (28\%) demonstrated moderate changes, and 175 (42\%) represented extreme changes in shoreline extent (Table 26 \& Figure $34[\mathrm{C}]$ ). The minor changes covered an area of $0.77 \mathrm{~km}^{2}$, the moderate changes spanned $2.13 \mathrm{~km}^{2}$, while the extreme changes depicted a total change area of $33.42 \mathrm{~km}^{2}$ (Table 27). These 422 polygons represented a total land change area of erosion of $36.32 \mathrm{~km}^{2}$.

The total land area change in this sixth vector was calculated by subtracting the area change of erosion polygons from the deposition polygons, which resulted in an area of $35.20 \mathrm{~km}^{2}$. This indicates that throughout the entire study period spanning 1985 to 2013, there was an immense amount of shoreline erosion in excess of 35 square kilometres (Table 27). Over this period, the gain of shoreline is therefore inconsequential and pales in comparison to the extent of shoreline loss (Figure 35 and Figure 36) which provides a clearer understanding into the state of the shorelines in Tuktoyaktuk. The rate of deposition for this sixth temporal change vector was of 0.04 $\mathrm{km}^{2} /$ year while the rate of erosion was of $1.30 \mathrm{~km}^{2} /$ year (Table 28 ). 


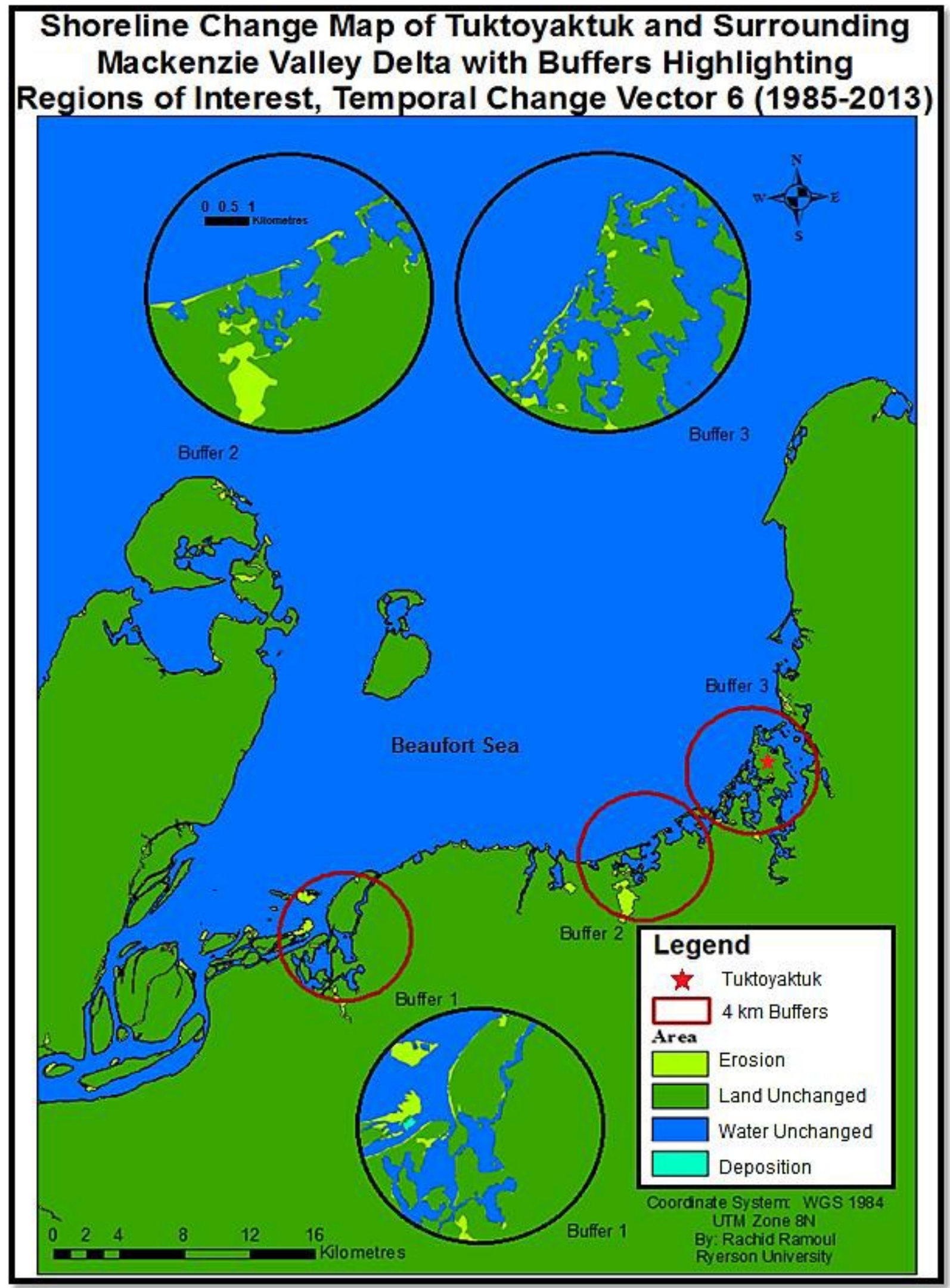

Figure 33. Shoreline change map of Tuktoyaktuk and surrounding Mackenzie Valley Delta with buffers highlighting regions of interest, temporal change vector 6 (1985-2013) 


\begin{tabular}{c|cc} 
Area Class & Deposition & Erosion \\
Extreme & $\mathbf{1 0}$ & $\mathbf{1 7 5}$ \\
Moderate & $\mathbf{1 4}$ & $\mathbf{1 1 9}$ \\
Minor & $\mathbf{4 1}$ & $\mathbf{1 2 8}$ \\
Total & $\mathbf{6 5}$ & $\mathbf{4 2 2}$
\end{tabular}

Table 26. Number of polygons in each area class which have undergone deposition or erosion in temporal change vector 6 (1985-2013)

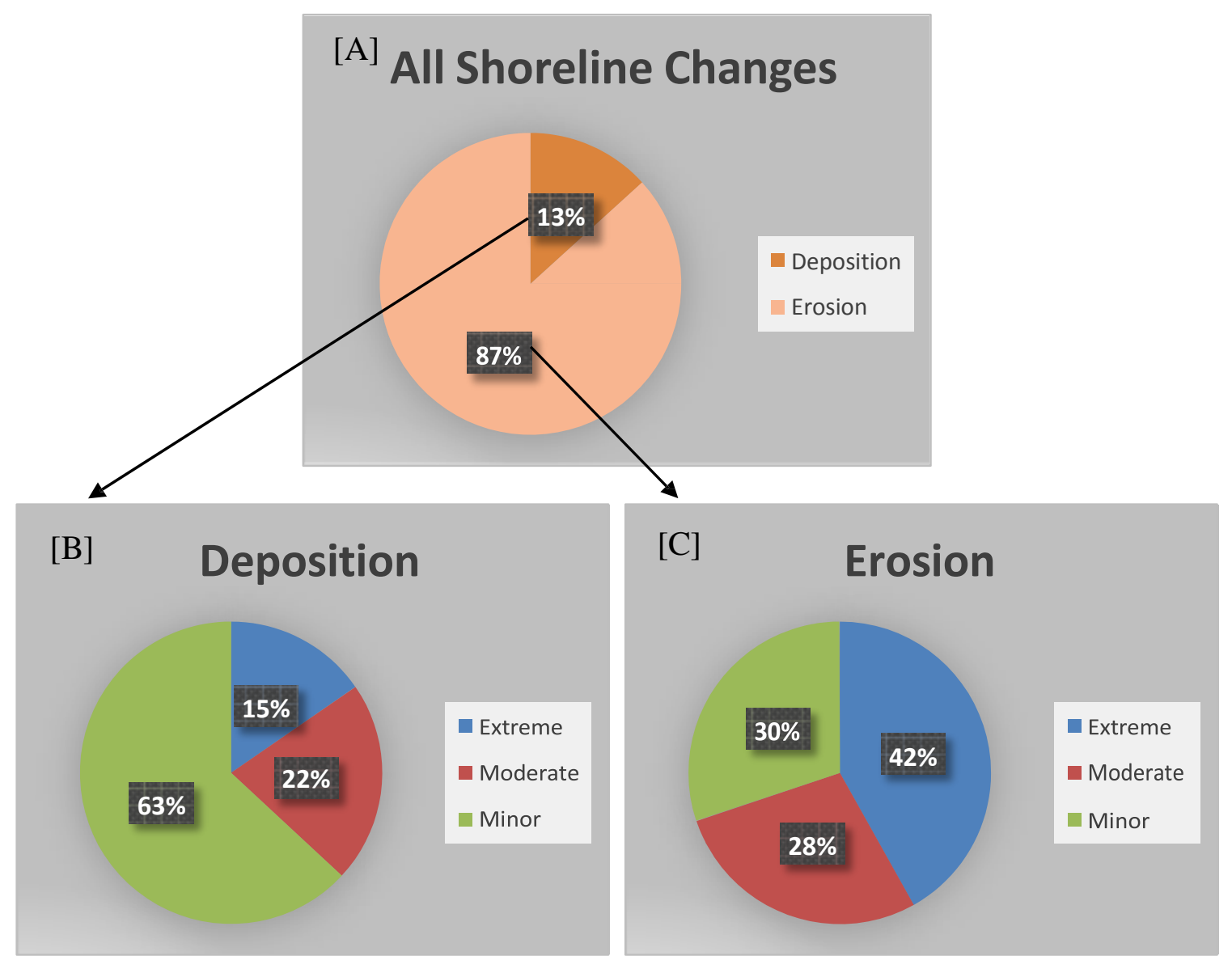

Figure 34. Percentage of all polygons which have undergone deposition or erosion [A]. Percentage of polygons in each area class which have undergone deposition $[B]$ and erosion $[C]$ in temporal change vector 6 (1985-2013) 


\begin{tabular}{|c|c|c|}
\hline Area Class & Deposition & Erosion \\
\hline Extreme & 0.61 km$^{2}$ & $33.42 \mathrm{~km}^{2}$ \\
\hline Moderate & $0.26 \mathrm{~km}^{2}$ & $2.13 \mathrm{~km}^{2}$ \\
\hline Minor & $0.25 \mathrm{~km}^{2}$ & $0.77 \mathbf{k m}^{2}$ \\
\hline Total & $1.12 \mathrm{~km}^{2}$ & $36.32 \mathrm{~km}^{2}$ \\
\hline
\end{tabular}

Table 27. Area size of polygons in each area class which have undergone deposition or erosion in temporal change vector $6(1985-2013)$

$\begin{array}{ccc} & \text { Deposition } & \text { Erosion } \\ \text { Total Rates } & \mathbf{0 . 0 4} \mathbf{~ k m}^{2} / \text { year } & 1.30 \mathbf{~ k m}^{2} / \text { year }\end{array}$

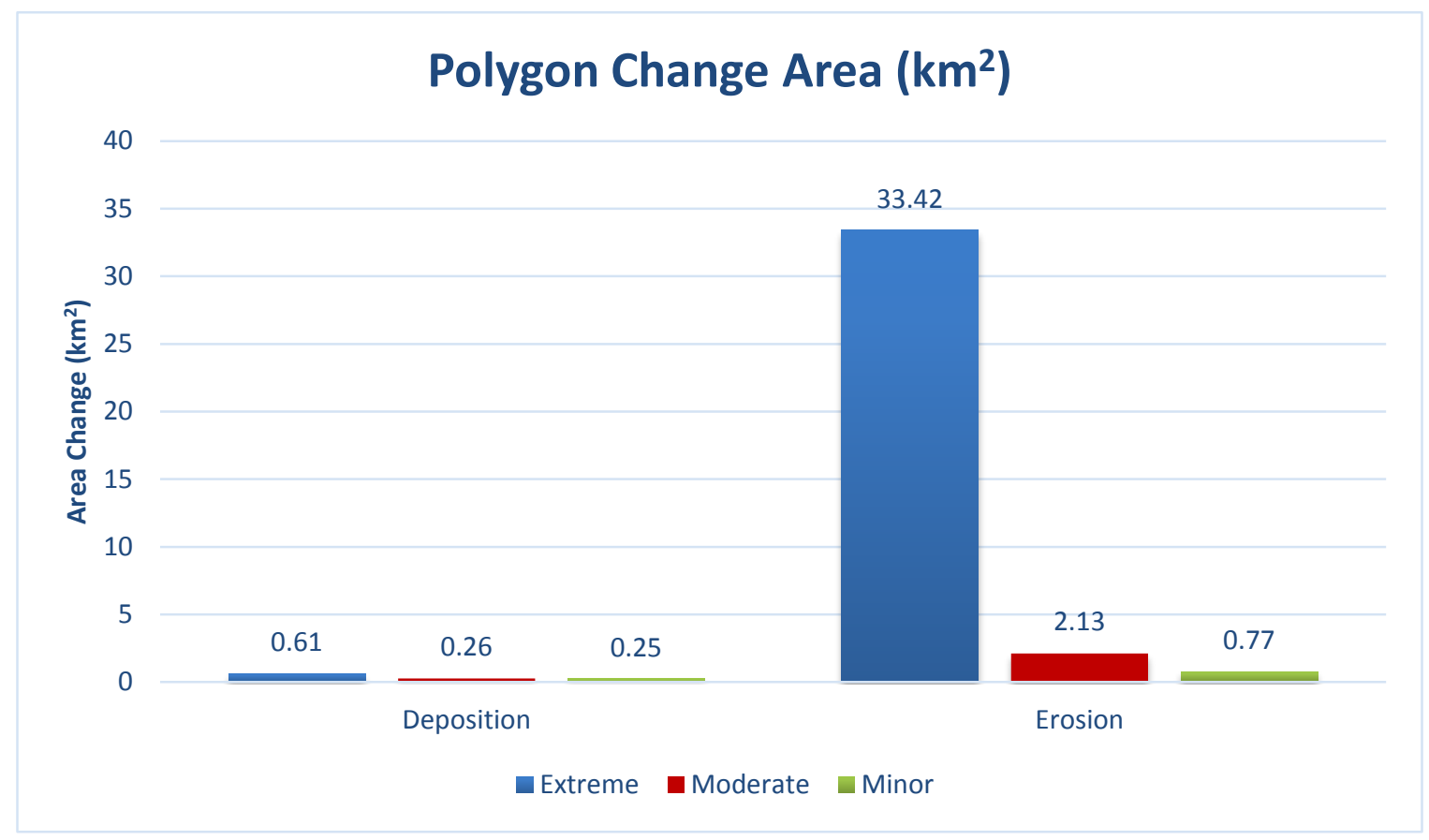

Figure 35. Bar graph displaying the total area size in each area class which have undergone deposition and erosion in temporal change vector 6 (1985-2013 


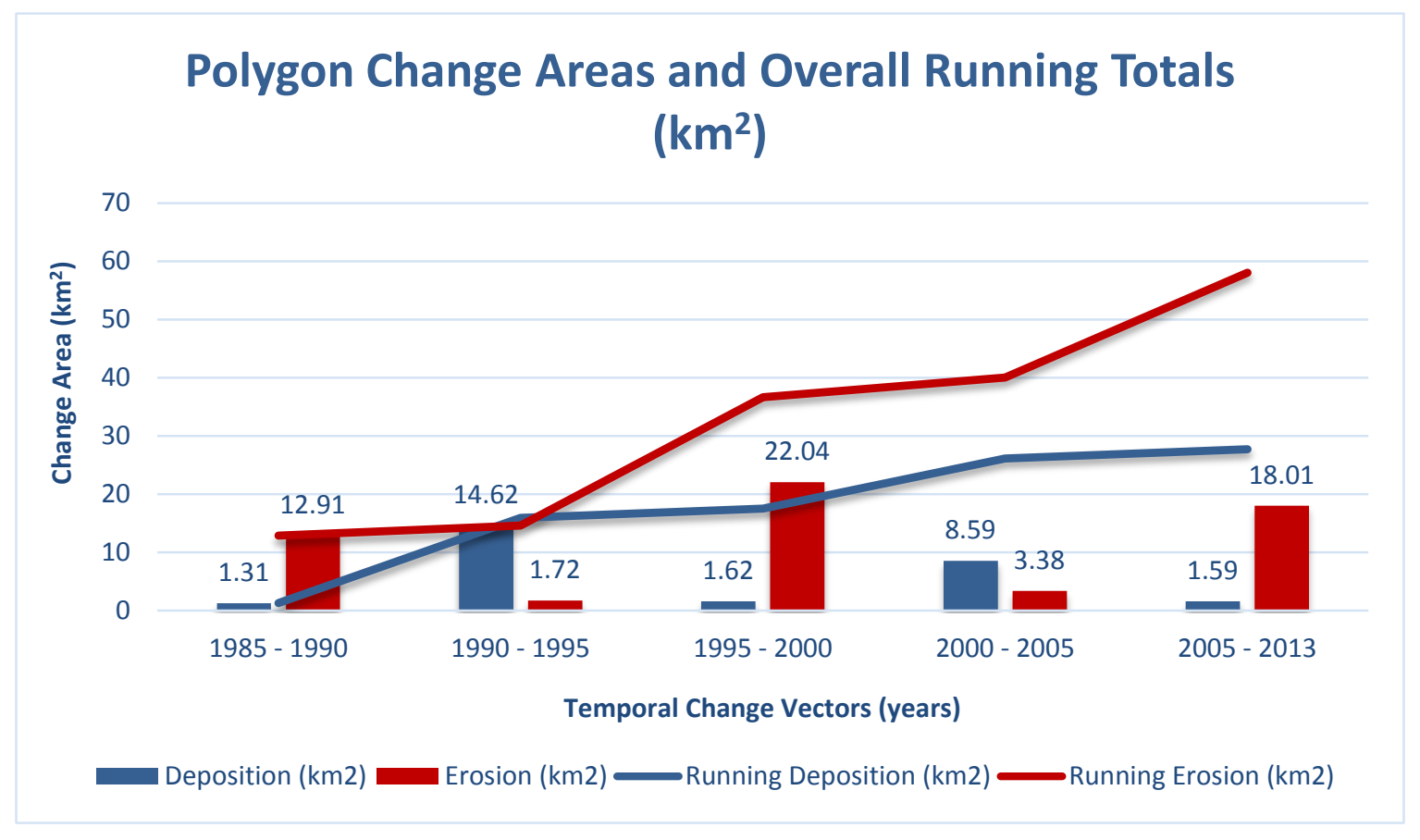

Figure 36. Bar area graph displaying the total polygon change areas which have undergone deposition and erosion in each temporal change vector as well as the running total (line graph) 


\section{DISCUSSION}

This chapter is reserved for a detailed discussion of the results presented in the preceding chapter. It begins with an investigation into the impacts of tidal activity on the results as well as some important observations made throughout this research. This section then elucidates the true extent and nature of the changes previously reported and places them within the larger context of other prominent research in this field as a comparative analysis. It concludes by explaining why these results matter in the larger scope of the Arctic; the environment, the offshore activities of industry, and the people who inhabit it.

\subsection{Tidal Activity Impacts}

Tuktoyaktuk’s location in an ocean coastal area signifies that tides are important aspects to consider. Fundamentally, tides are long-period waves that travel through the oceans in a direct response to forces that are applied by the moon and sun (NOAA, 2008). They originate in the oceans and make their way toward the shorelines where they appear simply as the rise and fall of the ocean surface (NOAA, 2008). High tide occurs when the highest part of a wave or crest reaches a specific location and low tide corresponds to the lowest part of the wave, or its trough (NOAA, 2008). The variance in height between the two is known as the tidal range (University of Guelph, 2002). Failure to account for tides can lead to erroneous conclusions being drawn since tides can give the appearance of eroded shorelines in a given satellite image or deposition of land in others (Dallimore et al., 1995). Therefore, to avoid such errors when comparing different imagery, it is important to only employ images that are taken at similar times of the day and during similar tidal conditions. Luckily, with the lengthy temporal image record that exists for Landsat-5 and Landsat-8, there were ample images available from which to select.

\begin{tabular}{cccccc} 
Image & Satellite & $\begin{array}{c}\text { Date } \\
\text { Acquired }\end{array}$ & $\begin{array}{c}\text { Time } \\
\text { Acquired }\end{array}$ & $\begin{array}{c}\text { Tide Level at Time } \\
\text { Acquired (metres) }\end{array}$ & Tide Cycle \\
& Landsat-5 & $\mathbf{1 9 8 5 / 0 8 / 0 7}$ & $\mathbf{1 9 : 5 7 : 4 0}$ & $\mathbf{0 . 5 8} \mathbf{~ m}$ & High Tide \\
\hline & Landsat-5 & $\mathbf{1 9 9 0 / 0 7 / 0 4}$ & $\mathbf{1 9 : 4 8 : 0 5}$ & $\mathbf{0 . 4 2} \mathbf{~ m}$ & Low Tide \\
3 & Landsat-5 & $\mathbf{1 9 9 5 / 0 7 / 0 2}$ & $\mathbf{1 9 : 3 3 : 2 1}$ & $\mathbf{0 . 7 0} \mathbf{~ m}$ & High Tide \\
4 & Landsat-5 & $\mathbf{2 0 0 0 / 0 7 / 2 3}$ & $\mathbf{2 0 : 1 9 : 1 2}$ & $\mathbf{0 . 6 6} \mathbf{~ m}$ & High Tide \\
5 & Landsat-5 & $\mathbf{2 0 0 5 / 0 8 / 1 4}$ & $\mathbf{2 0 : 1 5 : 5 9}$ & $\mathbf{0 . 4 8} \mathbf{~ m}$ & Mid Tide \\
6 & Landsat-8 & $\mathbf{2 0 1 4 / 0 7 / 0 1}$ & $\mathbf{2 0 : 4 2 : 1 4}$ & $\mathbf{0 . 5 6} \mathbf{~ m}$ & High Tide
\end{tabular}


One of the advantages of tides is that they are largely consistent in their level at comparable times of the year. Consequently, the imagery selected also had to be captured at a consistent time each interval in order to allow for the highest level of reliability to be upheld. As aforementioned, the images collected were all captured in early July to mid-August at the latest which ensures they are comparable. Nevertheless, in order to account for the tidal cycle, the time of day when they were captured also had to be consistent (Table 29). During the selection process of the original images, careful consideration was taken to ensure each image was not captured during low or high tide since these images could not be analysed reliably. Luckily, due to Tuktoyaktuk's location, the disparity in tidal heights is not very significant between low and high tide although there have been some irregularities historically during the open water season (Godin \& Barber, 1980). For this study’s purposes, the peak high tide level was not greater than $0.70 \mathrm{~m}$ and the lowest not lesser than $0.42 \mathrm{~m}$ which meant that even images captured during extremes in the tide cycle could be reliably analysed and compared.

\begin{tabular}{|c|c|c|c|c|}
\hline & Year Range & $\begin{array}{l}\text { Tidal } \\
\text { Range }\end{array}$ & $\begin{array}{l}\text { Expected } \\
\text { Outcome }\end{array}$ & $\begin{array}{l}\text { Actual } \\
\text { Outcome }\end{array}$ \\
\hline $\begin{array}{c}\text { Temporal } \\
\text { Change Vector } 1\end{array}$ & $1985-1990$ & $-0.16 \mathrm{~m}$ & Deposition & Erosion \\
\hline $\begin{array}{c}\text { Temporal } \\
\text { Change Vector } 2\end{array}$ & $1990-1995$ & $+0.28 \mathrm{~m}$ & Erosion & Deposition \\
\hline $\begin{array}{c}\text { Temporal } \\
\text { Change Vector } 3\end{array}$ & $1995-2000$ & $-0.04 \mathrm{~m}$ & Deposition & Erosion \\
\hline $\begin{array}{c}\text { Temporal } \\
\text { Change Vector } 4\end{array}$ & $2000-2005$ & - $0.18 \mathrm{~m}$ & Deposition & Deposition \\
\hline $\begin{array}{c}\text { Temporal } \\
\text { Change Vector } 5\end{array}$ & $2005-2013$ & $+0.08 \mathrm{~m}$ & Erosion & Erosion \\
\hline $\begin{array}{c}\text { Temporal } \\
\text { Change Vector } 6\end{array}$ & $1985-2013$ & $-0.02 \mathrm{~m}$ & Deposition & Erosion \\
\hline
\end{tabular}

Table 30. The expected and actual outcomes observed due to tidal ranges

In this study, an important task was the quantification of the tidal ranges between each temporal change vector. This was done by determining the difference in the tide levels previously established in Table 29. In temporal change vector 1 , the tidal range was of $-0.16 \mathrm{~m}$ (Table 30). This was due to the fact, the tide level was $0.58 \mathrm{~m}$ in 1985 and lowered to $0.42 \mathrm{~m}$ in 1990 . Though the vertical change is only a decrease of $0.16 \mathrm{~m}$, the horizontal change is dependent on the slope of the shore. This signifies that a shoreline that has a high slope will not experience such severe changes due to such a change in tidal range as would a shoreline with a lower slope (Figure 37). In fact, if a shoreline found in the first change vector had a low slope for instance, it could express 
several metres of shoreline change resulting from a vertical decrease in tidal range of only $0.16 \mathrm{~m}$, while a shoreline with a higher slope would experience less stark change. In temporal change vector 1, composed of two images captured at the two extremes of the tidal range, deposition is not the primary coastal process taking place despite the decrease in water level. In other words, even though the water level decreased in this vector which should have revealed more land likely interpreted as deposition in the satellite imagery, this was not the case. In fact, the level of deposition pales in comparison to the erosion levels actually observed in this time period.

[A]

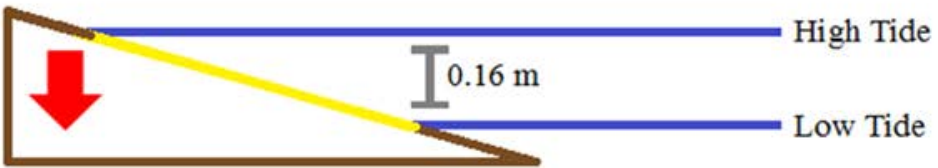

[B]

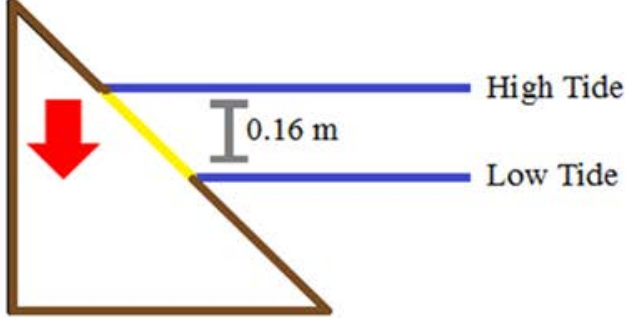

Figure 37. Impacts of tidal range on shorelines with different slopes. Shorelines with lower slopes [A] are more seriously impacted by tidal variations than shorelines with higher slopes [B].

In temporal change vector 2 , the tidal range was of $+0.28 \mathrm{~m}$ (Table 30) which signifies that this increase in water levels should result in more erosion; however, once again this is not the actual outcome observed. In temporal change vector 3, the tidal range decreased again, although only by $-0.04 \mathrm{~m}$. While this change is very subtle, theoretically it should have as outcome more deposition; however, this was once again not the case since erosion was far more influential. Temporal change vector 4 was the first change vector in which the expected theoretical outcome resulting from tidal variations matched the actual outcome observed. The tidal range of $-0.18 \mathrm{~m}$ which should bring about more deposition, did in fact display this result. The same was concluded in temporal change vector 5 in which a tidal range of $+0.08 \mathrm{~m}$ resulted in more erosion. In temporal change vector 6 which represented changes taking place throughout the entire duration of the study, the tidal range was of -0.02 . While this change is minimal, it should led to more deposition; however, this is not what was observed. In fact, erosion was significantly more important.

In this study, since the expected outcome did not match the actual outcome in four of the six temporal change vectors, this appears to refute the notion that low tides necessarily result in deposition, and high tides in erosion. This could be attributed to the fact that most shorelines in Tuktoyaktuk are not characterised by low sloped beaches, but rather by 5 to 15 metre high cliffs (Shaw et al., 1998). This could also signify that changes in tidal ranges have less substantial impacts on coastal changes, at least in this region of the world. In addition, these observations 
reinforce the notion that other more significant mechanisms of shoreline change could be in play.

\subsection{Important Observations}

Following the completion of the change detection procedure, the creation of the final temporal change vector maps was undertaken. Despite the evident importance of creating tables and charts summarising the amounts of shoreline changes observed, explaining such a complex natural process requires far more investigation. The final maps produced were therefore instrumental in helping visually represent the data gathered. This allowed for geographical patterns that would otherwise have gone undetected to be identified and examined more carefully in order to explain what is occurring and how.

As previously described, there were three regions of particular interest that were highlighted through the application of $4 \mathrm{~km}$ buffers. Buffer 3 represented the hamlet of Tuktoyaktuk which was central to this research while buffers 1 and 2 denoted sensitive regions that contained several spits, beaches, and barrier islands that would more likely be strongly affected by shoreline changes. By analysing these specific sites, some very noticeable geographical patterns could be discerned. For instance, in temporal change vector 1 (from 1985 to 1990), while there was some noticeable erosion taking place in Tuktoyaktuk, buffer 1 displayed the most significant changes. Erosion in this region affected several of the barrier islands including some rather large landforms that saw their area size diminish by more than half over the temporal change vector. The coastline itself was also impacted by erosion and retreated landward while very little deposition could be detected. This was confirmed by the figures which indicated only $1.31 \mathrm{~km}^{2}$ of total deposition in the entire change vector compared to $12.91 \mathrm{~km}^{2}$ of eroded land.

However, in the temporal change vector 2 (from 1990 to 1995), the pattern changed significantly. In buffer 3, Tuktoyaktuk’s coastline was almost exclusively subjected to sediment deposition hence reversing the original results. Despite this important observation, an even more noteworthy change was noticed in buffer 1 where a large amount of land was classified as deposition. By comparing this second temporal change vector with the first, it is clear that the area in question was once a bay with a narrow mouth. Due to the accumulation of sediment at the mouth of this bay, the classification labelled the pixels in question as land and consequently this was represented as the coastline expanding. The entire inland area which was actually the bay was therefore presumed to have been "filled" by sediment and therefore appeared as deposition. By 
verifying this change with the original Landsat-5 images that composed this temporal change vector, this phenomenon was rapidly clarified. It was immediately evident that the bay was not filled with sediment as the change detection map would appear to indicate, but rather, the mouth was essentially closed off due to a significant amount of deposition. Once the mouth of this bay eroded in the following change vector, it was reopened and did not close again due to the considerable amount of erosion occurring onwards.

The final most noticeable observation made throughout the remaining temporal change vectors was initially discovered in vector 3 from 1995 to 2000. In buffer 2, a vast amount of land underwent change which was displayed as erosion indicating the area was now another large bay. In the first two change vectors, this area was solid land which immediately required further investigation. By comparing the 1985 Landsat-5 image which helped form the first change vector with the 2000 image which formed the third vector, it became clear that the opposite process was taking place here. It is hypothesised that originally this area was an inland lake or most likely a thermokarst lake which is a shallow marsh-like water body formed from the thawing of ground ice (Hinkel et al., 2012). Two rivers may have begun forming (Figure 38) and over time, they reached each other thus connecting the thermokarst lake to the Ocean (Figure 39). It is perhaps at this point in time that the thermokarst lake, having one of its sides exposed to the Ocean, transformed and became more aptly described as a bay. This transformation from change vectors 1 and 2 to vector 3 was therefore classified as erosion, though only the mouth of the lake truly eroded. This is fundamentally the same phenomenon observed in change vector 2; however, in reverse. The mouth of this bay underwent a succession of fluctuations (from erosion to deposition and vice versa) before finally eroding to such an extent that it remained open, hence exposing the bay to the Ocean. This was classified as erosion in the final change vector 6 . 


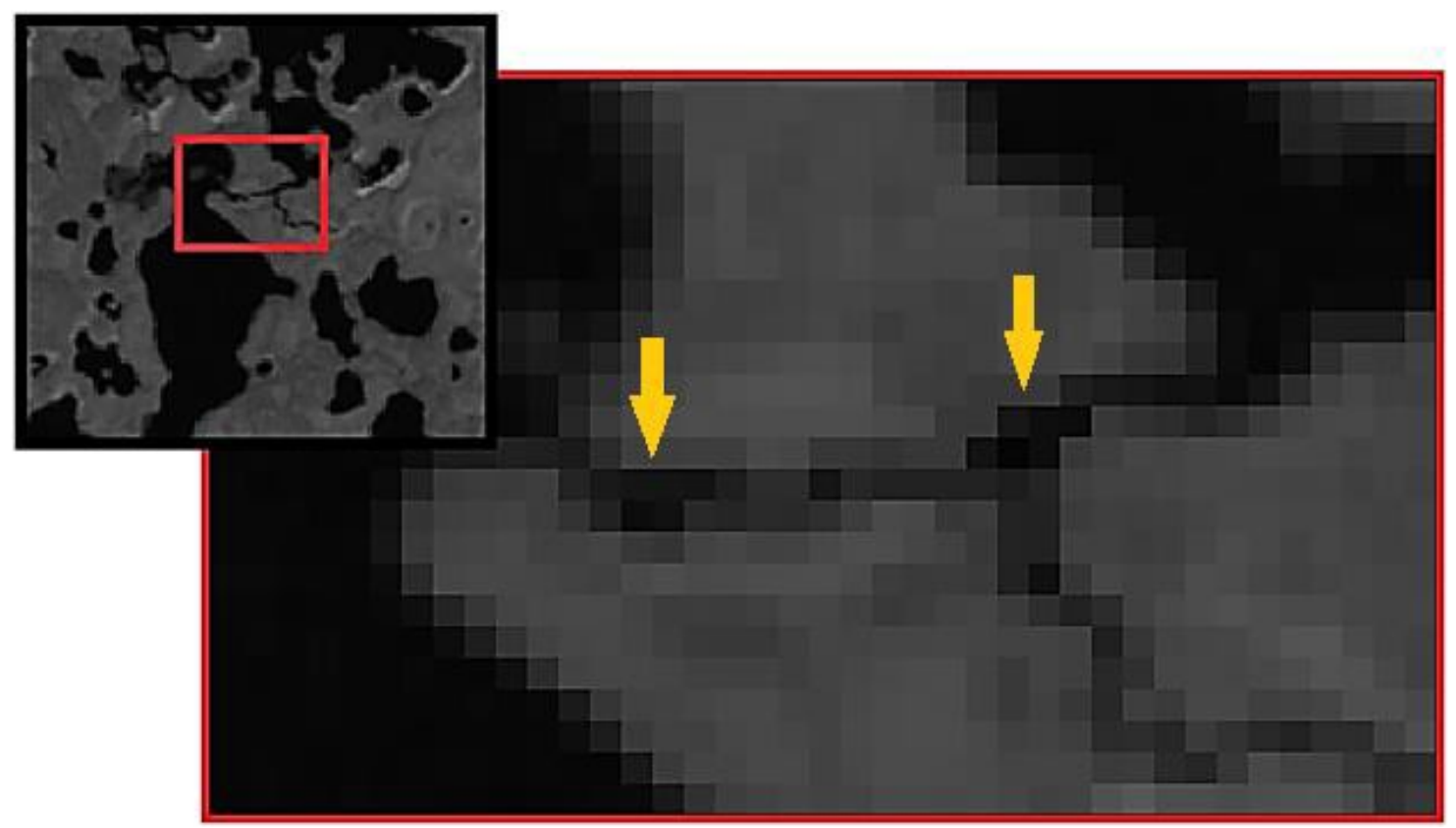

Figure 38. The 1985 Landsat-5 image which helped form the first change vector. The arrows help identify two rivers conceivably forming

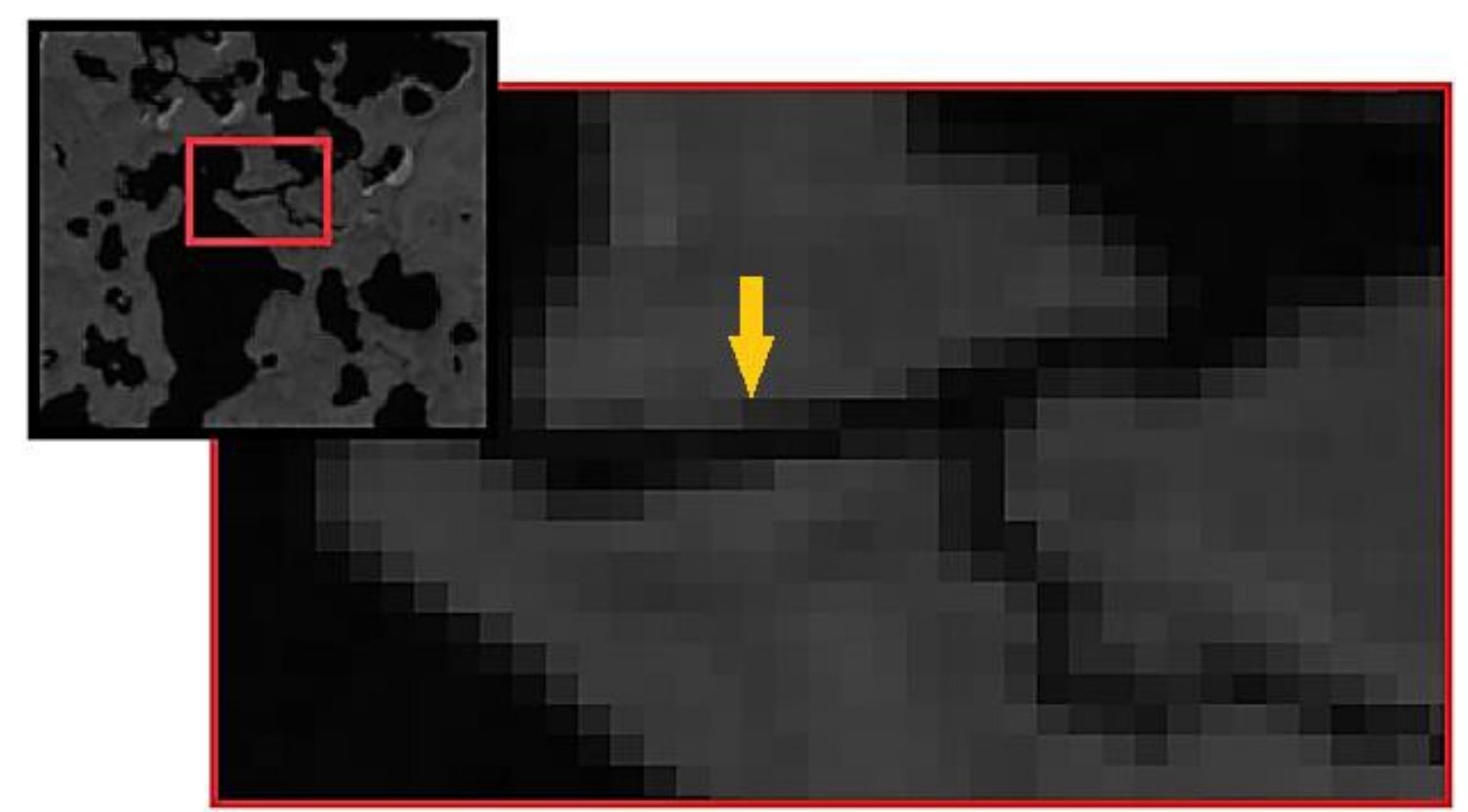

Figure 39. The 2000 Landsat-5 image which helped form the third change vector. The arrow helps highlight the possible location where the two previously forming rivers eventually connected, merging the thermokarst lake with the Ocean

This is a very important observation because it can help avoid erroneous conclusions from being drawn. As a result, it was decided that these large inland thermokarst lakes and bays would not be considered in the results. The polygons which represented these larger areas, were therefore located and subtracted from the erosion and deposition figures previously presented in the results chapter. While it is true that the total amounts and rates would change to a certain extent if these large areas were not included in the results, inland bays 
are ultimately not considered as belonging to the coastal environment and should therefore be excluded from observation. It is also important to note that the 30 metre spatial resolution of Landsat-5 and Landsat-8 could be responsible for some of these changes described. Since each pixel represents a 30 metre area on the ground, changes smaller than this area size will not be specifically sensed which may result in some inaccurate results. For instance, even if the mouth of some of these bays is not completely closed on the ground, if they are not greater than 30 metres in extent then they may not be classified as water which could explain some of the results. That being said, considering that some of these areas do alternate from erosion to deposition, this may also indicate that the changes are significant enough in spite of the average spatial resolution. Erosion and deposition can therefore be considered as having quite some influence on the changes in the shoreline extent.

\subsection{Comparative Analysis of Shoreline Changes}

While the results of this research presented in the previous chapter are rooted in empirical reality and with a confident level of reliability, they alone do not convey the entire state of affairs of shorelines in the Arctic. In order to highlight the true extent of shoreline erosion and deposition in this report, these results need to be further discussed and compared to other similar studies in this field conducted at various sites. Through this comparative lens, greater insight will be developed on the conditions observed at other locations in the Arctic. While each study is undertaken through a slightly different methodology and often using different metrics, the results can be adjusted to allow for simple comparisons. If the results are comparable this greatly validates the current research; however, if there is a significant disparity, this can help raise some necessary questions about the final outcomes and the processes that lead to them.

As previously described, Mars \& Houseknect's (2007) study offers good research to use for comparative purposes with the work conducted in this present thesis. This study determined that there was a significant increase in the rate of erosion over time at the study site in Alaska. In fact, from 1985 to 2005 land loss resulting primarily from shoreline erosion accounted for roughly

$21.6 \mathrm{~km}^{2}$ (Mars \& Houseknect, 2007). This represented an average erosion rate of $1.08 \mathrm{~km}^{2}$ annually along a $130 \mathrm{~km}$ segment of coastline. Although the total amount of land erosion was of $36.32 \mathrm{~km}^{2}$ in this current thesis, the rate observed was $1.30 \mathrm{~km}^{2} /$ year which is comparable with Mars \& Houseknect's findings. Given the fact the tidal impacts were negligible due to the low tidal range experienced in the region, the increase in erosion rate can be potentially attributed to this 
current thesis gathering data up until 2013 which is 8 years later than Mars \& Houseknect's paper. Many more factors can evidently be at play and in their study, the impact of marine flooding was particularly investigated. It was determined that in one of the Landsat images employed in this study, roughly 70\% of the former bed lake near the coast was inundated, presumably by marine water (Mars \& Houseknect, 2007). This suggests that the shoreline erosion observed is not necessarily due to coastal erosion, but rather by the ocean flooding the shores. However, this is less likely the cause of the shoreline erosion observed in the current thesis. Tuktoyaktuk's shores and those of the surrounding Mackenzie Delta are not low-lying, but rather 5 to 15 metre cliffs signifying inundation would be less likely. Unfortunately, this study makes no mention of the other major mechanisms of shoreline changes previously discussed hence making comparisons of the root cause of coastal changes less definitive. In addition, the rate of deposition was also not accounted for which indicates the complementary process cannot be compared to the results gathered throughout this present thesis. The lack of a holistic approach to Mars \& Houseknect's (2007) paper does not provide information on the trends of shoreline changes.

Irina Overeem’s (2014) study was the second comparative research already noted. In that analysis, it was concluded that accelerating shoreline erosion rates in the region resulted in roughly $27 \mathrm{~km}^{2}$ of total land lost by 2007 along a 3,000 kilometre segment of the northern shoreline at the study site in the Beaufort Sea near Alaska’s Drew Point. That land loss occurred at an erosion rate of roughly $0.96 \mathrm{~km}^{2} /$ year (Overeem, 2014). In this thesis, while the total amount of land lost due to erosion was of $36.32 \mathrm{~km}^{2}$ at a rate of $1.30 \mathrm{~km}^{2} /$ year, the rate was somewhat comparable to the one of $0.96 \mathrm{~km}^{2} /$ year determined by Overeem. The rate in Overeem's article could potentially be even higher if her study included data gathered up until 2013 as was the case in this present thesis. In addition, considering the fact Tuktoyaktuk is one of the regions where erosion rates are greatest in the Canadian Arctic, it is not surprising that rates established in various other study sites are not as elevated. Overeem also investigated other possible causes of the rapidly changing coastal landscape including properties of the ground ice to changing atmospheric conditions, increasing water levels, and the receding sea ice. She concluded that, while natural erosion was occurring, it was not the only source of change. Ground ice thawing was one of the most influential other mechanisms of shoreline change identified in the study site. This was perhaps due to an increase in average temperatures which in turn left the coast more vulnerable to erosion. This mechanism may also be responsible for some of the drastic changes described in this current thesis. Overeem's article like many others failed to mention the deposition amounts 
observed; however, these are considered to be significantly lower that erosion rates which could explain their omission. This does unfortunately signify that this study could not be employed to comment on the nature of the changes observed in this study; that is whether they are linear or cyclical.

While there are several other prominent studies addressing this subject matter, the majority of these are not easily comparable with this thesis because their results do not provide the total amount of land lost during the study period. Most are more concerned with simply establishing rates based on some extrapolation from various points and segments created. This methodology is useful in determining rates; however, it does not provide a great indication of the total amount of land lost which is a very important measurement. This being said, one constant according to nearly all studies investigated in this thesis is that the overall trend in Arctic shoreline change is towards erosion rather than deposition. While some studies differed in rates to some extent especially at different locations, erosion appears to be much more significant than deposition. As it was perhaps best described by Shaw et al. (1998), discussing the relationship between coastal and marine processes: “...even relatively large increases in sediment supply are unlikely to alter the dominance

of erosion over accretion”. The evidence seems to point towards shoreline erosion as being the most influential process affecting Arctic shorelines and the multitude of different studies supporting this claim leads to a conclusion that this is not an isolated instance, but rather a tangible and worrisome trend.

\subsection{Linear or Cyclical Changes?}

In order to ensure this thesis was completed holistically, it was important to approach it within a framework of the Arctic as a whole through a chronological lens which would provide better context into the shoreline changes to determine whether they are systematic or haphazard. One of the main objectives of this research was to determine if shoreline changes are strictly linear and in constant state of change, or if another trend was discernible. This could be accomplished by analysing the results obtained in the previous chapter. If these results are linear, then it can be concluded that changes are undeviating and the trend is strictly towards erosion or deposition; however, if there are deviations then the trend may be cyclical rather than linear.

As previously described in the results section, erosion accounted for a total land loss of $12.91 \mathrm{~km}^{2}$ from 1985 to 1990 ; however, in the following temporal change vector from 1990 to 
1995 the total land loss was much lower at only $1.72 \mathrm{~km}^{2}$. From 1995 to 2000, the erosion total augmented greatly with over $22.04 \mathrm{~km}^{2}$ of land lost only to plummet once again from 2000 to 2005 when only $3.38 \mathrm{~km}^{2}$ of land eroded in Tuktoyaktuk and the surrounding regions. Lastly, in the final temporal change vector from 2005 to 2013 the amount of land lost to erosion was of 18.01 $\mathrm{km}^{2}$. On the other hand, deposition displayed the same, but contrasting trend to erosion. This signifies that when erosion occurred in overwhelming amounts in any given temporal change vector, the amount of deposition would be very low and vice versa. This trend was consistent throughout the entire study. By observing the bar graph with lines in Figure 36, which displays the total polygon change areas which have undergone deposition and erosion in each temporal change vector from 1985 to 2013 it is immediately clear that erosion and deposition are non-linear in their combined occurrence. However, individually, the running totals of all erosion and deposition changes which occurred over this study are both escalating although at different rates (i.e. there was more erosion taking place cumulatively than deposition).

What is not necessarily readily observable in the erosion and deposition cycles is that there may have been a lot of erosion in the first temporal vector; however, the erosion may have slowed down due to multiple factors. For instance colder time periods could result in less sea ice loss in the summer months and consequently in less erosion due to wave action (USEPA, 2014). In addition, more resistant material can also explain the variations in shoreline erosion and deposition (Johnson et al., 2003; Solomon, 2003). For instance, if the first segment of the shoreline (i.e.: the frontshore, as in Figure 3) is composed of soft material that is easier to erode, this segment of the coastal zone is more likely to erode at a faster rate (Johnson et al., 2003; Solomon, 2003). If the backshore (Figure 3) is composed of ice-rich ground ice that needs to melt before it can be eroded away then it will take a longer period of time to erode (Johnson et al., 2003; Solomon, 2003). Consequently, since different sediments have different erosion rates, it is to be expected that erosion and deposition are not linear but rather cyclical. This trend is also observed in other studies although predominantly to a lesser extent. In William Manley's (2004) shoreline change study near Barrow, Alaska while erosion of the mainland coast accounted for roughly 91\% of all changes, the remaining 9\% was attributed to sediment deposition. While the trend is overwhelmingly in support of erosion as the main driver of coastal change which is mirrored to a certain extent in this current research, the cyclical nature of this change is not isolated. However, it is important to note that this study determined that the areas that experienced the highest levels of deposition were primarily limited to short coastal stretches of beaches and near shore creating 
spits and bars (Manley, 2004). While these results were not unexpected since such landforms are fundamentally created through the deposition of sediment, what was somewhat surprising was that deposition in these areas occurred at rates upwards of $3.7 \mathrm{~m} /$ year which are quite considerable (Manley, 2004). These changes could help explain some of the elevated deposition amounts and rates observed in this current thesis and presented in the previous chapter.

This trend was also observed in Barnes \& Rollyson's (1991) paper which investigated the relationship between erosion and deposition along the Alaskan coast over a 30 year period from 1951 to 1981 . Their study demonstrated that while ocean-facing coastal bluffs were unmistakeably retreating, deltas conversely were rapidly expanding through deposition (Barnes \& Rollyson, 1991). According to this study, coasts that were fronted by a lagoon, coast-parallel sand and gravel islands, and spits, significantly reduced bluff erosion while rapid delta expansion appears to have originated in the last 200 years approximately. Ground ice thawing due to climate change was cited as a very likely cause (Barnes \& Rollyson, 1991). In addition, "The extensive bluff erosion was volumetrically balanced by accretion at the mouths of deltas” (Barnes \& Rollyson, 1991). While this suggests an equilibrium is ultimately achieved through this cyclical process, there may be periods where erosion or deposition occur in greater amounts and at differing rates which could also help explain the changes observed in this current thesis.

As it was observed from the results in this present thesis, shoreline changes appear to be cyclical. While the total amount of land lost $\left(36.32 \mathrm{~km}^{2}\right)$ throughout the entire study is far greater than the amount of land gained $\left(1.12 \mathrm{~km}^{2}\right)$, there are distinct periods where deposition far outweighs erosion. The comparative analysis of other similar studies, supports these observations and suggests that deposition is primarily taking place in the delta regions where coastal landforms such as spits, beaches, and barrier islands are created and expanded over time from the settling of eroded sediment. While some studies in other regions of the Arctic may display less extreme fluctuations in the cyclical process of erosion and deposition, this may be due to differences in coastal environments. For instance, spits, beaches, and barrier islands along Tuktoyaktuk's Peninsula represent nearly 30\% of the region's coastline (Hill et al., 1991). Since these are landforms formed by past deposition, this could help explain why deposition plays a more important role in the cyclical trend observed in the study area of this current thesis. 


\subsection{Implications on the Beaufort Sea Ecosystem}

Despite the fact that the shoreline changes previously presented are a cause for concern for the state of Arctic coastlines, history and science have continuously demonstrated that it is even more imperative to observe the planet as a whole and consider the interconnectedness of the many biomes that constitute it. This is especially true since the repercussions of environmental changes rarely manifest themselves in a single contained form, but are rather perpetuated and magnified throughout the many links in the system. Therefore, this study would be incomplete if it did not attempt to draw a parallel between the issue of shoreline erosion and the many other changes that could potentially emanate from the shifting coast. These causal links will be made by investigating the entire cycle of shoreline change which will in turn help elucidate the questions posed by many - why is this important? And why should people care?

As it has been cemented throughout this paper, the root cause of many of the environmental issues experienced today is unquestionably the current warming of the planet (NOAA, 2014; IPCC, 2007). The escalating production of carbon dioxide released in the atmosphere mostly due to anthropogenic activities has resulted in a plethora of negative by-products. As previously discussed in greater detail, the most basic is the melting of sea ice and snow. This melting combined with a lengthening of the open water season has signified that Arctic ground ice shorelines such as those that form Tuktoyaktuk's coast have been exposed to unfamiliar level of wave activity in recent times (Overeem et al., 2011). The empirical data points to an evident causal link between this reduction in sea ice and increase of coastal erosion (Overeem et al., 2011). While this may seem like the endpoint of shoreline erosion to some, it is argued here that this only constitutes the initial phase of this complex process which affects many more components of the environment. In fact, once shorelines erode, the natural equilibrium of the ecosystem commands that the soil lost must settle elsewhere (USEPA, 2012). It is at this point that deposition must be taken into consideration (USEPA, 2012). Deposition is the evident complementary process ensuing erosion. Once the sediments that constitutes a ground ice shoreline begins to soften and loosen through the repeat action of waves, wind, or changing soil fertility, it logically finds itself washed away into the ocean. When this suspended soil, or sediment, settles against a surface it completes the deposition phase and through this continual process, the ocean can accumulate a significant amount of eroded soil depending on the rate of erosion. 
Shoreline dynamics directly reflect the land-ocean relations and maintain the balance between organic carbon, nutrients, and sediments in the Beaufort Sea (Rachold et al., 2000). In Tuktoyaktuk - particularly in the coastal lowlands to the east of the Mackenzie Valley Delta - the coast is characterised by 5 to 15 metre high unlithified cliffs (Shaw et al., 1998). Unlithified soil describes ground that is in loose form which has not been compacted by cementing, fusion, or pressure (Gale \& Hoare, 2011). These cliffs are composed of frozen sandy soil which are eroding, resulting in the creation of barrier beaches and spits which undergo rapid changes due to wash over and changes in sediment supply (Shaw et al., 1998). While the shallow waters surrounding Tuktoyaktuk are biologically very productive, particularly in the summer months due to nutrients mixing, organic carbon, plankton, as well as sediments originating from the Mackenzie River, erosion of the shorelines can significantly disrupt this delicate balance (Carmack \& Macdonald, 2002; Tremblay et al., 2011). The uppermost soil layer is the richest in organic matter and when it begins to erode and settle in the ocean, the organic matter evidently alters the water quality (Ministry of Agriculture and Food, 2012). While this may seem trivial at the scale of Tuktoyaktuk, it is important to remember that if this process is occurring simultaneously across the entire Arctic coastline of the Beaufort Sea, these inputs can then actually have cumulative impacts on coastal ecosystems. An increase in carbon and nutrient loading in the Beaufort Sea as a result of thawing ground ice, erosion, and deposition of the coastline coupled with an increase of solar radiation absorbed by oceans due to melting sea ice, could consequently lead to an increase in productivity and changes to wildlife habits and patterns (Figure 40). 


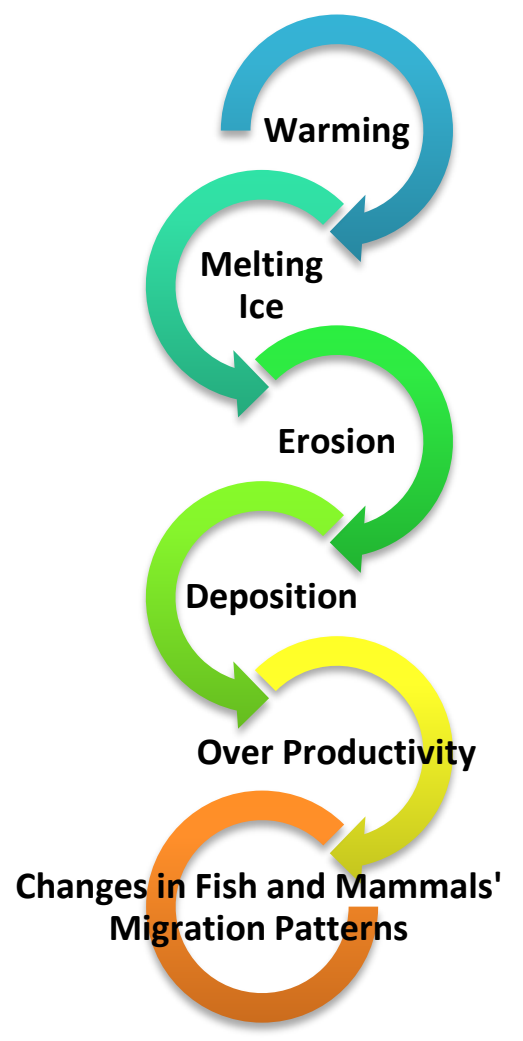

Figure 40. Complete Interconnected Erosion Cycle from start (top) to finish (bottom)

While such increase may appear to be a benefit, this is not always the case (Arrigo, 2013). Over productive marine ecosystems are referred to as being eutrophic which is described as "an increase in the rate of supply of organic matter in an ecosystem" and is considered as one of the most significant threats to the health and stability of marine biomes (Nixon, 1995). Once the Beaufort Sea begins to accumulate an excess of nutrients, primarily nitrogen and phosphorus both present in arctic ground ice shorelines - there begins to be an accelerated growth of algae and other plants (Andersen et al., 2006). This can then lead to an increase in the number of food web levels in an ecosystem which is not accustomed to such elevated productivity (Thompson et al., 2012). Common negative ecological effects of this over productivity include increased biomass of phytoplankton (some toxic species), decreased water transparency (increased turbidity), and a depletion of the dissolved oxygen levels (Thompson et al., 2012). Over time, fish stocks begin depleting and this then becomes very important on the larger scale of Tuktoyaktuk and the Beaufort Sea (Arrigo, 2013). These changes can alter the migration and travel patterns of larger mammals such as whales and belugas which feed on smaller fish. This will in turn affect the First Nations people who rely on them for survival (Arrigo, 2013). In addition, this will have a deep-seated impact on any oil excavation ventures or other industries which is a factor that is not seriously considered today since these impacts are forthcoming and not necessarily currently happening. It 
is the interconnected dynamics of the land and marine ecosystems that we may not see today that need to be considered in greater detail. While it is important to complete this study and state the shoreline changes observed, it is the higher level scope that truly matters.

\subsection{Implications on Shoreline Development}

Throughout this research, the continuously recurring theme which has framed this entire thesis and led to the results obtained has been that of uncertainty. That is, the uncertainty surrounding changes taking place within very sensitive ecosystems which could potentially lead to irreversible damages if the complexity of ecosystems is not carefully considered. It is therefore important to consider the larger picture when making business decisions which can have far-reaching implications. Several development projects have already been identified in Tuktoyaktuk; however, the uncertainty with regards to the impacts of shoreline changes have hindered these projects' progress (UMA, 2001). It is for this reason that one of the main objectives of this thesis was to link the coastal changes observed to shoreline development in Tuktoyaktuk and the surrounding delta region.

Given the results obtained in this present research indicating the amount of erosion can far outweigh the amount of deposition, it is not surprising that shoreline development projects in Tuktoyaktuk should only be undertaken where careful thought, evaluation, and planning have been carried out. While the municipal boundaries of the Hamlet of Tuktoyaktuk are defined by just

over $11 \mathrm{~km}^{2}$ of land, the demand for that land to be developed is growing (Statistics Canada, 2002). In fact, it is projected that the demand for residential land in the hamlet will an increase by 30 to 50\% over the next two decades (Johnson et al., 2003). Of the roughly 350 buildings within the community's confines most are private dwellings, although, some are public structures such as the elementary school and RCMP post (Andrachuk \& Smit, 2012). While this may not seem like significant changes in comparison to major cities in the south for instance, it is important to remember the location and history of Tuktoyaktuk and place this growth in its proper perspective. For such a small hamlet, the community can be accessed year-round by plane, helicopter, or by some land vehicles on ice roads which is not a privilege many other northern communities share (Andrachuk \& Smit, 2012). The oil and gas exploration in the mid to late 1970's led to the construction of a port on Tuktoyaktuk's $6 \mathrm{~km}$ long and $2 \mathrm{~km}$ wide harbour which made it also accessible by boat (Harwood et al., 2007). This growth has slowly continued and intensified in recent years due to a renewed interest in oil and gas exploration in the region. 
Unfortunately, with more than $36 \mathrm{~km}^{2}$ of land erosion taking place in Tuktoyaktuk and its surrounding region over the duration of this current study, at a rate of $1.30 \mathrm{~km}^{2}$ per year, the existing infrastructure and future shoreline development projects to accommodate the current growth are in evident jeopardy. This extensive land erosion will undoubtedly place the airport, harbour, private dwellings, and other buildings in the community in grave danger of being destroyed and washed away into the Beaufort Sea given their close proximity to the shoreline. In addition, due to the degradation of Arctic ground ice, many buildings further inland are in similar danger of collapsing since there is no exposed bedrock in the region on which to erect structures (Manson et al., 2005). While ground ice construction methods and technologies have greatly improved in the past several decades, many of the challenges associated with construction ventures in this demanding environment persist (GNWT, 2008). Foundations are very vulnerable especially due to the warming global climate which is resulting in the thawing of the ground ice layers in Tuktoyaktuk. These issues are underlined by the difficulties in generating the funding needed to relocate the community further inland, which is a real possibility, given the monumental erosion figures involved (Andrachuk \& Smit, 2012). The progression of shoreline erosion in Tuktoyaktuk is threatening to directly impact more than 15 structures in the community over the next 10 to 25 years (Johnson et al., 2003). While there is much uncertainty regarding the exact timeline, the fact remains that this process is occurring and adaptive measures must be undertaken immediately to counter it where possible and ensure shoreline development can be carried out as safely as possible moving forward.

\subsection{Implications on Offshore Activities}

While the impacts of erosion are more readily evident onshore since they directly manifest themselves on the coastal environment and affect shoreline development, they are often much less apparent offshore. It can be difficult for some to associate the amount of erosion taking place in Tuktoyaktuk and along the Beaufort Sea coastline with offshore development since the two are geographically distant. However, as stressed in the environmental science field and throughout this

thesis, ecosystems are interconnected and must therefore be considered within a larger scope in order to appreciate their intricacies and nuances. Establishing and describing the link between shoreline erosion and Arctic offshore drilling activities in search of natural resources was one of the main objectives of this research. This connection can help reveal the true extent of the impacts shoreline changes previously detailed can potentially have on offshore development projects. 
Shoreline erosion has significant implications on both the Beaufort Sea ecosystem as well as the development of shorelines for commercial and habitation purposes. The prospect for over productivity of the marine ecosystem due in large part to the influx or nutrients resulting from soil erosion into the Beaufort Sea is resulting in a several undesirable impacts such as the depletion of dissolved oxygen which can negatively affect fish stocks (Arrigo, 2013). Consequently, this has profound repercussions on the migration patterns of larger marine mammals such as the endangered bowhead whales who depend on these fish to survive (Sustainalytics, 2012; Goodyear \& Clusen, 2012). The uncertainty regarding the new travel patterns these animals will adopt to survive in these harsh and unusual conditions can in turn negatively affect offshore development Goodyear \& Clusen, 2012). The construction of offshore drilling platforms and wells to access more remote oil and gas deposits in the Arctic Ocean is not only costly but also time consuming to undertake. In addition, according to oil companies and the Arctic Offshore Drilling Review by the National Energy Board, there is a stringent system of assessing the safety of offshore projects (National Energy Board, 2011). These well developments cannot be undertaken safely given all this uncertainty because these constructions can affect the potentially new marine migration routes of many species which can then lead to the deaths and decrease in population size of these important animals.

Furthermore, in order to complete these offshore projects there is often a need to carry out dredging or sand mining which in combination with natural forces previously discussed (subsidence, isostatic rebound, rising sea level amongst others) exacerbate the coastal erosion observed in Tuktoyaktuk and surrounding regions (FAO, 2013). This can also "jeopardise opportunities for coasts to fulfill their socio-economic and ecological roles in the long term at a reasonable societal cost” (FAO, 2013). The shocking shoreline erosion figures presented in the previous chapter can therefore have deep impacts on offshore activities; however, the causal link is not unidirectional. In fact, offshore industrial endeavours equally affect shoreline erosion, and the importance of this positive feedback loop cannot be understated since failure to recognise its significance can result in irresponsible economic ventures that can lead to irreparable damage to an otherwise pristine environment. This substantiates, at least in part, one of the founding hypotheses of this thesis, that increased human interest and presence in the Arctic due to resource extraction will only intensify the rate of shoreline change in Tuktoyaktuk. 


\section{CONCLUSION}

This chapter begins with a detailed synthesis of all the findings of this research and continues with conclusions from those findings. Subsequently, the limitations of this thesis are discussed which will lead to a suggestion of future research and opportunities to further investigate shoreline changes in perhaps an even greater and more complete fashion. Therefore, this chapter is not only meant to bring about the conclusion of this research, but also simultaneously open the door to future academics to push these efforts beyond the boundaries and parameters of this current work.

\subsection{Summary of Findings}

Following the research undertaken, it was established that there were several areas that experienced shoreline changes. While these changes varied from one temporal change vector to the next, some trends became evident. The areas which experienced significant changes were located on maps and they appeared to be fairly widespread throughout the study area. However, they shared some similar traits in that they were typically spits, beaches, and barrier islands, near Tuktoyaktuk's coastline which are very sensitive to environmental changes. In addition, it was revealed that bays also significantly changed. While many of these landforms experienced significant deposition in some time periods, most, completely moved over the 28 year study period (or increased in the case of bays) which characterised some of the greater shoreline losses. However, due to their inland location geographically away from the shoreline, they were not included in the results.

In Tuktoyaktuk and its surrounding Mackenzie Delta region, it was discovered that the most significant shoreline erosion changes occurred in the first, third, and fifth temporal change vectors. In the first vector (1985 to 1990), $12.91 \mathrm{~km}^{2}$ of land was lost to erosion at a rate of 2.58 $\mathrm{km}^{2}$ per year. In the third vector (1995 to 2000), there was $22.04 \mathrm{~km}^{2}$ of land eroded away at an alarming rate of $4.41 \mathrm{~km}^{2}$ per year, while the fifth vector (2005 to 2013) revealed $18.01 \mathrm{~km}^{2}$ of land lost at a rate of $2.25 \mathrm{~km}^{2}$. There were only two temporal change vectors which displayed significant land gained through deposition and they were vectors two and four. In the second temporal change vector (1990 to 1995) $14.62 \mathrm{~km}^{2}$ of land was deposited onto the shoreline of Tuktoyaktuk and its surrounding region at a rate of $2.92 \mathrm{~km}^{2}$ per year. In the fourth vector (2000 to 2005), a total of $8.59 \mathrm{~km}^{2}$ of land was gained by the shorelines through deposition of sediment 
at a rate of $1.72 \mathrm{~km}^{2}$ per year. By observing the changes throughout the entire study period of 28 years (1985 to 2013) in the sixth temporal change vector, a total of $36.32 \mathrm{~km}^{2}$ of land was lost to erosion while only $1.12 \mathrm{~km}^{2}$ was gained through sedimentation. This provided a much better overall indication of the changes and therefore it became clear that erosion was a much more dominant process than deposition over this time period.

Separating the study into five distinct time periods, provided for a greater opportunity to observe the trends in shoreline changes and from the results presented, it was evident that there is a cyclical trend to the shoreline changes. In fact, each temporal change vector which displayed erosion, was immediately followed by a change vector which was dominated by deposition and vice versa. This was the case for every single change vector which refuted the hypothesised trend that shoreline changes are strictly linear and in constant state of change. This trend remains strongly influenced by erosion. While the two processes are opposing, erosion is overwhelmingly more significant than deposition in its overall impact.

The final major discovery was centered on the hypothesis that increased anthropogenic activity in the Arctic will serve to intensify the rate of shoreline erosion in Tuktoyaktuk and the Mackenzie Delta and affect the animal species in the region. Despite the varying rate of shoreline erosion presented in this thesis, it remains factually accurate that erosion rates in the Arctic are increasing and this is supported by other studies in the field. The rates calculated in this research, particularly in the third change vector from 1995 to 2000 (4.41 km² of land lost annually), are significantly higher than rates in previous years. This can be attributed to multiple cumulative factors; however, the impacts of offshore as well as onshore development projects on the increasing rates of land loss in an otherwise pristine region of the world cannot be summarily dismissed.

\subsection{Conclusions}

The goal of this research was essentially twofold: to establish the amounts, rates, and trends in shoreline changes observed in Tuktoyaktuk and its surrounding Mackenzie Delta region using multi-spectral imagery from LANDSAT-5 and LANDSAT-8, and if possible, to determine if these changes could be linked to resource exploration and development in the Arctic. 
The findings of this study indicate that there are several areas which experienced changes; however, none more significant than spits, beaches, and barrier islands which make up roughly a third of the region's coasts. The results also indicate that while a cyclical pattern was detected in which periods of overwhelming erosion were followed by periods of vast deposition, shoreline erosion was a much more significant process than shoreline deposition. This was clear when analysing the progressive running totals of each process and in the overall changes observed over the study's duration. This was supported frequently throughout the literature.

The second overarching aim of this thesis was to determine if these shoreline changes could be influenced or they themselves influence resource exploration and development in the Arctic. While this was not immediately evident or firmly demonstrated through the results gathered, the rates of erosion are good broad figures to help make the case that that shoreline changes are influenced by economic activity in the Arctic which has resumed in recent years. The rates of erosion have been increasing when compared to historical figures, which can indicate that there is potentially a correlation with increased development in this region of the globe. In addition, the changing marine ecosystem resulting from shoreline erosion, coupled with the pressures resulting from shoreline and offshore development has altered migration patterns of important species which has threatened other links in the environmental chain. While this was unfortunately not conclusively demonstrated given the parameters of this research, the rapidly changing environment in this region commands that the precautionary principle be applied in order to ensure irreversible ecological damage is not allowed to take place.

\subsection{Limitations}

As is the case of any scientific study, limitations will always be present; however, acknowledging these hurdles will highlight its successes and shortcomings while also helping improve future work. Despite this research's attempt to conclusively establish the shoreline changes at the study site, this could only be accomplished within a moderate level of certainty. This is often the case when employing satellite record imagery because there are multiple factors than can reduce the accuracy of the results. For instance, the satellite chosen itself can strongly influence the results. Ideally, a sensor with a higher spatial resolution than the 30 metre resolution of Landsat-5 and Landsat-8 would have been selected given the significance of processes of erosion identified. This would have signified that more specific changes would have been detected. Unfortunately, considering the cost of acquiring high resolution imagery, and this thesis' 
logistical and monetary constraints, the choice was rather limited. However, to reduce the impacts of this constraint, only larger changes that would be picked up by Landsat-5 and Landsat-8 were analysed since they would less likely be attributable to processing errors. In other words, if a change was detected, it signified that it was most likely a true indicator of change since it was large enough to be captured by the satellites chosen.

In addition, the difficulty in carrying out perfect image pre-processing steps for each scene employed, particularly geometric correction, was unavoidable. Despite having strict parameters, this could only be done to a certain level of precision as displayed in Table 7, previously. Errors were also introduced in the classification stage despite careful attention being placed on this task. While the accuracy report indicates very few overall errors, when investigating shoreline changes at this level, even slight errors in classification could have serious impacts on the changes detected. Despite these unavoidable errors, the stringent parameters of this research helped reduce their impact on the results.

Another significant limitation to the study was the lack of inclusion of other mechanisms that could contribute to the changes detected in the results. Unfortunately, while most major mechanisms of shoreline changes were described, each one's actual contribution to the shoreline changes observed was not directly established. This was due to the difficulty in accomplishing this task at the scale chosen for this study as well as a lack of data.

Lastly, one of the objectives of this study was not demonstrated unequivocally. It was very difficult to determine if shoreline changes could be linked to resource exploration and development in the Arctic since this was not testable. Far too many other variables had to be

analysed before such assertions could be made with confidence. However, with the increase in shoreline changes demonstrated in this study along with other environmental impacts taking place in the Arctic, enough doubt can be raised to invoke the precautionary principle.

\subsection{Future Research}

In all academic research endeavours, individual studies should not be perceived as an end, but rather a means to an end. This end should be the continuous accumulation of knowledge to better understand the world. This is what was intended with this current research. 
This study provided insight on the current state in the Arctic with regards to coastal changes more specifically at the scale of Tuktoyaktuk and its surrounding Mackenzie Delta region. The results, implications, and limitations of this work does; however, suggest a need for more research in this field. To accomplish this, future work could perhaps focus exclusively on a specific site and employ higher resolution sensors to detect all changes regardless of size. By selecting a single constrained site, other mechanisms of shoreline changes such as sea level rise, isostatic rebound, and subsidence could then be included in order to determine each mechanism's actual influence on shoreline change. This would achieve a slightly different goal than that of this current research which was more broadly focused on establishing changes in erosion and deposition.

It would also serve a great purpose if future work could help establish a more direct and impactful connection between shoreline changes, and the repercussions on the people and wildlife in the region. This would be very important considering the impact increased economic development can potentially have on shoreline changes. 


\section{APPENDIX A}

1985

Separability Measure: Bhattacharyya Distance

Average separability: 1.926168

Minimum separability: 1.819582

Maximum separability: 1.998492

Signature pair with

Minimum separability: (Water, No Data)

\begin{tabular}{|l|l|r|} 
Name 1 & Name 2 & Separability | \\
Land & Water & 1.960432 \\
No Data & Water & 1.819582 \\
No Data & Land & 1.998492
\end{tabular}

1990

Separability Measure: Bhattacharyya Distance

Average separability: 1.635108

Minimum separability: 0.949449

Maximum separability: 1.988284

Signature pair with

Minimum separability: (Water, No Data)

\begin{tabular}{l|l} 
Name 1 & Name 2 \\
Land & Water \\
No Data & Water \\
No Data & Land
\end{tabular}

Separability

1.967591

0.949449

1.988284

\section{5}

Separability Measure: Transformed Divergence

Average separability: 1.641275

Minimum separability: 0.923825

Maximum separability: 2.000000

Signature pair with

Minimum separability: (Water, No Data)

Name 1

Land

Name 2

No Data

Water

No Data

Water

Land

Separability

2.000000

0.923825

2.000000 
2000

Separability Measure: Transformed Divergence

Average separability: 1.412504

Minimum separability: 0.240384

Maximum separability: 2.000000

Signature pair with

Minimum separability: (Land, No Data)

Name 1

Land

No Data

No Data

Name 2
Water
Water
Land

Separability

2.000000

1.997128

0.240384

\section{5}

Separability Measure: Transformed Divergence

Average separability: 1.818070

Minimum separability: 1.454210

Maximum separability: 2.000000

Signature pair with

Minimum separability: (Water, No Data)

| Name 1

Land

No Data

No Data

\begin{tabular}{|l} 
Name 2 \\
Water \\
Water \\
Land
\end{tabular}

Separability

2.000000

1.454210

2.000000

\section{3}

Separability Measure: Bhattacharyya Distance

Average separability: 2.000000

Minimum separability: 2.000000

Maximum separability: 2.000000

Signature pair with

Minimum separability: (Water, Land)

Name 1

Land

No Data

Name 2

Water

No Data

Water

Land

Separability

2.000000

2.000000

2.000000 


\section{References}

Aboriginal Affairs and Northern Development Canada, (2012). Oil and Gas in Canada's North - Active Exploration and New Development. Retrieved January 2013, from http://www.aadnc-aandc.gc.ca/eng/1100100037301/1100100037302

Aboriginal Affairs and Northern Development Canada, (2011). Chapter 4 - Mackenzie Delta and Beaufort Sea. Retrieved January 2013, from http://www.aadncaandc.gc.ca/eng/1321378288752/1321378450630

Ahmed, N, (2013). Institute for Policy Research \& Development. Retrieved January 2013, from http://www.theguardian.com/environment/earth-insight/2013/dec/23/britishpetroleum-geologist-peak-oil-break-economy-recession

Alesheikh, A. A., Ghorbanali, A., \& Nouri, N., (2003). Coastline Change Detection Using Remote Sensing. International Journal of Environmental Science and Technology, Vol. 4, No. 1, pp. 61-66, 5.

Alfred Wegener Institute, (2011). Arctic Coasts on the Retreat - International Studies Describe Current State of the Arctic Coasts. Retrieved October 2013 from http://www.awi.de/index.php?id=71\&type=123\&tx_list_pi1[mode]=6\&tx_list_pi1[uid] =852\&cHash=e3e81f01b78dada712547a30525d56ba\&L=0\&filename=awi.pdf

Anderegg, W. R. L., Prall, J. W., Harold, J., \& Schneider, S. H., (2010). Expert Credibility in Climate Change. Proceedings of the National Academy of Sciences, Vol. 107, No. 27, pp. 12107-12109, 2.

Andersen, J. H., Schlüter, L., \& Ærtebjerg, G., (2006). Coastal Eutrophication: Recent Developments in Definitions and Implications for Monitoring Strategies. Journal of Plankton Research, Vol. 28, No. 7, pp. 621-628, 7.

Anderson, D. L., \& O’Connell, R., (1967). Viscosity of the Earth. Geophysical Journal of the Royal Astronomical Society, Vol. 14, No. 1-4, pp. 287-295, 8.

Andrachuk, M., \& Smit, B., (2012). Community-based Vulnerability Assessment of Tuktoyaktuk, NWT, Canada to Environmental and Socio-economic Changes. Reg Environ Change, Vol. 12, pp. 867-885, 18.

ArcGIS, (2014). Intersect (Analysis). Retrieved April 2013, from http://resources.esri.com/help/9.3/arcgisdesktop/com/gp_toolref/analysis_tools/how_int ersect_analysis_works.htm

Ardhuin, F., Herbers, T. H. C., Vledder, G. P. V., Watts, K. P., Jensen, R., \& Graber, H. C., (2007). Swell and Slanting-Fetch Effects on Wind Wave Growth. Journal of Physical Oceanography, Vol. 37 No 4, pp. 908-931, 23. 
Aré, F. E., (2003). Shoreface of the Arctic Seas - A Natural Laboratory for Subsea Permafrost Dynamics. Permafrost, pp. 27-32, 6.

Aré, F. E., (1988). Thermal Abrasion of Sea Coast. Polar Geography and Geology, pp. 1-157, 156.

Arrigo, K. R., (2013). The changing Arctic Ocean. Elementa Science of the Anthropocene, Stanford University, United States.

Atkinson, D., (2011). Classification. Environmental Applied Science and Management ES8928 Special Topics: Environmental Management. Retrieved November 2013, from class lectures.

Atkinson, D., (2004). A Canadian Raised Beach, Cornwallis Island. Personal photo.

Atkinson, D. E., (2005). Observed Storminess Patterns and Trends in the Circum-Arctic Coastal Regime. Geo-Marine Letters, Vol. 2, pp. 98-109, 11.

Barnes, P. W. \& Rollyson, B. P., (1991). Erosion and Accretion along the Arctic Coast of Alaska. The Influence of Ice and Climate. Coastal Sediments, Vol. 2, pp. 1518-1531, 13.

Berger, T. R., (1977). Northern Frontier, Northern Homeland: The Report of the Mackenzie Valley Pipeline Inquiry. Vancouver: Douglas \& McIntyre, c1988.

Boak, E. H., \& Turner, I. L., (2005). Shoreline Definition and Detection: A Review. Journal of Coastal Research, Vol. 21, No. 4, pp. 688-703, 16.

British Columbia Ministry of Environment, (2006). What is Erosion? Retrieved July 2014, from http://www.env.gov.bc.ca/wsd/public_safety/flood/pdfs_word/erosion_qa.pdf

British Geological Survey, (2014). What is Subsidence? Retrieved February 2013, from http://www.bgs.ac.uk/science/landuseanddevelopment/shallow_geohazards/whatisShri nkSwell.html

Buddemeier, R. W., Smith S. V., Swaaney D. P., \& Crossland C. J., (2002). The Role of the Coastal Ocean in the Disturbed and Undisturbed Nutrient and Carbon Cycles. United Nations Environment Programme, pp. 1-44, 43.

Bulman, D., (2000). Is the Application of Remote Sensing To Weed Mapping Just 'S-Pie In? The Sky’? Plant Protection Quarterly, Vol. 15, pp. 127-131, 4.

Canadian Broadcasting Corporation, (2009). Tuktoyaktuk on Front Line of Climate Change. Retrieved November 2013, from http://www.cbc.ca/news/technology/tuktoyaktuk-onfront-line-of-climate-change- 1.845397

Carmack, E. C., \& Macdonald, R. W., (2002). Oceanography of the Canadian Shelf of the Beaufort Sea: a Setting for Marine Life. Arctic, Vol. 55, pp. 29-45, 16. 
Center for Ocean Solutions, (2014). Coastal Erosion. Retrieved January 2013, from http://centerforoceansolutions.org/climate/impacts/cumulative-impacts/coastal-erosion/

Chen, C. H., (2003). Frontiers of Remote Sensing Information Processing. World Scientific Publishing Co., Singapore, 2003.

Clark, J. R., (1994). Integrated Management of Coastal Zones. FAO Fisheries, pp. 16-75, 59. Retrieved March 2014, from http://www.fao.org/docrep/003/t0708e/T0708E04.htm

Comaniciu, D., Ramesh, V., \& Meer, P., (2000). Real-Time Tracking of Non-Rigid Objects using Mean Shift. IEEE Conference, Hilton Head Island, South Carolina, Vol. 2, pp. 142- $149,7$.

Council on Foreign Relations, (2014). The Emerging Arctic. Retrieved January 2013, from http://www.cfr.org/arctic/emerging-arctic/p32620\#!/\#resources

Dallimore, S. R., Wolfe, S. A., Solomon, S. M., (1995). Influence of Ground Ice and Permafrost on Coastal Evolution, Richards Island, Beaufort Sea Coast, N.W.T. Canada. Canadian Journal of Earth Sciences, Vol. 33, pp. 664-675, 12.

Danchuk, S., \& Willson, C. S., (2010). Effects of Shoreline Sensitivity on Oil Spill Trajectory Modeling of the Lower Mississippi River. Environmental Science and Pollution Research International, pp. 331-340, 9.

DeWitt, H., \& Weiwen Feng, J. R. (2002). Semi-Automated Construction of the Louisiana Coastline Digital Land-Water Boundary Using Landsat TM Imagery. Louisiana's Oil Spill Research and Development Program, Louisiana State University, Baton Rouge, LA, 70803.

Dunton, K. H., \& Cooper, L., (2005). Feedbacks Associated with Sea-level Rise along Arctic Coasts. Coastal Fluxes in the Anthropocene, pp. 52-53, 2.

Environmental Systems Research Institute, (2014). GIS Dictionary. Retrieved June 2013, from http://support.esri.com/en/knowledgebase/GISDictionary/term/band\%20ratio

EPodunk, (2007). Tuktoyaktuk, Northwest Territories. Retrieved July 2014, from http://ca.epodunk.com/profiles/northwest-territories/tuktoyaktuk/2002855.html

Food and Agriculture Organization, (2013). Remote Sensing as a Data Source. Retrieved October 2013, from http://www.fao.org/docrep/003/t0446e/t0446e04.htm

Forbes, D. L., Craymer, M., Henton. J., Piraszewski, M., (2007). Integrating GPS and Tide Gauge Data with Geological Evidence and Other Tools to Estimate Vertical Motion and Sea-Level Change in the Western Arctic. Natural Resources Canada. Retrieved June 2014, from ftp://geod.nrcan.gc.ca/pub/GSD/craymer/pubs/sealevel_cgu2007.pdf 
Forbes, D. L., Craymer, M., Manson, G. K., \& Solomon, S. M., (2004). Defining Limit of Submergence and Potential for Rapid Coastal Change in the Canadian Arctic. Ber. Polar-Meeresforsch, pp. 196-202, 6.

Gale, S. J. \& Hoare, P. G., (2011). Quaternary Sediments: Petrographic Methods for the Study of Unlithified Rocks. Second Edition, pp. 12-19, 7.

Godin, G., \& Barber, F.G., (1980). Variability of the Tide at Some Sites in the Canadian Arctic. Arctic, Vol. 33, No. 1, pp. 30-37, 8.

Goodyear, J., \& Clusen, C., (2012). Environmental Risks with Proposed Offshore Oil and Gas Development off Alaska's North Slope. Natural Resources Defense Council Issue Paper, pp. 1-15, 16.

Goudas, C., Katsiaris, G., May, V., \& Karambas, T., (2003). An Environmental Innovation in Coastal Engineering. Coastal Systems and Continental Margins, Vol. 7, pp. 117-125, 9.

Government of the Northwest Territories, (2014). Bob McLeod - Inuvik to Tuktoyaktuk Highway Ground-breaking Ceremony. Retrieved January 2014, from http://news.exec.gov.nt.ca/bob-mcleod-inuvik-to-tuktoyaktuk-highwaygroundbreaking-ceremony/

Government of the Northwest Territories, (2008). Northwest Territories Climate Change Impacts and Adaptation Report. Retrieved March 2014 from http://www.enr.gov.nt.ca/sites/default/files/reports/nwt_climate_change_impacts_and_ adaptation_report.pdf

Harwood, L. A., Pokiak, F., \& Walker-Larson, J., (2007). Assessment of Subsistence Fishing and Population Structure of Arctic Cisco in Tuktoyaktuk Harbour, NT, Canada, 19971999. Retrieved April 2014, from http://www.dfo-mpo.gc.ca/Library/335077.pdf

Hill, P. R., Héquette, A., Ruz, M-H., Jenner, K. A., (1991). Geological Investigations of the Canadian Beaufort Sea Coast. Geological Survey of Canada Open File Report (2387), pp. 75-95, 20.

Hinkel, K. M., Sheng, Y., Lenters, J. D., Lyons, E. A., Beck, R. A., Eisner, W. R., \& Wang, J., (2012). Thermokarst Lakes on the Arctic Coastal Plain of Alaska: Geomorphic Controls on Bathymetry. Permafrost and Periglacial Processes, Vol. 23, No. 3, pp. 218-230, 12

Holt, Rinehart, \& Winston Staff, (2014). Holt Science and Technology: Earth Science: Agents of Erosion. Holt, Rinehart, \& Winston Staff, $5^{\text {th }}$ Edition.

Hulme, M., Jenkins, G. J., Lu, X., Turnpenny, J. R., Mitchell, T. D., Jones, R. G., Lowe, J., \& Murphy, J. M., (2002). Climate Change Scenarios for the United Kingdom: The UKCIP02 Scientific Report. Tyndall Centre for Climate Change Research, pp. 5-120. 
Intergovernmental Panel on Climate Change, (2007). Climate Change 2007: Working Group II: Impacts, Adaptation and Vulnerability. 6.4 Key future impacts and vulnerabilities. Retrieved September 2013 from http://www.ipcc.ch/publications_and_data/ar4/wg2/en/ch6s6-4.html

Intergovernmental Panel on Climate Change, (2007). Climate Change 2007: Working Group I: The Physical Science Basis. 5.1 Is Sea Level Rising? Retrieved July 2014, from http://www.ipcc.ch/publications_and_data/ar4/wg1/en/faq-5-1.html

Intergovernmental Panel on Climate Change, (2007). Climate Change 2007: Working Group II: Impacts, Adaptation and Vulnerability. Retrieved May 2014, from http://www.ipcc.ch/publications_and_data/ar4/wg2/en/ch1s1-3-3-1.html

International Study of Arctic Change, (2012). Responding to Arctic Environmental Change. Retrieved September 2013, from http://www.arcticchange.org/sites/arcticchange.civicrm.ca/files/RespondingtoArcticEn vironmentalChange.pdf

Jensen, J. R., (2005). Introductory Digital Image Processing: A Remote Sensing Perspective $\left(3^{\text {rd }}\right.$ edn). Prentice-Hall, Upper Saddle River, NJ.

Jinga, L., \& Riddb, P. V., (1997). Modelling Of Suspended Sediment Transport in Coastal Areas under Waves and Currents. Estuarine, Coastal and Shelf Science, Vol. 45, No. 1, pp. 1- 16, 17.

Johnson, K., Solomon, S., Berry, D., \& Graham, P., (2003). Erosion Progression and Adaptation Strategy in a Northern Coastal Community. Permafrost, pp. 489-494, 5.

Jones, B. M., Hinkel, K. M., Arp, C. D., \& Eisner, W. R., (2008). Modern Erosion Rates and Loss of Coastal Features and Sites, Beaufort Sea Coastline. Alaska, Vol. 61, pp. 361372, 11.

Joseph, L. H., (2004). Sedimentary Characteristics through Glacial/Interglacial Transitions at ODP Site 1233. EOS Transactions American Geophysical Union, Vol. 85, No. 47, pp. 51-71, 20.

Kattsov, V., \& Källén, E., (2005). Future Changes Of Climate: Modelling and Scenarios For The Arctic Region. In Arctic Climate Impact Assessment (ACIA), ed. C. Symon, L. Arris, and B. Heal, pp. 99-150, 51. New York: Cambridge University Press.

Kelley, G. W., Hobgood, J. S., Bedford, K. W., \& Schwab D. J., (1998). Generation of ThreeDimensional Lake Model Forecasts for Lake Erie. Vol. 13, pp. 305-315, 10.

Kingston, P. F., (2002). Long-term Environmental Impact of Oil Spills, Spill Science \& Technology Bulletin, Vol. 7, pp. 53-61, 8.

Kobayashi, N., Vidrine, J. C., Nairn, R. B., \& Solomon, S., (1999). Erosion of Frozen Cliffs Due To Storm Surge. Journal of Coastal Research, Vol. 15, pp. 332-344, 12. 
Kumar, A., \& Singh, L. S., (2012). Is Isostatic Rebound in Slow Spreading Gakkel Ridge of Arctic Region Due to the Climate Change? A Case Study. International Journal of Geosciences, Vol. 3, pp. 339-348, 9.

Lantuit, H., Overduin, P. P., Couture, N., Wetterich, S., Aré, F., et al., (2011). The Arctic Coastal Dynamics Database: A New Classification Scheme and Statistics on Arctic Permafrost Coastlines. Estuaries and Coasts, pp. 383-400, 17.

Legislative Assembly of the NWT, (2010). Tuktoyaktuk. Retrieved October $2^{\text {nd }}$, 2012 from http://web.archive.org/web/20130705001114/http://www.assembly.gov.nt.ca/_live/pag es/wpPages/maptuktoyaktuk.aspx

Lillesand, T. M., Kiefer, R. W, \& Chipman, J. W., (2007). Remote Sensing and Image Interpretation (6th Ed.). New Jersey, U.S.A.: John Wiley \& Sons Inc.

Malgorzata, W., (2010). Data Acquisition and Integration. Retrieved November 2013, from http://www.tankonyvtar.hu/hu/tartalom/tamop425/0027_DAI6/ch01s04.html

Manley, W. F., (2004). Spatial Analysis of Coastal Erosion over Five Decades near Barrow, Alaska. University of Colorado. Retrieved July 2014, from http://nome.colorado.edu/HARC/Publications/aw04_barrow_wfm.pdf

Manson, G. K., Solomon, S. M., Forbes, D. L., Atkinson, D. E., \& Craymer, M., (2005). Spatial Variability of Factors Influencing Coastal Change in the Western Canadian Arctic. Geo-Marine Letters, Vol. 25, 138-145, 7.

Mars, J. C., \& Houseknecht, D. W., (2007). Quantitative Remote Sensing Study Indicates Doubling of Coastal Erosion Rate in Past 50 years along A Segment of the Arctic Coast of Alaska. Geology, pp. 583-586, 4.

Martínez, M. L., Intralawan, A., Vázquez, G., Pérez-Maqueo, O., Sutton, P., \& Landgrave, R., (2007). The Coasts of Our World: Ecological, Economic and Social Importance. Ecological Economics, Vol. 63, 254-272, 18.

Meehl, G. A., Stocker, T. F., Collins, W. D., Friedlingstein, P., Gaye, A. T., Gregory, J. M., Kitoh, A., Knutti, R., Murphy, J. M., Noda, A., Raper, S. C. B., Watterson, I. G., Weaver, A. J., \& Zhao, Z.-C., (2007). Global Climate Projections. Climate change 2007: the physical science basis. Contribution of Working Group I to the fourth assessment report of the Intergovernmental Panel on Climate Change, pp. 789-812, 23. Cambridge: Cambridge University Press.

Meier, W. N., Stroeve, J. C. \& Fetterer, F., (2006). Whither Arctic sea ice? A clear signal of decline regionally, seasonally and extending beyond the satellite record. Annals of Glaciology, Vol. 46, pp. 428-434, 7.

Ministry of Agriculture and Food, (2012). Soil Erosion - Causes and Effects. Retrieved April 2014, from http://www.omafra.gov.on.ca/english/engineer/facts/12-053.htm\#9 
Moorman, B., (2010). Arctic Coastal and Near-Shore Dynamics Project. Retrieved November, 2013 from https://geog.ucalgary.ca/research/groups/177-5492

Nagurnyi, A. P., (2009). Climate Tendencies of Changes in Multiyear Sea Ice Thickness in the Arctic Basin (1970-2005). Russian Meteorology and Hydrology, 2009, Vol. 34, No. 9, pp. 613-617, 10.

National Aeronautics and Space Administration, (2014). Global Climate Change. Retrieved June 2014, from http://climate.nasa.gov/key_indicators/

National Aeronautics and Space Administration, (2014). The Thematic Mapper. Retrieved November 2013, from http://landsat.gsfc.nasa.gov/?p=3229

National Aeronautics and Space Administration, (2014). Arctic Sea Ice Maximum 2014. Retrieved April 2014, from http://earthobservatory.nasa.gov/IOTD/view.php?id=83451

National Aeronautics and Space Administration, (2014). Landsat Science: Landsat 5.

Retrieved March 2014, from http://landsat.gsfc.nasa.gov/?p=3180

National Aeronautics and Space Administration, (2013). Landsat 8 Instruments. Retrieved December 2013 from http://www.nasa.gov/mission_pages/landsat/spacecraft/index.html\#.U3T_pfldXwg

National Aeronautics and Space Administration, (2010). How Will Global Warming Change Earth? Retrieved September 2013 from http://earthobservatory.nasa.gov/Features/GlobalWarming/page6.php

National Energy Board, (2011). Arctic Offshore Drilling Review. Retrieved November 2011, from http://www.neb-one.gc.ca/clfnsi/rthnb/pplctnsbfrthnb/rctcffshrdrllngrvw/rctcffshrdrllngrvw-eng.html

National Oceanic and Atmospheric Administration, (2014). Global Climate Change Indicators. Retrieved January 2014, from http://www.ncdc.noaa.gov/indicators/

National Oceanic and Atmospheric Administration, (2014). Trends in Atmospheric Carbon Dioxide. Retrieved March 2014, from http://www.esrl.noaa.gov/gmd/ccgg/trends/

National Oceanic and Atmospheric Administration, (2012). Cumulative and Secondary Impacts of Development. Retrieved April 2013, from http://coastalmanagement.noaa.gov/impacts.html

National Oceanic and Atmospheric Administration, (2008). Tides and Water Levels. What are Tides? Retrieved October 2013, from http://oceanservice.noaa.gov/education/kits/tides/tides01_intro.html 
National Oceanic and Atmospheric Administration, (2008). Temperature Change and Carbon Dioxide Change. Retrieved March 2014, from

http://www.ncdc.noaa.gov/paleo/globalwarming/temperature-change.html

National Oceanic and Atmospheric Administration, (2002). Beach Nourishment: A Guide for Local Government Officials. Retrieved June 2014, from

http://www.csc.noaa.gov/archived/beachnourishment/html/geo/barrier.htm

National Snow and Ice Data Center, (2014). Arctic sea ice reaches maximum extent for 2014.

Retrieved April 2014, from http://nsidc.org/news/newsroom/2014_maximum_MA.html

National Snow and Ice Data Center, (2014). Melting in the North, Freezing in the South. Retrieved July 2014, from http://nsidc.org/arcticseaicenews/

National Snow and Ice Data Center, (2013). All about Arctic Climatology and Meteorology: Factors Affecting Arctic Weather and Climate. Retrieved September, 2013 from http://nsidc.org/cryosphere/arctic-meteorology/factors_affecting_climate_weather.html

National Snow and Ice Data Center, (2013). State of the Cryosphere: Is the Cryosphere Sending Signals about Climate Change. Retrieved November, 2013 from http://nsidc.org/sotc/sea_ice.html

Natural Resources Canada, (2013). Implications of Changing Climate for the Arctic Environment. Retrieved May, 2013 from http://www.nrcan.gc.ca/environment/resources/publications/impactsadaptation/reports/assessments/2008/ch3/10325

Natural Resources Canada, (2013). Radiometric Resolution. Retrieved November, 2013 from http://www.nrcan.gc.ca/earth-sciences/geomatics/satellite-imagery-air-photos/satelliteimagery-products/educational-resources/9379

Natural Resources Canada, (2013). Spectral Resolution. Retrieved November, 2013 from http://www.nrcan.gc.ca/earth-sciences/geomatics/satellite-imagery-air-photos/satelliteimagery-products/educational-resources/9393

Natural Resources Canada, (2013). Pre-Processing. Retrieved June, 2013 from http://www.nrcan.gc.ca/earth-sciences/geomatics/satellite-imagery-air-photos/satelliteimagery-products/educational-resources/9403

Natural Resources Canada, (2012). Spatial Resolution, Pixel Size, and Scale. Retrieved November, 2013 from http:/www.nrcan.gc.ca/earth-sciences/geomatics/satelliteimagery-air-photos/satellite-imagery-products/educational-resources/9407

Natural Resources Canada, (2011). Temporal Resolution. Retrieved November, 2013 from https:/www.nrcan.gc.ca/earth-sciences/geomatics/satellite-imagery-air-photos/satelliteimagery-products/educational-resources/9365 
Natural Resources Canada, (2005). Mackenzie Valley Permafrost Monitoring Network. Retrieved June 2014, from http://www.bsstrpa.ca/pdf/nogr/permafrost_smith.pdf

New Zealand Ministry of the Environment, (2014). Coastal Erosion. Retrieved November, 2013 from http://www.mfe.govt.nz/publications/climate/coastal-hazards-climatechange-guidance-manual/page13.html

Newman, L. E., (2009). Fluvial Landform Processes. . Glendale Community College. Retrieved July 2014, from http://web.gccaz.edu/ Inewman/gph111/topic_units/fluvial/fluvial2.html

Nixon, S. W., (1995). Coastal Marine Eutrophication: a Definition, Social Causes, and Future Concerns. Ophelia, Vol. 41, 199-219, 20.

Overeem, I., (2014). Scientists go to Extremes to Monitor Arctic Permafrost Loss. American Geosciences Institute. Retrieved April 2014 from http://www.earthmagazine.org/article/scientists-go-extremes-monitor-arcticpermafrost-loss

Overeem, I., Anderson, R. S., Wobus, C. W., Clow, G. D., Urban, F. E., \& Matell, N., (2011). Sea Ice Loss Enhances Wave Action at the Arctic Coast. Geophysical Research Letters, Vol. 38, pp. 1-6, 6.

Parliament of Canada, (2008). The Arctic: Northern Aboriginal Peoples. Retrieved January 2013, from http://www.parl.gc.ca/content/lop/researchpublications/prb0810-e.htm

Peltier, W. R., (1998). Postglacial Variations in the Level of the Sea: Implications for Climate Dynamics and Solid-Earth Geophysics. Reviews of Geophysics, Vol. 36, No. 4, pp. 603- 689, 86.

Piwowar, J. M., (2009). Supervised Classification (of 8-bit multispectral imagery). Retrieved April 2013, from http://uregina.ca/piwowarj/PCI/SupervisedClassification.html

Prasetya, G., (2006). The Role of Coastal Forests and Trees in Protecting Against Coastal Erosion. Proceedings of the Regional Technical Workshop, Khao Lak, Thailand. Retrieved May 2014, from http://www.fao.org/docrep/010/ag127e/ag127e09.htm

Rachold, V., Bolshiyanov, D. Y., Grigoriev, M. N., Hubberten, H.-W., Junker, R., Kunitsky, V. V., Merker, F., Overduin, P. P., \& Schneider, W., (2007). Near-shore Arctic Subsea Permafrost in Transition. Eos, Transactions American Geophysical Union, Vol. 88, No. 13, pp. 149-150, 2.

Rachold, V., Grigoriev, M. N., Are, F. E., Solomon, S., Reimnitz, E., Kassens, H., \& Antonow, M., (2000). Coastal Erosion vs Riverine Sediment Discharge in the Arctic Shelf Seas. International Journal of Earth Sciences, Vol. 89, No. 3, pp. 450-460, 10.

Rosal, A. P., \& Triguis, J. A., (2007). Bioremediation Process on Brazil Shoreline. Environmental Science and Pollution Research International, pp. 470-476, 6. 
Scharper, S., (2010). The Gulf of Mexico Oil Spill. Retrieved January 2014, from http://www.research.utoronto.ca/the-gulf-of-mexico-oil-spill/

Shaw, J., Taylor, R. B., Solomon, S., Christian, H. A., Forbes, D. L., (1998). Potential Impacts of Global Sea-Level Rise on Canadian Coasts. Canadian Geographer, pp. 365-379, 15.

Smith, O. P., \& Levasseur, G., (2002). Impact of Climate Change on Transportation Infrastructures in Alaska. Arctic Climate Impact Assessment, pp. 920-928, 9.

Solomon, S. M., (2003). The Mineral Potential of the Proposed Mackenzie Delta Marine Protected Areas. Geological Survey of Canada, pp. 1-37, 38.

Sonune, M. B., (2014). Occurrence of Fish Parasites (Cestode) From West Coast of India. Bioscience Discovery, Vol. 5, No. 1, pp. 38-41, 3.

St-Hilaire-Gravel, D., Bell, T. J., \& Forbes, D. L., (2010). Raised Gravel Beaches as Proxy Indicators of Past Sea-Ice and Wave Conditions, Lowther Island, Canadian Arctic Archipelago. Arctic, Vol. 63, No. 2, pp. 213-226, 14.

Statistics Canada, (2012). Tuktoyaktuk, Northwest Territories (Code 6101036) and Region 1, Northwest Territories (Code 6101) (table). Census Profile. 2011 Census. Retrieved January 2013 from http://www12.statcan.gc.ca/census-recensement/2011/dppd/prof/index.cfm?Lang=E

Statistics Canada, (2002). 2001 Community Profiles: Tuktoyaktuk, Northwest Territories (Table). Retrieved March 2013 from http://www12.statcan.ca/english/ProfilOl/CP01/Index.cfm?Lang=E

Sustainalytics, (2012). The Impacts and Risks of Deepwater and Arctic Hydrocarbon Development. Retrieved December 2013, from http://www.sustainalytics.com/sites/default/files/unconventional-oil-and-gas-arcticdrilling_0.pdf

Szostak-Chrzanowski, A., Chrzanowski, A., (2013). Study of Natural and Man-Induced Ground Deformation in Mackenzie Delta Region. Acta Geodynamica ET Geomaterialia, Vol. 11, No. 2, pp. xx1-xx7, 7.

Tape, K. D., Verbyla, D., \& Welker, J. M., (2011). Twentieth Century Erosion in Arctic Alaska Foothills: the Influence of Shrubs, Runoff, and Permafrost. Journal of Geophysical Research, Vol. 116, pp. 1-11, 11.

The Community of Tuktoyaktuk, the Wildlife Management Advisory Council (NWT), \& the Joint Secretariat, (2008). Tuktoyaktuk Community Conservation Plan: A Plan for the Conservation and Management of Natural Resources and Lands within the Inuvialuit Settlement Region in the Vicinity of Tuktoyaktuk, Northwest Territories. Retrieved January 2013 from http://www.eirb.ca/pdf/ccp/Tuktoyaktuk_CCP.pdf 
The Globe and Mail, (2012). As Shale Deposits Multiply, Energy Self-Sufficiency Becomes a Reality. Retrieved July 2014, from http://www.theglobeandmail.com/report-onbusiness/rob-commentary/as-shale-deposits-multiply-energy-self-sufficiency-becomesa-reality/article1358609/

The Globe and Mail, (2012). Reviving Arctic Oil Rush, Ottawa to Auction Rights in Massive Area. Retrieved December 2013, from http://www.theglobeandmail.com/news/politics/reviving-arctic-oil-rush-ottawa-toauction-rights-in-massive-area/article4184419/

The Guardian, (2013). Drilling in the Arctic. Retrieved October 2013, from http://www.theguardian.com/environment/2013/oct/02/drilling-arctic-environmentalimpact-greenpeace-piracy

Thompson, M. S., Wrona, F. J., \& Prowse, T. D., (2012). Shifts in Plankton, Nutrient and Light Relationships in Small Tundra Lakes Caused by Localized Permafrost Thaw. Arctic, Vol. 65, No. 4, pp. 367-376, 9.

Tremblay, J-É., Bélanger, S., Barber, D. G., Asplin, M., Martin, J., Darnis, G., Fortier, L., Gratton, Y., Link, H., Archambault, P., Sallon, A., Michel, C., Williams, W. J., Philippe, B., \& Gosselin, M., (2011). Climate Forcing Multiplies Biological Productivity in the Coastal Arctic Ocean. Geophysical Research Letters, Vol. 38, pp. 1$5,5$.

UMA Engineering Limited, (1994). Tuktoyaktuk Shoreline Protection Study Phases 2 and 3. Retrieved March 2014, from http://nome.colorado.edu/HARC/members/Scanned_docs/UMAEngineering_1994.pdf

United Nations, (1992). Rio Declaration on Environment and Development 1992. Retrieved March 2014, from http://www.un.org/documents/ga/conf151/aconf15126-1annex1.htm

United Nations Educational, Scientific and Cultural Organization, (2005). The Precautionary Principle World Commission on the Ethics of Scientific Knowledge and Technology. Retrieved March 2014, from http://unesdoc.unesco.org/images/0013/001395/139578e.pdf

United Nations Environment Programme, (2013). New Awareness of and Opportunities for UNEP to Address Climate Change in the Arctic. Retrieved December 2013, from http://www.unep.org/gc/gc27/Docs/se/What\%20Future\%20for\%20the\%20Arctic.pdf

United Nations Environment Programme, (2012). Policy Implications of Warming Permafrost. Retrieved November 2013, from http://www.unep.org/pdf/permafrost.pdf

United States Environmental Protection Agency, (2014). Climate Change Indicators in the United States. Retrieved June 2014, from http://www.epa.gov/climate/climatechange/science/indicators/snow-ice/index.html 
United States Environmental Protection Agency, (2012). Channel Processes: River Stability Concepts. Retrieved May 2014, from http://water.epa.gov/scitech/datait/tools/warsss/rivstab.cfm

United States Geological Survey, (2014). Louisiana Coastal Wetlands: A Resource at Risk. Coastal \& Marine Geology Program. Retrieved July 2014, from http://pubs.usgs.gov/fs/la-wetlands/

United States Geological Survey, (2013). Landsat-5 History. Retrieved November, 2013 from https://landsat.usgs.gov/about_landsat5.php

United States Geological Survey, (2013). Remote Sensing Applications. Retrieved August, 2013 from http://landsat.usgs.gov/remote_sensing_applications.php

United States Geological Survey, (2013). USGS EarthExplorer. Retrieved March 2013, from https://lpdaac.usgs.gov/data_access/usgs_earthexplorer

United States Geological Survey, (2013). Frequently Asked Questions about the Landsat Missions. Retrieved December 2013, from

https://landsat.usgs.gov/best_spectral_bands_to_use.php

United States Geological Survey, (2013). Fact Sheet - Limited Sand Resources for Eroding Beaches. Coastal \& Marine Geology Program. Retrieved July 2014, from http://coastal.er.usgs.gov/wfla/factsheet/

United States Geological Survey, (2013). SLC-off Products: Background. Retrieved November 2013, from http://landsat.usgs.gov/products_slcoffbackground.php

United States Geological Survey, (2012). Benefits of Open Availability of Landsat Data. Retrieved November, 2013 from http://www.oosa.unvienna.org/pdf/pres/stsc2012/2012ind-05E.pdf

United States Geological Survey, (2008). Coastal Change: Natural Processes. Retrieved June 2014, from http://pubs.usgs.gov/circ/c1075/change.html

United States Geological Survey, (2006). Landsat 5 Solar Array Drive Anomaly. Retrieved May 2013, from http://web.archive.org/web/20071213041533/http://landsat.usgs.gov/technical_details/i nvestigations/15_solar_drive.php

University of Guelph, (2002). Canada’s Polar Environments. Retrieved June 2014, from http://www.arctic.uoguelph.ca/cpe/environments/land/glaciers/features/rbeach.htm

University of Guelph, (2002). Canada’s Polar Environments. Retrieved July 2014, from http://www.arctic.uoguelph.ca/cpe/environments/marine_water/features/Tides/amplitu de.htm 
Whitehouse, P.L., Allen, M., \& Milne, G.A.B., (2007). Glacial Isostatic Adjustment as a Control on Coastal Processes: An Example from the Siberian Arctic. Geology, Vol. 35, pp. 747-750, 3.

Wolfe, S. A., Dallimore, S. R., \& Solomon, S. M., (1998). Coastal Permafrost Investigations along a Rapidly Eroding Shoreline, Tuktoyaktuk, N.W.T. Permafrost, pp. 1125-1131, 6.

World Wide Fund, (2014). Arctic Oil and Gas. Retrieved July 2014, from http://wwf.panda.org/what_we_do/where_we_work/arctic/what_we_do/oil_gas/

Yang, X., (2009). Remote Sensing and Geospatial Technologies for Coastal Ecosystem Assessment and Management. Springer-Verlag Berlin Heidelberg, pp. 302-312, 10.

Zamolodchikov, D., (2008). Global Warming Continues to Erode Arctic Coast. RIA Novosti. Retrieved July 2014, from http://en.ria.ru/analysis/20080125/97753436.html

Zhang, K., Douglas, B. C., \& Leatherman, S. P., (2004). Global Warming and Coastal Erosion. Climatic Change, Vol. 64, 41-58, 17. 